\title{
S2K-Leitlinie zur Diagnostik und Therapie der idiopathischen Lungenfibrose
}

\author{
German Guideline for Diagnosis and Management of Idiopathic \\ Pulmonary Fibrosis
}

Autoren

Institute

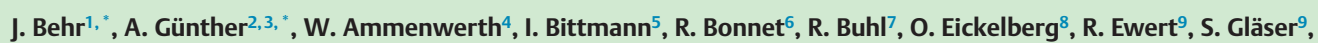
J. Gottlieb ${ }^{10}$, C. Grohé ${ }^{11}$, M. Kreuter ${ }^{12}$, C. Kroegel ${ }^{13}$, P. Markart' ${ }^{2}$, C. Neurohr ${ }^{14}$, M. Pfeifer ${ }^{15}$, A. Prasse ${ }^{16}$, N. Schönfeld ${ }^{4}$,

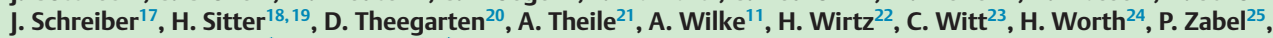
J. Müller-Quernheim ${ }^{16,}$, U. Costabel ${ }^{26,}$

Die Institutsangaben sind am Ende des Beitrags gelistet.
Bibliografie

DOI http://dx.doi.org/

10.1055/s-0032-1326009

Online-Publikation: 16.1.2013

Pneumologie 2013; 67: 81-111

(c) Georg Thieme Verlag KG

Stuttgart · New York

ISSN 0934-8387

\section{Korrespondenzadresse}

Prof. Dr. med. Jürgen Behr

Asklepios Fachkliniken München

Gauting

Medizinische Klinik und

Poliklinik V

Comprehensive Pneumology

Center

Klinikum der Ludwig-

Maximilians Universität

München

Marchioninistr. 15

81377 München

juergen.behr@med.uni-

muenchen.de

\section{Zusammenfassung \\ $\nabla$}

Die idiopathische pulmonale Fibrose (IPF) ist eine schwerwiegende und in der Regel zum Tod führende Erkrankung, die bisher nur unzureichend behandelt werden kann. Empfehlungen zur Diagnostik und Therapie wurden erstmals im ATSERS-Statement im Jahr 2000 publiziert [1]. Seither haben sich die diagnostischen Standards geändert und es liegen zahlreiche Therapiestudien zu diesem Krankheitsbild vor, die es erforderlich machten, die bestehenden Empfehlungen zu überarbeiten und eine wissenschaftlich begründete Leitlinie zu erstellen. Diese wurde von einer internationalen Expertengruppe in den Jahren 2006-2010 erarbeitet und publiziert [2]. Die folgenden Ausführungen beinhalten eine Übersetzung wesentlicher Inhalte der Originalleitlinie sowie die Interpretation und Adaptation der Empfehlungen an die speziellen Belange des deutschen Gesundheitssystems, wobei auch neue wissenschaftliche Erkenntnisse Berücksichtigung fanden. Die Deutsche Leitlinie zur Diagnostik und Therapie der IPF beruht auf einer Initiative deutscher Experten unter der Schirmherrschaft der Deutschen Gesellschaft für Pneumologie und Beatmungsmedizin (DGP) und auf den Ergebnissen einer Konsensuskonferenz, die am 3.12.2011 in Bochum unter Supervision der „Arbeitsgemeinschaft der Wissenschaftlichen Medizinischen Fachgesellschaften (AWMF)“ abgehalten wurde. Die Mehrzahl der Empfehlungen der internationalen Leitlinie konnten dabei übernommen werden. Basierend auf aktuellen Studienergebnissen, die zum Zeitpunkt der Verabschiedung der internationalen Leitlinie noch nicht bzw. nicht vollständig vorlagen wurden die schwach negativen Empfehlungen für die Antikoagulan-

\section{Abstract \\ $\nabla$}

Idiopathic pulmonary fibrosis is a fatal lung disease with a variable and unpredictable natural history and limited treatment options. Since publication of the ATS-ERS statement on IPF in the year 2000 diagnostic standards have improved and a considerable number of randomized controlled treatment trials have been published necessitating a revision. In the years 2006-2010 an international panel of IPF experts produced an evidence-based guideline on diagnosis and treatment of IPF, which was published in 2011. In order to implement this evidence-based guideline into the German Health System a group of German IPF experts translated and commented the international guideline, also including new publications in the field. A consensus conference was held in Bochum on December $3^{\text {rd }} 2011$ under the protectorate of the "Deutsche Gesellschaft für Pneumologie und Beatmungsmedizin (DGP)" and supervised by the "Arbeitsgemeinschaft der Wissenschaftlichen Medizinischen Fachgesellschaften" (AWMF). Most recommendations of the international guideline were found to be appropriate for the german situation. Based on recent clinical studies "weak negative" treatment recommendations for pirfenidone and anticoagulation were changed into "weak positive" for pirfenidone and "strong negative" for anticoagulation. Based on negative results from the PANTHER-trial the recommendation for the combination therapy of prednisone plus azathiorpine plus $\mathrm{N}$-acetlycsteine was also changed into strong negative für patients with definite IPF. This document summarizes essential parts of the international IPF guideline and the comments and recommendations of the German IPF consensus conference.

* geteilte Autorenschaft 
tientherapie und die Kombinationstherapie mit Prednison, Azathioprin und N-Acteylcystein in stark negative Empfehlungen umgewandelt, während für Pirfenidon, welches inzwischen in der Europäischen Union zugelassen ist, eine schwach positive Therapieempfehlung ausgesprochen wurde.

\section{Methodik}

$\nabla$

Die internationale Leitlinie wurde als evidenzbasierte Leitlinie von den Fachgesellschaften - American Thoracic Society (ATS), European Respiratory Society (ERS), Japanese Thoracic Society (JRS) und Latin American Thoracic Society (ALAT) - erstellt [2]. Als Grundlage diente das Konsensusstatement zum gleichen Thema, welches im Jahr 2000 von den Fachgesellschaften ATS und ERS in Kooperation mit dem American College of Chest Physicians (ACCP) publiziert worden war [1]. Aufgrund dieser Vorarbeiten wurde die Literaturrecherche der internationalen Leitlinie auf den Zeitraum 1996 bis 31.5.2010 beschränkt [2]. Die deutschen Experten haben im Rahmen der Vorbereitung der Konsensuskonferenz die nach dem 31.5.2010 bis einschließlich 30.11.2011 publizierten relevanten Studien ergänzt und inhaltlich berücksichtigt. Nachträglich wurden zwei Therapiestudien, die bis 31.8.2012 als Vollpublikation vorlagen, eingeschlossen $[375,378]$.

Ziel der deutschen IPF-Konsensuskonferenz war es, die evidenzbasierte internationale IPF-Leitlinie in die deutsche Sprache zu übersetzen und gleichzeitig inhaltlich an das Gesundheitswesen und den Arzneimittelmarkt in Deutschland anzupassen, um so eine Implementierung der Leitlinie zu erleichtern oder überhaupt erst zu ermöglichen. Zielgruppen dieser Leitlinie sind in erster Linie Fachärzte für Innere Medizin mit dem Schwerpunkt Pneumologie aber auch Facharztgruppen wie Radiologen und Pathologen, die vor allem in der Diagnostik eine bedeutende Rolle innehaben. Dementsprechend waren auch Vertreter der Deutschen Gesellschaft für Pneumologie und Beatmungsmedizin (DGP), der Deutschen Gesellschaft für Pathologie (DGP) und der Arbeitsgemeinschaft der Wissenschaftlichen Medizinischen Fachgesellschaften (AWMF) an der Erstellung der Leitlinie beteiligt. Die Patientenselbsthilfeorganisation für Lungenfibrose wurde gehört und hat sich aktiv an der Konsensuskonferenz beteiligt. In der internationalen IPF-Leitlinie wurden alle Empfehlungen zu Diagnostik und Therapie entsprechend der GRADE-Methodik anhand konkreter Fragen entwickelt. Dabei drückt die Stärke einer Empfehlung aus, wie sicher die Kommission war, dass die erwünschten Effekte einer Therapie die unerwünschten überwogen [3]. Die meisten Negativempfehlungen sind starke Empfehlungen, hier gibt es keine ausreichende Evidenz für die Verwendung der jeweiligen Therapien. Andere Behandlungsempfehlungen sind schwach, als Ausdruck dafür, dass Daten von höherer Qualität gebraucht werden und dass bezüglich Nutzen und Risiken der Therapie Unsicherheit besteht. Die Stärke einer Empfehlung hat wichtige Konsequenzen für Patienten, Ärzte und politische Entscheidungsträger ( $\bullet$ Tab. 1).

Die Stärke der Empfehlung wird auch im Formulierungstext reflektiert: „sollen“ steht für eine starke, „sollten“ für eine schwache Empfehlung.

Auch die Qualität der verfügbaren Studien als Grundlage der wissenschaftlichen Evidenz wurde entsprechend der GRADE-Methodik nach einem festen Schema beurteilt ( Tab.2) [3].

Dabei ist zu berücksichtigen, dass die Einschätzung der Qualität der Evidenz eine Aussage darüber beinhaltet, wie sicher die Be-

\begin{tabular}{|c|c|c|}
\hline \multicolumn{3}{|c|}{ Inhaltsverzeichnis } \\
\hline 1 & Methodik & 82 \\
\hline 2 & Definition und Epidemiologie & 83 \\
\hline 2.1 & Definition & 83 \\
\hline 2.2 & Klinisches Bild & 83 \\
\hline 2.3 & Inzidenz und Prävalenz & 83 \\
\hline 2.4 & Potenzielle Risikofaktoren & 84 \\
\hline 2.5 & Genetische Faktoren & 84 \\
\hline 3 & Diagnostik & 85 \\
\hline 3.1 & Definition des Usual Interstitial Pneumonia (UIP)-Musters & 85 \\
\hline 3.2 & Diagnostische Kriterien & 88 \\
\hline 3.3 & Ausschluss anderer bekannter Ursachen & 88 \\
\hline 4 & Spontanverlauf der IPF & 90 \\
\hline 4.1 & Unterschiedliche Verläufe bei IPF prägen das Bild & 90 \\
\hline 4.2 & Akute Exazerbation der IPF & 90 \\
\hline 4.3 & Mortalität & 91 \\
\hline 5 & Stadieneinteilung und Prognose & 91 \\
\hline 5.1 & Demografische Faktoren & 91 \\
\hline 5.2 & Ausmaß der Dyspnoe & 91 \\
\hline 5.3 & Physiologische Parameter & 91 \\
\hline 5.4 & HRCT-Veränderungen & 92 \\
\hline 5.5 & Zusammengesetzte Scoring-Systeme & 92 \\
\hline 5.6 & Sechs-Minuten-Gehstrecke & 92 \\
\hline 5.7 & Histopathologische Parameter & 93 \\
\hline 5.8 & Pulmonale Hypertonie & 93 \\
\hline 5.9 & Emphysem & 93 \\
\hline 5.10 & Biomarker in Serum und BAL & 93 \\
\hline 6 & Therapie & 93 \\
\hline 6.1 & Pharmakologische Therapie & 93 \\
\hline 6.2 & Nichtpharmakologische Therapie & 97 \\
\hline \multirow[t]{2}{*}{7} & Behandlung ausgewählter Komplikationen und & \\
\hline & Begleiterkrankungen & 99 \\
\hline 8 & Palliativmedizin & 99 \\
\hline 9 & Klinische Verlaufskontrolle & 100 \\
\hline 9.1 & Krankheitsprogression & 100 \\
\hline 9.2 & Verschlechterung der Symptome & 101 \\
\hline 9.3 & Verschlechterung der Oxygenierung & 101 \\
\hline 9.4 & Erkennung von Komplikationen und Begleiterkrankungen & 101 \\
\hline 9.5 & Zusammenfassung des klinischen Managements der IPF & 101 \\
\hline 10 & Ausblick & 102 \\
\hline \multicolumn{2}{|c|}{ Literatur } & 104 \\
\hline
\end{tabular}

wertung des beobachteten Effektes ist, bzw. wie wahrscheinlich es ist, dass zukünftige Studienergebnisse diese Bewertung verändern werden. Eine hohe Qualität der Evidenz bedeutet demnach, dass es sehr unwahrscheinlich ist, dass zukünftige Forschungsergebnisse eine Änderung in der Bewertung des Effektes zur Folge haben, während bei geringer Qualität der Evidenz diese Wahrscheinlichkeit sehr hoch ist; bei sehr geringer Qualität der Evidenz besteht große Unsicherheit hinsichtlich der Einschätzung des Effektes [1,3].

Die deutsche IPF-Konsensuskonferenz war sich darin einig, dass die GRADE-Methodik im vorliegenden Dokument trotz ihrer Limitationen beibehalten werden soll. Dies beinhaltete auch Abstimmungen über die jeweiligen Empfehlungen, für die alle anwesenden Mitglieder der Konsensuskonferenz einschließlich der Patientenvertreter stimmberechtigt waren, nicht aber die Beobachter der Pharmaindustrie. Erklärungen zu möglichen Interessenskonflikten waren bereits im Vorfeld der Konsensuskonferenz und in Hinblick auf die Publikation deren Ergebnisse abgefragt worden. Das Abstimmungsverhalten in kritischen Fragen wurde protokolliert (Protokollführer: Andreas Günther) und wird in diesem Dokument wiedergegeben. Es wurde beschlossen, dass die Leitlinie eine maximale Gültigkeit von 5 Jahren nach ihrem 
Tab. 1 Bedeutung einer Empfehlung für Patienten, Ärzte, Gesetzgeber und Kostenträger.

\begin{tabular}{|c|c|c|}
\hline \multicolumn{3}{|l|}{ Starke Empfehlung } \\
\hline & dafür & dagegen \\
\hline Patienten & $\begin{array}{l}\text { Patienten würden sich in der Regel für die Intervention } \\
\text { entscheiden }\end{array}$ & $\begin{array}{l}\text { Patienten würden sich in der Regel gegen die Intervention } \\
\text { entscheiden }\end{array}$ \\
\hline Ärzte & $\begin{array}{l}\text { Patienten sollten entsprechend der Empfehlung behandelt } \\
\text { werden }\end{array}$ & \\
\hline Gesetzgeber/Kostenträger & $\begin{array}{l}\text { die Empfehlung (ob positiv oder negativ) kann als } \\
\text { Routinevorgehen angenommen werden }\end{array}$ & \\
\hline \multicolumn{3}{|l|}{ Schwache Empfehlung } \\
\hline & dafür & dagegen \\
\hline Patienten & $\begin{array}{l}\text { die Mehrzahl würde sich für die Intervention entscheiden, } \\
\text { eine beträchtliche Anzahl würde sie ablehnen }\end{array}$ & $\begin{array}{l}\text { die Mehrzahl der Patienten würde sich gegen die Interven- } \\
\text { tion entscheiden, eine beträchtliche Anzahl würde sie } \\
\text { wählen }\end{array}$ \\
\hline Ärzte & $\begin{array}{l}\text { müssen die Patienten informieren und ihnen bei der Ent- } \\
\text { scheidung für oder gegen die Intervention entsprechend } \\
\text { ihrer Bedürfnisse helfen }\end{array}$ & \\
\hline Gesetzgeber/Kostenträger & $\begin{array}{l}\text { es besteht Diskussionsbedarf, wobei alle betroffenen } \\
\text { Interessensgruppen beteiligt werden müssen }\end{array}$ & \\
\hline
\end{tabular}

Tab.2 Beurteilung der Qualität der Evidenz [3].

\begin{tabular}{|c|c|c|c|}
\hline Qualität der Evidenz & Studiendesign & Abwertung & Aufwertung \\
\hline Hoch & randomisiert-kontrollierte Studie & \multirow{4}{*}{$\begin{array}{l}\text { - limitierte Studienqualität } \\
\text { - indirekte Evidenz } \\
\text { - bedeutsame Inkonsistenz } \\
\text { - ungenügende oder ungenaue Daten } \\
\text { - hohe Wahrscheinlichkeit für } \\
\quad \text { Publikations-Bias }\end{array}$} & \multirow{4}{*}{$\begin{array}{l}\text { - starke Assoziation, keine Verzerrung } \\
\text { - Nachweis einer Dosis-Wirkungs-Beziehung } \\
\text { - plausible Einflussfaktoren, die den } \\
\text { beobachteten Effekt reduzieren }\end{array}$} \\
\hline Moderat & $\begin{array}{l}\text { abgewertete randomisiert-kontrol- } \\
\text { lierte Studie; aufgewertete Beob- } \\
\text { achtungsstudie }\end{array}$ & & \\
\hline Gering & $\begin{array}{l}\text { gut durchgeführte Beobachtungs- } \\
\text { studien mit Kontrollgruppe }\end{array}$ & & \\
\hline Sehr gering & $\begin{array}{l}\text { andere Studienformate } \\
\text { (z. B. Fallserien, Fallberichte) }\end{array}$ & & \\
\hline
\end{tabular}

Erscheinen haben soll, dass aber, falls erforderlich, eine frühere Überarbeitung erfolgen wird. In diesem Zusammenhang wurde Jürgen Behr als Leitlinienverantwortlicher bestimmt. Im folgenden Text sind Änderungen und Ergänzungen gegenüber der internationalen IPF-Leitlinie durch Kursivschrift hervorgehoben.

\section{Definition und Epidemiologie}

\subsection{Definition}

Die IPF ist definiert als eine bestimmte Form einer chronischen, progredient verlaufenden, fibrosierenden interstitiellen Pneumonie unbekannter Ursache, die primär bei älteren Erwachsenen auftritt, auf die Lungen begrenzt ist und mit dem nachfolgend definierten histopathologischen und/oder radiologischen Muster einer UIP einhergeht $[1,2,4,5]$.

Die Diagnose der IPF setzt den Ausschluss anderer Formen einer interstitiellen Pneumonie voraus, einschließlich anderer idiopathischer interstitieller Pneumonien und interstitieller Lungenerkrankungen (ILD) im Zusammenhang mit Umweltbelastungen, Medikamenten oder systemischen Erkrankungen [1,2,4].

\subsection{Klinisches Bild}

An eine IPF sollte bei jedem erwachsenen Patienten mit ungeklärter chronischer Belastungsdyspnoe gedacht werden. Häufig imponieren Husten, ein beidseits basal betontes inspiratorisches Knisterrasseln und Trommelschlegelfinger [6-8]. Die Inzidenz nimmt mit höherem Alter zu, wobei sich die Erkrankung typischerweise in der 6. und 7.Lebensdekade manifestiert [8-11]. IPF-Patienten unter 50 Jahren sind selten und entwickeln später oft Manifestationen einer zugrunde liegenden Kollagenose, die zum Zeitpunkt der Diagnose der IPF noch subklinisch war [12, 13]. Männer sind häufiger betroffen als Frauen und die Mehrzahl der Patienten hat eine positive Raucheranamnese [6-9,14,15].

\subsection{Inzidenz und Prävalenz}

Groß angelegte Studien zur Inzidenz oder Prävalenz der IPF, die als Grundlage für offizielle Schätzwerte dienen könnten, fehlen. In einer populationsbasierten Studie aus dem County Bernalillo in New Mexico wurde die Inzidenz der IPF für Männer auf jährlich 10,7 und für Frauen auf jährlich 7,4 Fälle pro 100000 Einwohner geschätzt [15]. Eine Studie aus dem Vereinigten Königreich gab die Gesamtinzidenz pro 100000 Personenjahre mit nur 4,6 an, schätzte aber, dass die Inzidenz der IPF zwischen 1991 und 2003 um jährlich 11\% anstieg [8]. Dieser Anstieg wurde als nicht auf das Altern der Population oder die vermehrte Erkennung auch leichterer Fälle zurückführbar betrachtet. Eine dritte Studie aus den USA setzt die Inzidenz der IPF anhand der umfangreichen Erstattungsdatenbank einer Krankenversicherung mit 6,8 bis 16,3 pro 100000 Personen an [12].

Schätzungen der Prävalenz der IPF reichen von 2 bis 29 Fällen pro 100000 in der Allgemeinbevölkerung [9,14-17]. Die breite Streuung dieser Zahlen ist durch das frühere Fehlen einer einheitlichen Definition der IPF sowie Unterschiede im Studiendesign und den untersuchten Populationen zu erklären. Eine kürzliche Analyse der Daten aus Kostenerstattungsansprüchen einer großen Krankenversicherung in den USA ergab je nach verwendeter Definition einen Prävalenzschätzwert zwischen 14,0 und 42,7 pro 100000 Personen [12]. Es ist nicht bekannt, ob Inzidenz und Prävalenz der IPF durch geografische, ethnische oder kulturelle Faktoren beeinflusst werden. 


\subsection{Potenzielle Risikofaktoren}

Obgleich es sich bei der idiopathischen Lungenfibrose definitionsgemäß um eine Erkrankung unbekannter Ätiologie handelt, wurden einige mögliche Risikofaktoren beschrieben.

Rauchen Es gibt eine enge Korrelation zwischen IPF und Rauchen, vor allem bei einer Raucheranamnese von mehr als $20 \mathrm{~Pa}-$ ckungsjahren [14,18-23]. Dies gilt sowohl für die familiäre als auch die sporadische IPF [21].

Umweltbelastung Ein Zusammenhang zwischen einem erhöhten Risiko für IPF und verschiedenen Umweltfaktoren wurde festgestellt $[14,18,19,22,24-26]$. Ein signifikant erhöhtes Risiko wurde nach Kontakt mit Metallstäuben (Messing, Blei und Stahl) sowie Holzstaub (Kiefer) beobachtet $[18,22,25]$. Tätigkeiten als Landwirt, Vogelhalter, Friseur, Steinmetz sowie häufiger Viehkontakt oder Belastung mit Pflanzen-/Tierstaub wurden ebenfalls mit IPF assoziiert [19]. Für eine umweltassoziierte Ätiologie spricht auch, dass bei der Obduktion von Patienten mit Lungenfibrose in den Lymphknoten vermehrt anorganische Partikel festgestellt wurden [27]. Diese Beobachtungen sind allerdings mit großer Vorsicht zu interpretieren, da epidemiologische Studien zu umweltbedingten Risikofaktoren einer Vielzahl von Verzerrungen und Einschränkungen unterliegen.

Mikrobielle Erreger In verschiedenen Studien wurde die mögliche Rolle chronischer Virusinfektionen in der Ätiologie der IPF untersucht [22, 28-44]. Die meisten Untersuchungen konzentrierten sich auf das Epstein-Barr-Virus (EBV) [30,32,33,36-38, $40,42,44]$ und Hepatitis C $[22,28,29,31,34,39,41]$. Sowohl Proteine als auch die DNA des EBV wurden im Lungengewebe von IPF-Patienten gefunden, meist in den Epithelzellen der Lungenalveolen $[30,36]$. Rearrangements des EBV-Genoms, wie sie bei der Replikation des Virus entstehen, wurden in 11 von 18 EBV-DNApositiven IPF-Biopsien festgestellt [40]. Tang et al. untersuchten Gewebeproben von 33 Patienten mit IPF auf 8 Herpesviren einschließlich EBV und stellten fest, dass sich bei fast allen IPF-Lungen mindestens ein Herpesvirus nachweisen ließ, im Vergleich zu einem Drittel der Kontrollproben [42]. Zu den nachgewiesenen Viren zählten EBV, Cytomegalievirus, humanes Herpesvirus (HHV)-7 und HHV-8. Allerdings wurden auch negative Assoziationen berichtet $[33,44]$. Studien zu Hepatitis C zeigten variable Ergebnisse [22, 28, 29,31,34,39,41]. Berichtet wurden Erhöhungen der Serum-Antikörper gegen das Cytomegalievirus [35], während Assoziationen mit anderen Viren einschließlich BKund JC-Polyomaviren nicht festgestellt wurden [43].

Die Analyse mutmaßlicher Zusammenhänge zwischen Viren oder anderen Mikroorganismen und IPF wird durch andere gemeinsame Faktoren (Confounding-Faktoren) erschwert. So ist wahrscheinlich, dass die Patienten in vielen älteren Studien eine Immunsuppression erhielten, daher kann es sich bei der Infektion möglicherweise um eine therapiebedingte Komplikation handeln [32]. Zudem ist die Prävalenz des EBV in der Allgemeinbevölkerung hoch: In einer Studie wurde EBV-DNA bei $96 \%$ der Patienten mit IPF, aber in $100 \%$ der Lungen mit Fibrose bei systemischer Sklerose und in 71\% der Kontrollen nachgewiesen [37]. Trotz der bislang großen Anzahl an Studien lassen sich keine definitiven Schlüsse zur Rolle von Infektionskrankheiten in der Ätiologie der IPF ziehen.

Gastroösophagealer Reflux Mehrere Studien fanden Hinweise darauf, dass ein abnormer saurer gastroösophagealer Reflux (GER) über die mutmaßlich damit verbundene Mikroaspiration einen Risikofaktor für IPF darstellt. Ein abnormer GER ist bei Patienten mit IPF häufig $[11,45,46]$. In einer Fallkontrollstudie der Veterans Administration war eine GER-bedingte erosive Ösopha- gitis mit einer Reihe von Atemwegserkrankungen einschließlich Lungenfibrose verbunden [47]. Bei der Mehrzahl der IPF-Patienten ist der Reflux klinisch stumm $[11,45]$ und seine typischen Symptome Sodbrennen und Regurgitation unterscheiden nicht zwischen IPF-Patienten mit und ohne GER [46]. GER ist auch in der lungengesunden Population häufig, ebenso bei Patienten mit anderen fortgeschrittenen Lungenerkrankungen wie z.B. sekundärer Lungenfibrose bei Sklerodermie [48]. Da ein abnormer GER auch nichtsaure Komponenten haben kann, mag auch ein basischer GER bei IPF-Patienten eine wichtige Rolle spielen. Es ist nicht bekannt, ob Veränderungen des intrathorakalen Drucks infolge einer verminderten Lungencompliance zu abnormem GER führen. Immerhin rechtfertigt die mutmaßliche Rolle des GER bei der IPF weitere Studien.

Weitere Risikofaktoren für die IPF wie Diabetes mellitus wurden kürzlich beschrieben [49].

\subsection{Genetische Faktoren}

Familiäre Lungenfibrose Familiäre Formen der IPF (d.h. IPF bei mindestens 2 Mitgliedern derselben biologischen Primärfamilie) wurden berichtet, betreffen aber weniger als $5 \%$ aller IPF-Patienten [50 - 56]. Die Kriterien der Definition der IPF sind bei familiären und sporadischen Fällen dieselben, klinisch und histologisch ist die familiäre IPF nicht von der sporadischen zu unterscheiden [51,52], auch wenn die familiären Formen in einem früheren Alter zu entstehen $[51,52,56]$ und andere Gentranskriptionsmuster aufzuweisen scheinen [57]. Der Nachweis eines „Founder-Effekts“ (d.h. eine signifikante geographische Häufung von Fällen) bei der familiären Lungenfibrose in der finnischen Bevölkerung untermauert die Bedeutung genetischer Faktoren für die Entstehung der Lungenfibrose [52]. Die Ergebnisse einer jüngsten genomweiten Recherche derselben Autoren erlauben den Schluss, dass ELMOD2, ein Gen mit ungeklärter biologischer Funktion, das auf dem Chromosom 4q31 sitzt, ein Suszeptibilitätsgen für die familiäre IPF sein kann [58]. Viele Studien offensichtlicher „familiärer IPF“ sind eigentlich Studien familiärer Lungenfibrosen, da sich in mindestens der Hälfte der Stammbäume mehr als ein Typus einer idiopathischen interstitiellen Pneumonie (IIP) nachweisen lässt (z.B. IPF, nicht-spezifische interstitielle Pneumonie [NSIP], kryptogene organisierende Pneumonie [COP], nicht klassifizierbare ILD) [21].

Für das genetische Auftreten der Lungenfibrose ist ein autosomal-dominanter Erbgang mit variabler Penetranz am wahrscheinlichsten $[21,53,54,59,60]$. Postuliert wurde eine Kopplung mit dem Chromosom 14 [60]. Eine weitere enge Assoziation wurde zwischen Mutationen des Gens für das Surfactant-Protein $C$ und der familiären idiopathischen interstitiellen Pneumonie beobachtet [61], während ein solcher Zusammenhang bei Patienten mit der sporadischen Erkrankungsform nicht festgestellt wurde [62 -64]. Seltene Mutationen des Gens, das ein anderes Surfactant-Protein-A2 (SFTPA2) kodiert, wurden mit familiärer Lungenfibrose und Lungenkrebs in Verbindung gebracht [65]. Der Genort wurde durch genetische Kopplungsanalyse in einem großen Stammbaum identifiziert, darüber hinaus wurden durch Sequenzierung von Kandidatengenen innerhalb des Kopplungsabstandes zwei seltene Mutationen gefunden.

Jüngste Berichte verschiedener Untersucher dokumentieren, dass genetische Varianten innerhalb von Komponenten des Telomerase-Komplexes, nämlich der reversen Transkriptase (hTERT = human telomerase reverse transcriptase) oder der RNA der Telomerase (hTR=human telomerase RNA) mit familiärer Lungenfibrose assoziiert sind und auch bei einigen Patienten mit sporadi- 
scher IPF auftreten. Diese seltenen Mutationen lassen sich bei bis zu 15\% der Fälle von Familien mit familiärer Lungenfibrose und bei $3 \%$ der Fälle mit sporadischer IIP nachweisen [66-70]. Sie bewirken eine Verkürzung der Telomere und führen somit zur Apoptose von Zellen einschließlich der alveolaren Epithelzellen. Genetische Faktoren bei sporadischer IPF. Bei Patienten mit sporadischer IPF wird ein gehäuftes Auftreten von Genpolymorphismen von Zytokinen (Interleukin [IL]-1 a, Tumornekrosefaktor [TNF-]a, Lymphotoxin a, IL-4, IL-6, IL-8, IL-10 und IL-12 [71 - 80]), Enzymen (a1-Antitrypsin [81, 82] und Angiotensin Converting Enzyme [ACE] [83]), profibrotischen Molekülen (Transforming Growth Factor [TGF-]b1 [84]), Genen des Gerinnungssystems (Plasminogen Activator Inhibitors [PAI-]1 und 2), Genen für die Surfactant-Proteine A und B [62], immunmodulatorischen Genen (Komplementrezeptor 1, NOD2/CARD15 [85]) sowie Matrixmetallproteinasen (MMP-)1 [86] berichtet. Viele dieser Polymorphismen korrelieren auch mit der Krankheitsprogression, wobei allerdings keine dieser Korrelationen in späteren Studien validiert werden konnte. Festgestellt wurde eine abweichende Verteilung der Allele der humanen Klasse I- und Klasse-II Leukozytenantigene (HLA) bei Patienten mit IPF [87], zudem könnte die ethnische Herkunft eine wichtige Rolle für das klinische Endresultat spielen [88]. Neuere Daten aus einer mexikanischen Population lassen eine Korrelation zwischen MICA (MHC class I chainrelated gene A) und IPF erkennen [86]. Diese Assoziationsstudien bedürfen allerdings der Bestätigung durch größere Kohorten. Bislang konnten keine genetischen Faktoren gefunden werden, die konsistent mit sporadischer IPF assoziiert sind. Microarray-Analysen der Genexpression werden zur Klärung der Pathogenese, zu einer differenzierteren Klassifikation und zur gezielten Auswahl von geeigneten Kandidaten für die Therapie führen, befinden sich aber noch in der Anfangsphase der Entwicklung [89]. Zwar konnten genetische Studien zur familiären Lungenfibrose nützliche Einblicke in die Pathogenese der IPF liefern, doch sind weiterführende Studien erforderlich, um die Bedeutung dieser Aussagen zu bestätigen und weitere Mutationen, Assoziationen und Zusammenhänge zwischen Genetik und Umwelt zu untersuchen. Unserem aktuellen Stand der Erkenntnisse entsprechend empfiehlt die Kommission derzeit keine Gentests für Patienten mit familiärer oder sporadischer IPF im Rahmen der klinischen Diagnostik.

\section{Kommentar}

Eine aktuelle Arbeit zeigt, dass eine Promotorvariante des MUC5B-Gens auf Chromosom 11 bei familiärer IPF gehäuft auftritt und auch durch eine vermehrte Mucin-Expression von pathogenetischer Relevanz ist [90]. Die im Vergleich zu anderen genetischen Markern der IPF starke Assoziation konnte auch bei sporadischer IPF in zwei großen Kohorten reproduziert werden [91]. Trotz dieser neu erkannten starken Assoziation bleibt die Empfehlung bestehen: eine genetische Diagnostik bei Verdacht auf eine sporadische IPF ist nicht indiziert.

Aktuell häufen sich für genetische Familienuntersuchungen relevante neue Befunde. Eine detaillierte Familienanamnese mit Hinweisen auf weitere fibroseassozierte, gastroenterologische oder hämatologische Erkrankungen sollte zu weiteren Untersuchungen Anlass geben, da bei asymptomatischen Mutationsträgern bereits früh radiologische Veränderungen im Sinne einer IPF beobachtet werden können. Dies kann Anlass zu einer familiengenetischen Beratung, Motivation Kofaktoren zu meiden und Basis für eine Therapieentscheidung sein [92-94]. Nach neuesten Studien sind genetisch bedingte familiäre Formen, insbesondere solche mit SP-C-Mutationen, häufiger als bisher vermutet [95].

\section{Diagnostik}

\section{$\nabla$}

Da der Nachweis des Befundmusters einer „gewöhnlichen Lungenfibrose“ (Usual Interstitial Pneumonia, UIP) einen integralen Bestandteil in der Diagnostik der IPF darstellt, wird im folgenden zunächst die Definition des UIP-Musters in HRCT und Biopsie erläutert.

\subsection{Definition des Usual Interstitial Pneumonia (UIP)-Musters}

3.1.1 UIP-Muster in der HRCT

Die HRCT (high resolution Computertomographie) ist in der Diagnostik der IPF unerlässlich ( Tab.3, Abb.1). Die optimale HRCT-Technik zur Beurteilung einer ILD ist im Online-Supplement der internationalen IPF-Leitlinie (s. Tab.E6) dargestellt [1]. In der HRCT ist die UIP durch retikuläre Verdichtungen oft im Verbund mit Traktionsbronchiektasien charakterisiert [96,97]. Meist liegt ein Honigwabenmuster vor, das für die sichere Diagnose entscheidend ist. Die Honigwaben sind in der HRCT als Cluster zystischer Lufträume zu erkennen, in typischen Fällen mit Durchmessern in der Größenordnung von 3-10 mm, gelegentlich auch bis zu $2,5 \mathrm{~cm}$. In der Regel liegen sie subpleural und weisen deutlich gezeichnete Wände auf [98]. Milchglasverschattungen sind häufig, meist aber weniger ausgedehnt als die retikulären Zeichnungen. Die Lokalisation der UIP ist charakteristischerweise basal und peripher, oft auch fleckig. Das gleichzeitige Vorliegen von pleuralen Veränderungen (z.B. Plaques, Verkalkungen, signifikanter Pleuraerguss) sollte an eine andere Ätiologie des UIP-Musters denken lassen. Dies gilt auch für Mikroknötchen, Air-trapping, Zysten ohne Honigwabenmuster, extensive Milchglasverschattungen, Konsolidierungen oder ein vorwiegend peribronchovaskuläres Verteilungsmuster. Eine leichte Vergrößerung der mediastinalen Lymphknoten (in der Regel bis zu $1,5 \mathrm{~cm}$ in der kurzen Achse) kann vorkommen $[99,100]$. Zur Beurteilung von Patienten mit Verdacht auf IPF ist das Thoraxröntgenbild weniger geeignet als die HRCT [101].

In verschiedenen Studien wurde dokumentiert, dass der positiv prädiktive Wert der HRCT-Diagnostik der UIP bei 90 - 100\% liegt [101 - 106]. Diese Studien sind allerdings durch einen SelektionsBias verzerrt, da nur Patienten mit bioptisch gesicherter Diagnose eingeschlossen wurden. Dennoch kann ein UIP-Muster in der HRCT mit höchster Treffsicherheit ein UIP-Muster in der chirurgischen Lungenbiopsie vorhersagen. Wenn die Honigwaben fehlen, aber das HRCT-Muster sonst den Kriterien einer UIP entspricht, ist das HRCT-Muster als mögliche UIP zu werten, und eine chirurgische Lungenbiopsie ist erforderlich, um eine sichere Diagnose zu stellen. Allerdings kann auch bei Patienten ohne das HRCTMuster einer UIP die Lungenbiopsie das histopathologische Muster der UIP aufweisen.

\subsubsection{UIP-Muster in der Histopathologie}

Histopathologisch kennzeichnend und wichtigstes diagnostisches Kriterium ist das heterogene Erscheinungsbild bei geringer Vergrößerung, wobei sich fibrotische Areale mit narbigen und honigwabenförmigen Veränderungen und Areale mit weniger 
Tab. 3 HRCT-Kriterien für ein UIP-Muster.

\begin{tabular}{|c|c|c|}
\hline $\begin{array}{l}\text { UIP-Muster } \\
\text { (alle vier Charakteristika) }\end{array}$ & $\begin{array}{l}\text { Mögliches UIP-Muster } \\
\text { (alle drei Charakteristika) }\end{array}$ & $\begin{array}{l}\text { Unvereinbar mit UIP-Muster } \\
\text { (jedes der sieben Charakteristika) }\end{array}$ \\
\hline $\begin{array}{l}\text { - subpleurale und basale Prädominanz } \\
\text { - retikuläre Veränderungen } \\
\text { - Honigwaben mit oder ohne Traktions- } \\
\text { bronchiektasen } \\
\text { - Fehlen von Charakteristika, die als } \\
\text { unvereinbar mit UIP-Muster gelistet sind } \\
\text { (siehe dritte Säule) }\end{array}$ & $\begin{array}{l}\text { - subpleurale und basale Prädominanz } \\
\text { - retikuläre Veränderungen } \\
\text { - Fehlen von Charakteristika, die als } \\
\text { unvereinbar mit UIP-Muster gelistet sind } \\
\text { (siehe dritte Säule) }\end{array}$ & $\begin{aligned} & \text { - } \text { Ober- oder Mittelfeldprädominanz } \\
& \text { - } \text { peribronchovaskuläre Prädominanz } \\
& \text { - extensive Milchglasveränderungen } \text { (Ausmaß> retikuläre Veränderungen) } \\
& \text { - profuse mikronoduläre Veränderungen } \text { (bilateral, prädominant Oberlappen) } \\
& \text { - diskrete Zysten (außerhalb der Areale mit } \text { Honigwaben) } \\
& \text { - diffuses Mosaikmuster/air-trapping (bilateral, } \text { in } 3 \text { oder mehr Lappen) } \\
& \text { - Konsolidierung in bronchopulmonalen } \\
& \text { Segmenten/Lappen }\end{aligned}$ \\
\hline
\end{tabular}
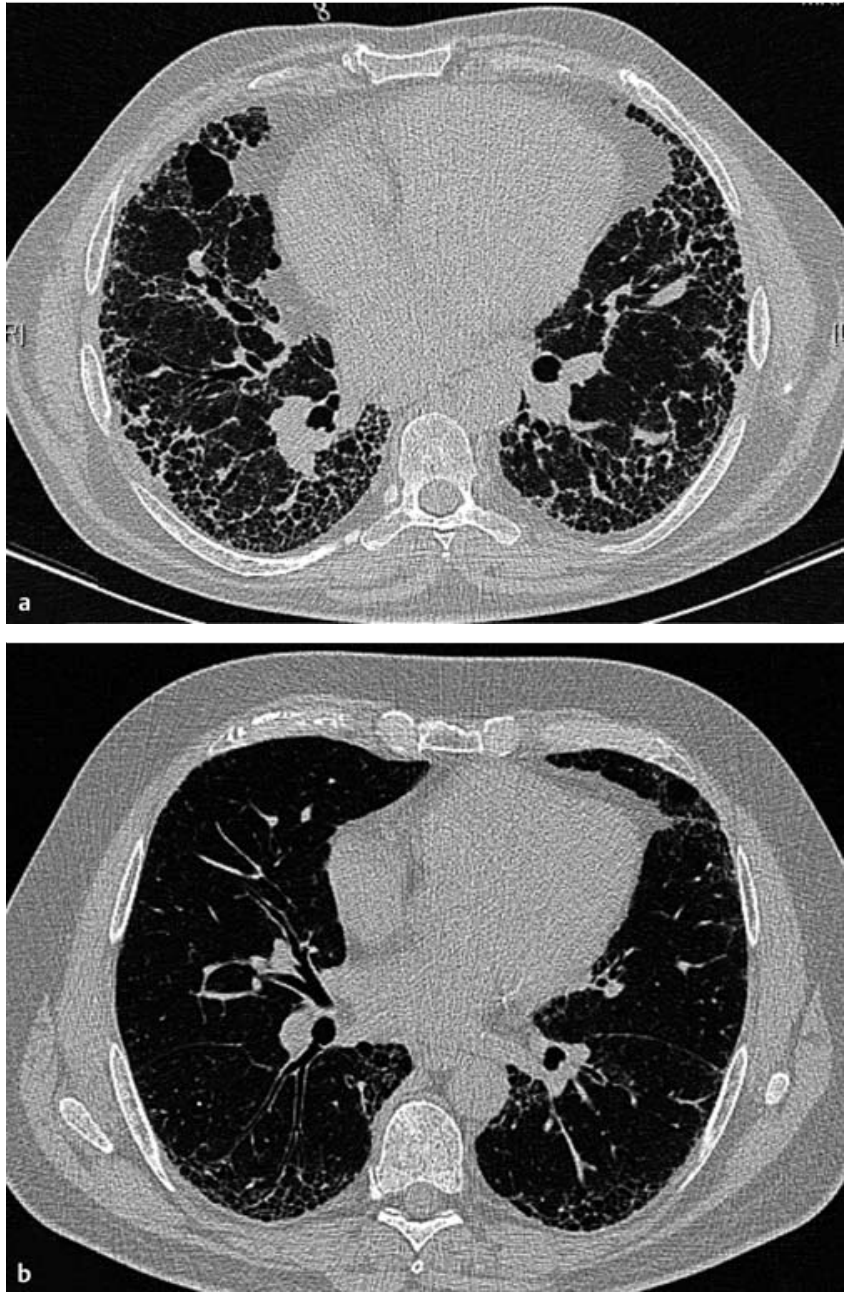

veränderten oder normalen Parenchyms abwechseln [1,2,4] ( Tab.4, $\bullet$ Abb.2). Diese histopathologischen Veränderungen betreffen oft am stärksten das subpleurale und paraseptale Parenchym. Eine meist geringgradige Entzündung zeigt sich als fleckförmiges interstitielles Infiltrat von Lymphozyten und Plasmazellen, verbunden mit einer Hyperplasie der Typ-II-Pneumozyten und des Bronchiolenepithels. Die fibrotischen Zonen bestehen überwiegend aus dichtem Kollagen, wobei aber regelmäßig verstreute konvexe subepitheliale Herde proliferierender Fibroblasten und Myofibroblasten (sog. Fibroblastenherde) zu finden sind. Die Honigwaben bestehen aus zystischen fibrotischen Luft-

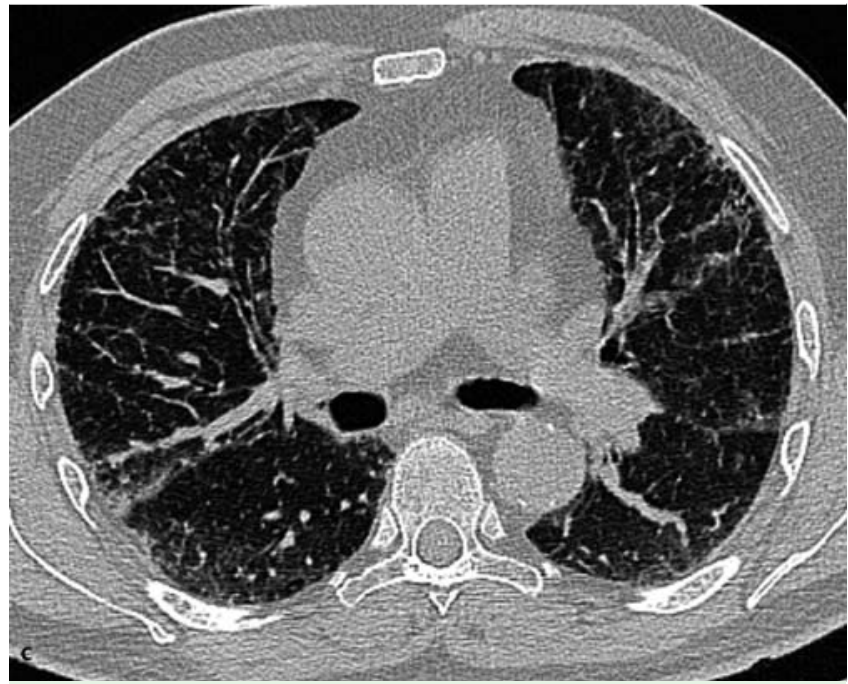

Abb. 1 HRCT (high resolution-CT)-Bilder eines UIP (Usual Interstitial Pneumonia)-Musters und des Musters einer möglichen UIP. (a) UIP-Muster mit deutlichem Wabenumbau: basal und peripher betont retikuläre Verdichtungen und mehrschichtige Honigwaben. (b) UIP-Muster mit weniger ausgeprägten subpleuralen Honigwaben. (c) Muster einer möglichen UIP: peripher und basal betont retikuläre Verdichtungen mit mäßiggradigen Milchglasverschattungen aber ohne Wabenumbau.

räumen, die häufig von Bronchiolenepithel ausgekleidet und mit Schleim und Entzündungszellen gefüllt sind. Meist ist in den fibrotisch und wabenförmig umgebauten Arealen eine Metaplasie der glatten Muskelzellen im Interstitium zu erkennen.

Bei Vorliegen des histopathologischen Musters der UIP existieren nur wenige Differenzialdiagnosen, vor allem wenn man sich an die strengen Kriterien der UIP hält. Am wichtigsten ist die differenzialdiagnostische Abgrenzung der IPF gegenüber einem UIPMuster in anderen klinischen Kontexten wie Kollagenosen, arzneimittelinduzierten Veränderungen, chronischer exogen-allergischer Alveolitis und Pneumokoniosen (insbesondere Asbestose).

In manchen Fällen kann die Biopsie ein Fibrosemuster erkennen lassen, das nicht die eingangs genannten Kriterien für das UIPMuster erfüllt [2]. Diese Biopsien können als „nicht klassifizierbare Fibrose“ bezeichnet werden. In Ermangelung histologischer Befunde, die für eine andere Erkrankung (z.B. Hypersensitivitätspneumonitis, Sarkoidose etc.) diagnoseleitend wären, sind solche Biopsien bei entsprechenden klinischen und radiologi- 
Tab.4 Histopathologische Kriterien für ein UIP-Muster.

\begin{tabular}{|c|c|c|c|}
\hline $\begin{array}{l}\text { UIP-Muster } \\
\text { (alle vier Kriterien) }\end{array}$ & Wahrscheinliches UIP-Muster & $\begin{array}{l}\text { Mögliches UIP-Muster } \\
\text { (alle drei Kriterien) }\end{array}$ & $\begin{array}{l}\text { Kein UIP-Muster } \\
\text { (jedes der sechs Kriterien) }\end{array}$ \\
\hline $\begin{array}{l}\text { - deutliche Fibrose/Architektur- } \\
\text { zerstörung, +/- Honigwaben in } \\
\text { einer prädominant subpleura- } \\
\text { len/paraseptalen Verteilung } \\
\text { - fleckförmiger Befall des Lungen- } \\
\text { parenchyms durch Fibrose } \\
\text { - Vorhandensein von Fibroblas- } \\
\text { tenherden } \\
\text { - Fehlen von Charakteristika, } \\
\text { die gegen eine UIP und für eine } \\
\text { alternative Diagnose sprechen } \\
\text { (siehe vierte Säule) }\end{array}$ & $\begin{array}{l}\text { - deutliche Fibrose Architektur- } \\
\text { zerstörung, +/- Honigwaben } \\
\text { - Fehlen von entweder fleckförmi- } \\
\text { gem Befall oder von Fibroblas- } \\
\text { tenherden, aber nicht von bei- } \\
\text { dem } \\
\text { - Fehlen von Charakteristika, die } \\
\text { gegen eine UIP und für eine al- } \\
\text { ternative Diagnose sprechen } \\
\text { (siehe vierte Säule) ODER } \\
\text { - ausschließlich Honigwaben- } \\
\text { bildung }{ }^{1}\end{array}$ & $\begin{array}{l}\text { - fleckförmiger oder diffuser } \\
\text { Befall des Lungenparenchyms } \\
\text { durch Fibrose ohne interstitielle } \\
\text { Inflammation } \\
\text { - Fehlen von anderen Kriterien für } \\
\text { UIP (siehe UIP-Muster) } \\
\text { - Fehlen von Charakteristika, die } \\
\text { gegen eine UIP und für eine } \\
\text { alternative Diagnose sprechen } \\
\text { (siehe vierte Säule) }\end{array}$ & $\begin{array}{l}\text { - hyaline Membranen }{ }^{2} \\
\text { - organisierende Pneumonie }{ }^{2,3} \\
\text { - Granulome } \\
\text { - deutliche interstitielle inflam- } \\
\text { matorische Zellinfiltrate außer- } \\
\text { halb von Honigwaben } \\
\text { - prädominante bronchiolozentri- } \\
\text { sche Veränderungen } \\
\text { - andere Charakteristika, die für } \\
\text { eine alternative Diagnose spre- } \\
\text { chen }\end{array}$ \\
\hline
\end{tabular}

1 Dieses Szenario repräsentiert meist das Endstadium einer Lungenfibrose, wobei Segmente mit Honigwabenbildung biopsiert wurden, und das UIP-Muster in anderen, nicht biopsierten Bereichen vorliegen kann. Diese Biopsien mit ausschließlichem Honigwabenmuster zeichnen sich durch Honigwaben im HRCT aus. Solche Stellen sollten als Biopsieort vermieden werden.

${ }^{2}$ Kann mit akuter Exazerbation einer IPF assoziiert sein.

${ }^{3}$ Isolierte oder vereinzelte Granulome und/oder eine diskrete Komponente einer organisierenden Pneumonie können in Lungenbiopsien mit UIP-Muster vorkommen.

Tab.5 Kombination von HRCT und chirurgischer Lungenbiopsie in der Diagnostik der IPF (multidisziplinäre Diskussion erforderlich).

\begin{tabular}{|c|c|c|}
\hline HRCT-Muster ${ }^{1}$ & $\begin{array}{l}\text { Chirugisches Lungenbiopsie- } \\
\text { muster }^{1}\end{array}$ & Diagnose IPF?² \\
\hline \multirow[t]{2}{*}{ UIP } & $\begin{array}{l}\text { UIP } \\
\text { wahrscheinliche UIP } \\
\text { mögliche UIP } \\
\text { nicht klassifiziertbare Fibrose }{ }^{3}\end{array}$ & ja \\
\hline & keine UIP & nein \\
\hline \multirow[t]{3}{*}{ mögliche UIP } & $\begin{array}{l}\text { UIP } \\
\text { wahrscheinliche UIP }\end{array}$ & ja \\
\hline & $\begin{array}{l}\text { mögliche UIP } \\
\text { nicht klassifizierbare Fibrose }{ }^{3}\end{array}$ & wahrscheinlich \\
\hline & keine UIP & nein \\
\hline unvereinbar mit & UIP & möglich ${ }^{4}$ \\
\hline UIP & $\begin{array}{l}\text { wahrscheinliche UIP } \\
\text { mögliche UIP } \\
\text { nicht klassifizierbare Fibrose }{ }^{3} \\
\text { keine UIP }\end{array}$ & nein \\
\hline
\end{tabular}

${ }^{1}$ Muster siehe Tab. 3 und Tab. 4

2 Die Sicherheit der IPF-Diagnose wird durch eine multidisziplinäre Diskussion verbessert. Dies ist besonders relevant in Fällen, bei denen die radiologischen und histologischen Muster diskordant sind (z. B. HRCT unvereinbar mit UIP und histopathologischem UIP-Muster).

${ }^{3}$ Nicht klassifizierbare Fibrose: Manche Biopsien können ein Fibrosemuster aufweisen, welches nicht den Kriterien des UIP-Musters oder der anderen idiopathischen interstitiellen Pneumonien entspricht. Diese Biopsien können als „nicht klassifizierbare Fibrose" bezeichnet werden.

${ }^{4}$ Die multidisziplinäre Diskussion sollte die Möglichkeit eines „sampling errors“ (einer nicht repräsentativen Biopsie) und die Möglichkeit einer unzureichenden HRCTTechnik diskutieren. Beachte: In Fällen mit einem HRCT-Muster, das als „unvereinbar mit UIP“ beurteilt wird, und einem UIP-Muster in der chirurgischen Lungenbiopsie, kann doch eine IPF-Diagnose vorliegen, und die Klärung durch eine multidisziplinäre Diskussion unter Beteiligung von ILD-Experten ist angezeigt.

schen Anzeichen sowie nach sorgfältiger multidisziplinärer Würdigung mit der Diagnose IPF vereinbar $($ Tab.4 und $\bullet$ Tab.5).

Die diagnostischen Kriterien und der Algorithmus für erwachsene Patienten mit ILD und Verdacht auf IPF sind in $\bullet$ Abb. 3 und - Tab. 5 dargestellt. Der gewissenhafte Ausschluss alternativer Ätiologien durch ein multidisziplinäres Konsil von Pneumologen, Radiologen und Pathologen mit Erfahrung in der Diagnose von ILD ist von höchster Wichtigkeit für eine sichere Diagnose. Falls ein multidisziplinäres Konsil nicht möglich ist, wird die Überwei-

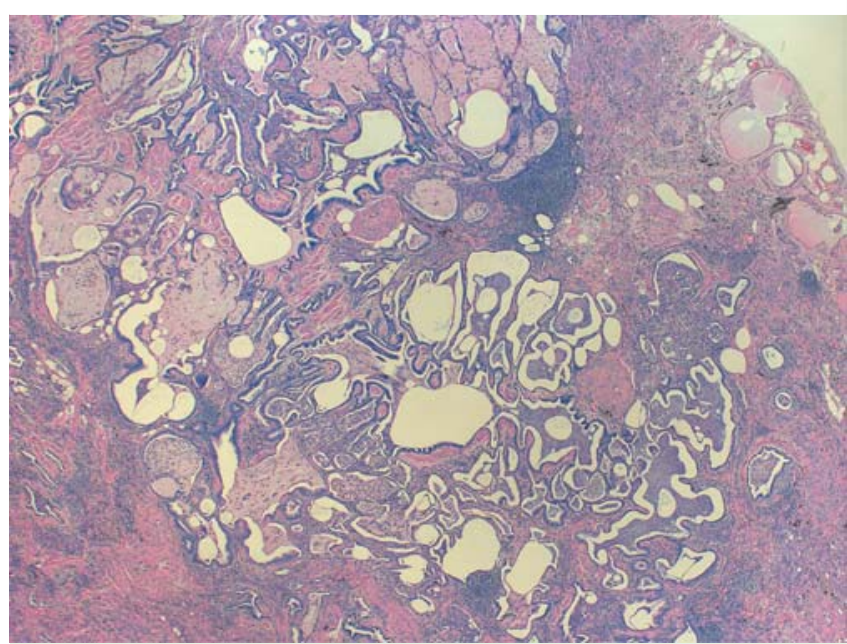

Abb.2 Chirurgische Lungenbiopsate mit UIP-Muster. In der Übersichtsmikroskopie zeigt sich ein heterogener Prozess mit wabenförmigen Räumen, Gebieten noch erhaltenen Lungenparenchyms und fibrotischen Veränderungen, die sich von der subpleuralen Region in die Lunge erstrecken.

sung zu erfahrenen klinischen ILD-Experten zwecks Konsultation empfohlen.

Die im vorliegenden Dokument präsentierten diagnostischen Kriterien für IPF wurden gegenüber dem früheren ATS/ERSStatement erheblich modifiziert [2]. Angesichts der hochrangigen Evidenz für die Spezifität der HRCT in der Erkennung des histopathologischen Musters einer UIP ist die chirurgische Lungenbiopsie nicht mehr obligat $[102,103,107,108]$. Unter bestimmten klinischen Voraussetzungen (s. Abschnitt „Klinisches Bild“; dazu zählen eine gründliche medizinische, arbeits-/umweltmedizinische und familiäre Anamnese sowie körperliche, Lungenfunktions- und Laboruntersuchungen) reicht das Vorliegen eines UIP-Musters in der HRCT für die Diagnose IPF aus. Somit entfallen die Major- und Minor-Kriterien für die klinische (d.h. nicht pathologische) Diagnose der IPF [2]. 


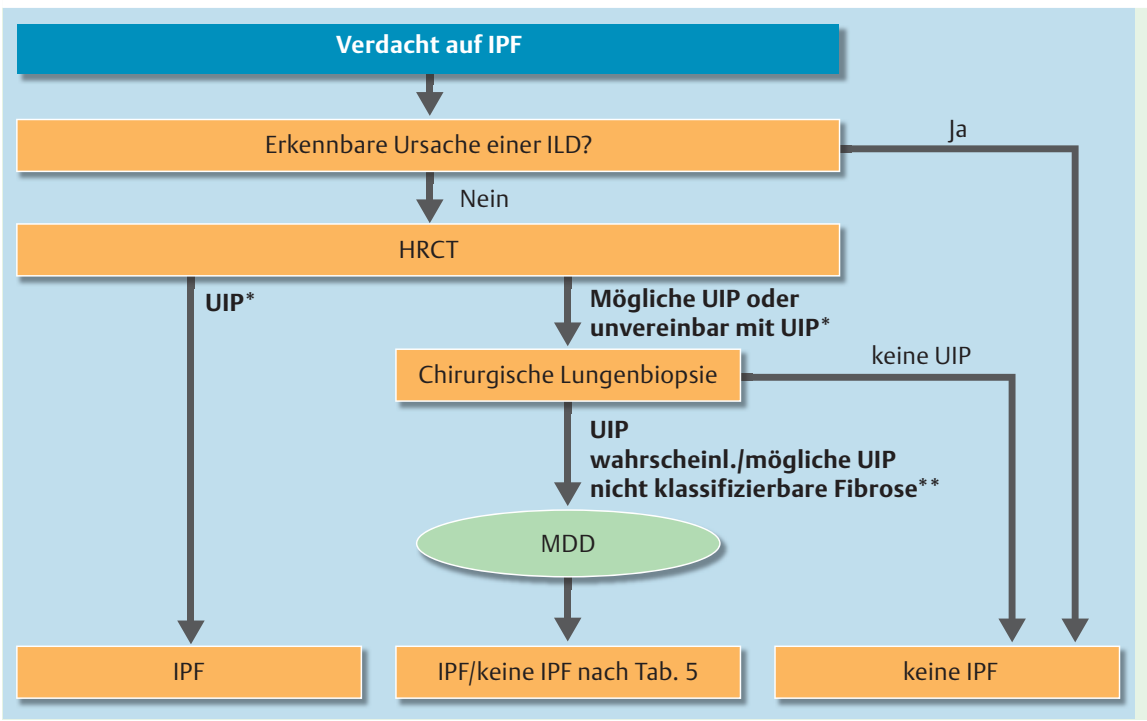

Abb. 3 Diagnostischer Algorithmus bei idiopathischer Lungenfibrose (IPF).

* Definitionen siehe Tab.3.

** Definitionen siehe $\bullet$ Tab.4.

\subsection{Diagnostische Kriterien}

Die Diagnose IPF setzt Folgendes voraus:

1. Ausschluss anderer bekannter Ursachen einer ILD (z. B., häusliche und berufliche Umweltbelastung insbesondere im Hinblick auf eine exogen-allergische Alveolitis, Pneumokoniosen, Kollagenosen, Medikamente)

2. Bei Patienten ohne chirurgische Lungenbiopsie Vorliegen eines UIP-Musters im HRCT-Befund (s. $\odot$ Tab.3)

3. Bei Patienten mit chirurgischer Lungenbiopsie bestimmte Musterkombinationen im HRCT- und Biopsiebefund

(s. Tab.4 und $\odot$ Tab.5)

Somit wird die Diagnose IPF mit der Korrelation klinischer, radiologischer und histopathologischer Befunde zunehmend sicherer und lässt sich durch ein multidisziplinäres Konsil erfahrener klinischer Experten auf dem Gebiet der ILD erhärten [109]. Dies ist insbesondere in den Fällen von Bedeutung, in denen das radiologische und histopathologische Muster diskordant sind (wenn also beispielsweise die HRCT nicht mit einer UIP vereinbar ist, wohl aber die Histopathologie). Ein UIP-Muster im HRCT- oder Histologiebefund ist nicht $100 \%$ ig spezifisch [2,4,110-112]. Diskordante histologische Muster in chirurgischen Lungenbiopsaten aus verschiedenen Lungensegmenten wurden beschrieben. Fälle, in denen ein UIP-Muster und das Muster einer fibrotischen NSIP gleichzeitig vorliegen (diskordante UIP), scheinen sich ähnlich zu verhalten wie solche mit einem UIP-Muster in allen Lungenlappen (konkordante UIP) $[113,114]$. Dies spricht dafür, bei Verdacht auf IPF chirurgische Lungenbiopsate aus mehreren Lappen (d.h. zwei bis drei) zu entnehmen.

\section{Kommentar}

Präoperativ und interdisziplinär sollen die Seite und die Segmente der Biopsie unter Berücksichtigung der HRCT festgelegt werden. Gebiete, die ausschließlich aus Honigwaben bestehen, sollen nicht biopsiert werden.

(Abstimmung: 22 Ja, 0 Nein, 0 Enthaltung)

In mehreren Studien wurde die Video-assistierte Thorakoskopie (VATS) mit der offenen Thorakotomie verglichen [115-118]. Die diagnostische Ausbeute der chirurgischen Lungenbiopsie ist bei beiden Verfahren vergleichbar. Auch wenn die VATS mit einer geringeren Morbidität und kürzeren Verweildauer als der offene
Eingriff verbunden sein mag, sollte die Wahl des Verfahrens die Gegebenheiten des Einzelfalls und der chirurgischen Erfahrung berücksichtigen. Bei Patienten mit schweren Lungenfunktionsstörungen oder erheblicher Begleitmorbidität können die Risiken der chirurgischen Lungenbiopsie die Vorteile einer gesicherten IPF-Diagnose überwiegen. Letztlich muss die Entscheidung, ob eine chirurgische Lungenbiopsie angezeigt ist oder nicht, maßgeblich von der klinischen Situation des jeweiligen Patienten abhängig gemacht werden.

\subsection{Ausschluss anderer bekannter Ursachen}

Der Ausschluss anderer bekannter Ursachen einer ILD ist ein weit gefasstes und naturgemäß subjektives Kriterium, auf das hier aber näher eingegangen werden soll. Eine sorgfältige Anamnese und körperliche Untersuchung mit Schwerpunkt auf Systemerkrankungen, Medikamenteneinnahme, Umweltbelastungen und Familienanamnese ist unerlässlich, wobei sich eine standardisierte Vorgehensweise empfiehlt. Dafür gibt es zwar keine validierten Instrumente, hilfreich ist aber ein Fragebogen wie er z.B. über das American College of Chest Physicians erhältlich ist (http://www.chestnet.org/memberResources/downloads/networks/IDLDquestionnaire.pdf). Besonders wichtig ist es, die Patienten gründlich auf eine eventuelle chronische exogen-allergische Alveolitis zu untersuchen, da diese eine IPF vortäuschen kann. Das auslösende Antigen ist trotz sorgfältiger Suche nicht immer identifizierbar [119]. Bei einer Lymphozytose in der bronchoalveolären Lavage (BAL) von $40 \%$ oder mehr sollte man in diesem Kontext an eine bislang unbekannte exogen-allergische Alveolitis denken und weitere Untersuchungen auf Umweltbelastungen sowie eventuell eine chirurgische Lungenbiopsie veranlassen. Patienten, die den anerkannten Kriterien einer Kollagenose entsprechen, haben keine IPF. Jüngere Patienten - vor allem Patientinnen-ohne klinische oder serologische Zeichen entwickeln mitunter erst später die klinischen Zeichen einer Bindegewebserkrankung. Daher ist bei jüngeren Patienten (unter 50J.) ein hoher Verdachtsindex für Kollagenosen angezeigt.

\section{Kommentar}

Generell soll bei Patienten unter 50 Jahren die Diagnose einer sporadischen IPF kritisch hinterfragt werden.

(Abstimmung: 20 Ja, 1 Nein, 1 Enthaltung) 
Frage: Soll bei Verdacht auf IPF eine zelluläre BAL-Analyse durchgeführt werden?

Eine zelluläre BAL-Analyse kann in der Diagnostik bestimmter Formen von ILD sinnvoll sein. Bei der Abklärung von Patienten mit Verdacht auf IPF dient die BAL in erster Linie dem Ausschluss einer chronischen exogen-allergischen Alveolitis, wobei eine ausgeprägte Lymphozytose ( $>40 \%)$ die Diagnose nahe legt. Neueren retrospektiven Daten zufolge können bei $8 \%$ der Patienten mit einem UIP-Muster in der HRCT BAL-Befunde vorliegen, die auf eine andere Diagnose hinweisen [120]. Es ist unklar, ob die BAL bei einer sorgfältigen Expositionsanamnese und klinischer Beurteilung überhaupt einen relevanten Zugewinn an diagnostischer Spezifität bedeutet.

Empfehlung: Eine zelluläre BAL-Analyse sollte in der Diagnostik der IPF nicht durchgeführt werden (schwache Empfehlung, geringgradige Evidenz).

Wertung: Diese Empfehlung misst dem zusätzlichen Risiko und den Kosten der BAL bei Patienten mit IPF einen hohen, und der Möglichkeit einer höheren diagnostischen Spezifität einen geringen Wert bei.

Kommentar: Diese Empfehlung bezieht sich ausschließlich auf das Differenzialzellbild der BAL-Analyse. Sie bezieht sich nicht auf die Anwendung der Lavage zur Abklärung einer Infektion, oder malignen Neoplasie etc. Gegenwärtig sollte die Anordnung einer zellulären BAL-Analyse in der Diagnostik von IPF-Patienten nach Ermessen des behandelnden Arztes und je nach Kapazität sowie Erfahrung an der jeweiligen Einrichtung/in dem zuständigen Labor erwogen werden.

\section{Kommentar}

Das Risiko der BAL ist gering und die Kosten der Untersuchung sind moderat, der Zugewinn an therapierelevanten Informationen kann jedoch erheblich sein [120]. Daher wird in Europa die BAL in den meisten Zentren routinemäßig bei fast allen Patienten in der ILD-Diagnostik durchgeführt, auch bei solchen mit Verdacht auf IPF. Zur Abgrenzung von Differenzialdiagnosen sollte bei Verdacht auf IPF die BAL durchgeführt werden (schwache Empfehlung, geringe Evidenz).

(Abstimmung: 22 Ja, 0 Nein, 0 Enthaltung)

Frage: Sollte bei Verdacht auf IPF eine transbronchiale Lungenbiopsie durchgeführt werden?

Eine transbronchiale Lungenbiopsie ist zur Beurteilung ausgewählter Erkrankungen sinnvoll (z. B. granulomatöse Erkrankungen wie Sarkoidose). Liegt in der HRCT ein UIP-Muster vor, sind solche Erkrankungen unwahrscheinlich $[102,103,107]$. Die Spezifität und der positiv prädiktive Wert eines mittels transbronchialer Biopsie identifizierten UIP-Musters wurden bisher nicht hinlänglich an Fällen von IPF untersucht, die einer histopathologischen Untersuchung bedurften. Auch wenn transbronchiale Biopsate alle histologischen Zeichen einer UIP aufweisen können [121], sind Sensitivität und Spezifität dieser Methode für die Diagnose eines UIP-Musters unbekannt. Ebenso wenig ist bekannt, wo und wie viele transbronchiale Biopsate entnommen werden sollen.

Empfehlung: Eine transbronchiale Biopsie sollte in der Diagnostik der IPF nicht durchgeführt werden (schwache Empfehlung, geringe Evidenz).
Wertung: Diese Empfehlung misst der zusätzlichen Morbidität, die eine transbronchiale Lungenbiopsie für IPF-Patienten mit nachfolgender chirurgischer Lungenbiopsie bedeutet, einen hohen, und dem möglichen diagnostischen Spezifitätsgewinn einen geringen Wert bei.

Frage: Sollen bei Verdacht auf IPF serologische Tests auf Kollagenosen durchgeführt werden?

Zur Rolle des serologischen Screenings bei Patienten mit Verdacht auf IPF liegen keine zuverlässigen Daten vor. Kollagenosen können mit einem UIP-Muster einhergehen [122] und eine ILD kann als einzige klinische Manifestation dieser Krankheiten auftreten, bevor sich das Vollbild einer spezifischen Bindegewebserkrankung manifestiert [123].

Empfehlung: Serologische Tests auf Kollagenosen sollten in der Diagnostik der IPF durchgeführt werden (schwache Empfehlung, sehr geringe Evidenz).

(Abstimmung: 11 Ja, 8 Nein, 3 Enthaltungen)

Wertung: Diese Empfehlung misst der Abgrenzung von Kollagenosen gegenüber IPF einen hohen, und den Kosten einen geringen Wert bei.

Kommentar: Eine serologische Untersuchung sollte selbst dann durchgeführt werden, wenn keine Zeichen und Symptome einer Kollagenose vorliegen, und sollte die Bestimmung von Rheumafaktor, aCCP (Antikörper gegen zyklisch-zitrullinierte Peptide) sowie Titer und Fluoreszenzmuster von ANA (antinukleäre Antikörper) beinhalten. Die routinemäßige Testung auf weitere serologische Parameter wie Anti-Synthetase-Antikörper (z.B. Jo-1), Kreatininkinase und Aldolase, Sjögren-Antikörper (SS-A, SS-B) sowie Sklerodermie-Antikörper (scl-70, PM-1) ist von unklarem Wert, kann aber in ausgewählten Fällen hilfreich sein. IPF-Patienten können einen schwach positiven ANA-Titer und/oder Rheumafaktor ohne sonstige klinische Anzeichen einer Kollagenose haben. Solche Patienten sollten sorgfältig auf Zeichen und Symptome einer Kollagenose (z.B. Arthritis, Raynaud-Phänomen, Hautveränderungen, Ösophagusmotilitätsstörung) gescreent werden. Fehlen zusätzliche serologische oder klinische Zeichen zur Erhärtung der Diagnose Kollagenose, ist die Diagnose IPF zutreffend. Eine erneute serologische und klinische Untersuchung im Zuge der Verlaufsbeobachtung kann später die Entstehung einer Kollagenose bestätigen. In diesem Fall ist die Diagnose zu revidieren.

Frage: Soll bei Verdacht auf IPF ein multidisziplinäres Konsil durchgeführt werden?

Die Diagnostik der IPF ist per definitionem multidisziplinär, da sie auf der Kompetenz erfahrener Kliniker, Radiologen und Pathologen aufbaut. Es hat sich gezeigt, dass eine funktionierende Kommunikation zwischen den einzelnen an der Diagnose beteiligten Disziplinen (Pneumologie, Radiologie, Pathologie) die interindividuelle Übereinstimmung zwischen erfahrenen klinischen Experten hinsichtlich der endgültigen Diagnose erhöht $[109,124]$.

Empfehlung: Wir empfehlen, bei der Beurteilung der IPF ein multidisziplinäres Konsil einzusetzen (starke Empfehlung, geringe Evidenz).

Wertung: Diese Empfehlung misst der korrekten Diagnose der IPF einen hohen, und dem Zugang zu sowie der Verfügbarkeit von Experten für ein multidisziplinäres Konsil einen geringen Wert bei.

Kommentar: Es wird eingeräumt, dass in der Praxis ein formelles multidisziplinäres Konsil zwischen den behandelnden Pneumologen, Radiologen und Pathologen oft nicht möglich ist. Dennoch 


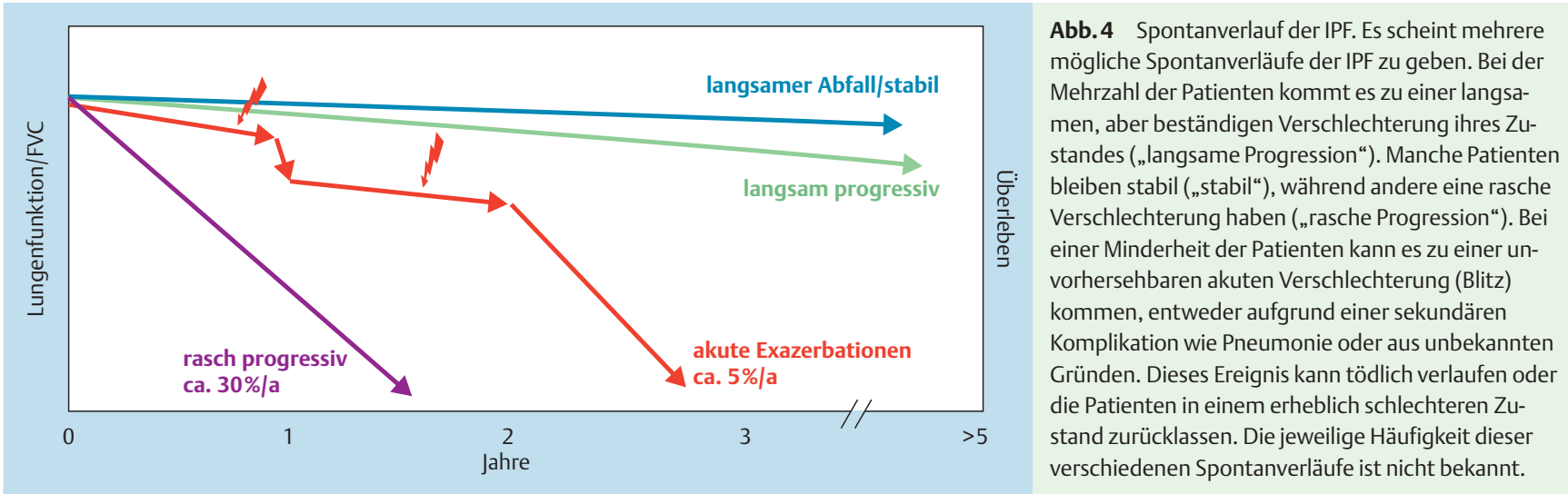

sollten sich die beteiligten Disziplinen im Rahmen der Beurteilung eines Falles zumindest um eine vermehrte verbale Kommunikation bemühen. Die Daten von Studien weisen darauf hin, dass die diagnostische Sicherheit durch ein multidisziplinäres Konsil zwischen ILD-Experten im Vergleich zu allgemeinen Spezialisten verbessert wird [124]. Eine frühzeitige Überweisung an ILD-Experten wird daher empfohlen.

Patienten mit Verdacht auf IPF (d.h. Patienten mit ungeklärter Belastungsdyspnoe und/oder Husten mit Anzeichen einer interstitiellen Lungenkrankheit [ILD]) sollten sorgfältig auf erkennbare Ursachen der ILD untersucht werden, einschließlich Erhebung einer gründlichen Expositionsanamnese, die die gesamte Lebenszeit des Patienten umfassen muss. Ist keine Ursache erkennbar, ist das Vorliegen eines UIP-Musters in der HRCT diagnosesichernd. Zeigt die HRCT kein UIP-Muster, kann die IPF durch die Kombination bestimmter Muster im HRCT- und histopathologischen Befund diagnostiziert werden. Die Sicherheit der Diagnose IPF erhöht sich durch eine multidisziplinäre Diskussion (MDD) zwischen ILD-Experten.

\section{Spontanverlauf der IPF \\ $\nabla$}

4.1 Unterschiedliche Verläufe bei IPF prägen das Bild

Der Spontanverlauf der IPF zeichnet sich durch eine progrediente Verschlechterung der subjektiv empfundenen bzw. objektiv gemessenen Funktion vom Erkrankungsbeginn bis zum Tod durch respiratorisches Versagen oder komorbiditätsbedingte Komplikationen aus [125-127]. Der mittlere Verlust der FVC (=forcierte Vitalkapazität) beträgt etwa 150-200 ml pro Jahr [128].

Eine eindeutige Bewertung des mittleren Überlebens bei IPF ist aufgrund der vorliegenden Längsschnittuntersuchungen nicht möglich. Mehrere retrospektive Längsschnittuntersuchungen geben ein medianes Überleben von $2-3$ Jahren ab Diagnosestellung an [129-133]. Anhand neuerer Daten aus klinischen Studien an Patienten mit erhaltener Lungenfunktion stellt sich dieses mediane Überleben jedoch als möglicherweise zu gering dar [134136]. Mittlerweile unbestritten ist, dass es unterschiedliche Spontanverläufe der IPF gibt ( $\bullet$ Abb.4) [137] und dass zum Zeitpunkt der Diagnose der individuelle Spontanverlauf im Einzelfall nicht vorhersagbar ist. Bei der Mehrzahl der Patienten ist eine langsame, allmähliche Progression über viele Jahre zu beobachten. Einige bleiben stabil, während sich bei anderen eine rasche Verschlechterung einstellt („Akute Exazerbation“, siehe unten) [138]. Bei manchen Patienten kommt es episodisch zu akuten Verschlechterungen der Atemfunktion. Es ist nicht hinreichend sicher beurteilbar, ob diese unterschiedlichen Spontanverläufe verschiedenen Phänotypen der IPF entsprechen, oder ob der Spontanverlauf geographischen, ethnischen, kulturellen oder anderen Einflüssen unterliegt. Auf den Krankheitsverlauf können zudem Begleiterkrankungen wie ein Emphysem oder eine pulmonale Hypertonie Auswirkungen haben [139-141].

Auch die familiäre Form der IIP ist durch eine deutliche Variabilität des Verlaufes gekennzeichnet: so wurden bei einer Familie Erstdiagnosen im Alter von 4 Monaten bis hin zu 57 Jahren [61] gestellt, was die Bedeutung Krankheits-modifizierender Gene wie auch exogener Faktoren belegt. Die familiäre Form der IIP mit UIP-Muster hat eine ähnlich schlechte Prognose wie die sporadische IPF [94].

\subsection{Akute Exazerbation der IPF}

Beobachtungen zufolge kommt es bei etwa 5-10\% [136, 142, 143], nach neueren Daten bis zu 14\% [144] der Patienten mit IPF jährlich zu einer akuten respiratorischen Dekompensation. Diese Episoden können sekundär infolge häufiger Komplikationen wie Pneumonien, Lungenembolien, Pneumothorax oder Herzinsuffizienz auftreten $[145,146]$. Lässt sich keine Ursache identifizieren, spricht man von einer „akuten Exazerbation der IPF“ [147-157]. Es konnte bisher nicht hinreichend sicher geklärt werden, ob eine akute Exazerbation der IPF einfach Manifestation einer nicht identifizierten respiratorischen Komplikation (z. B. Lungenembolie, Infektion) ist, die zur akuten Verschlechterung beiträgt, oder ob sie eine inhärente Beschleunigung der an der IPF beteiligten pathobiologischen Prozesse selbst darstellt. Neuere Genexpressionsstudien an Patienten mit akuten Exazerbationen einer IPF ergaben keinen sicheren Hinweis auf eine infektionsbedingte Ätiologie $[158,159]$.

Zu den Kriterien einer akuten Exazerbation der IPF zählen bislang eine nicht anderweitig erklärbare Zunahme der Dyspnoe innerhalb der letzten 4 Wochen, eine Verschlechterung oder schwere Beeinträchtigung des Gasaustausches (Hypoxämie), neu aufgetretene alveoläre Infiltrate und das Fehlen einer alternativen Erklärung wie Infektionen, Lungenembolie, Pneumothorax oder Herzinsuffizienz [142]. Eine akute Exazerbation kann zu jedem beliebigen Zeitpunkt im Verlauf der IPF auftreten und ist in einigen Fällen auch der Grund für die Erstdiagnose [149,153, 160,161]. Zum Spektrum der Symptome gehören weiterhin eine Verschlimmerung des Hustens, Fieber und/oder vermehrtes Sputum $[148,149,153]$. Obwohl bis dato keine Risikofaktoren für eine akute Exazerbation der IPF bekannt sind, existieren Berichte über eine akute respiratorische Dekompensation nach Thoraxchirurgie [162-166] und bronchoalveolärer Lavage [149,167]. Unklar ist, ob es sich dabei um echte akute Exazerbationen oder um Komplikationen der jeweiligen Eingriffe handelt. 
Histologisch manifestiert sich die akute Exazerbation der IPF als akuter oder organisierender, diffuser Alveolarschaden (diffuse alveolar damage, DAD) oder, weniger häufig, als organisierende Pneumonie in Zonen relativ gut erhaltenen Lungenparenchyms, fern von den am stärksten fibrotisch veränderten Regionen [142]. Wie aus Einzelfällen bekannt ist, kann eine unzureichende und unkritische Probenentnahme dazu führen, dass die Probe nur ein typisches UIP-Muster oder aber die organisierende Phase eines DADerkennen lässt, ohne histologische Hinweise auf die zugrunde liegende UIP zu liefern [153]. Die im Text zitierten Genomexpressionsstudien, auch die jüngst publizierte von Wootton et al. [159] weisen Schwächen im Design auf und erlauben keinen definitiven Ausschluss einer infektionsbasierenden Ätiologie (RNAViren z. B. aufgrund des Zeitfensters überhaupt nicht erfasst). In der Summe ist der Stellenwert respiratorischer Infekte bei der Entwicklung und der Progression noch nicht abschließend beurteilbar.

\subsection{Mortalität}

Die Zahl der Todesfälle durch Lungenfibrose steigt mit zunehmendem Lebensalter $[10,168]$. Zudem gibt es Anhaltspunkte für eine im Verlauf der letzten 2 Jahrzehnte angestiegene Mortalität durch Lungenfibrose $[10,168]$. In einer kürzlich erfolgten Auswertung der Totenscheine in den USA wurde eine signifikante Steigerung der Mortalität durch Lungenfibrose zwischen 1992 und 2003 festgestellt [168]. Auch im Vereinigten Königreich ist die IPF-bedingte Mortalität angestiegen [169]. Bei Anwendung der striktesten Definition der IPF lag die Mortalitätsrate in den USA 2003 bei 61,2 Todesfällen pro 1000000 Männern und 54,5 pro 1000000 Frauen [168]. In Japan betrug die geschätzte Mortalitätsrate durch IPF bei Männern 33, bei Frauen 24 pro 1000000 [14]. Die auf IPF zurückführbare Mortalitätslast ist höher als die einiger Karzinome [174]. Neuerer Evidenz zufolge ist die IPF-bedingte Mortalität in den USA in den Wintermonaten höher [171]. IPF-Patienten sterben auch nach neueren Untersuchungen überwiegend (zu 60\%) an den Folgen der Grunderkrankung [146, 168, 171,172]. Als weitere relevante Morbiditäts- und Mortalitätsursachen kommen koronare Herzkrankheit, Lungenembolien und Lungenkrebs hinzu [173].

\section{Stadieneinteilung und Prognose}

Schweregrad des Krankheitsstadiums und der Funktionseinschränkung variieren zum Zeitpunkt der Diagnose der IPF erheblich. Die Gründe dafür sind in der Variabilität der subjektiven Wahrnehmung und der unterschiedlichen Vertrautheit der Behandler gegenüber der Symptomatik zu vermuten. Für die Stadieneinteilung wurden Begriffe wie „leicht”, „mäßig”, „,hochgradig”, „früh” und „fortgeschritten” vorgeschlagen. Diese Stadien beruhen meist auf Lungenfunktionswerten in Ruhe und/oder dem Ausmaß radiologischer Veränderungen. Allerdings ist nicht bekannt, ob ein solcher Ansatz für die klinische Entscheidungsfindung relevant ist.

Neuere Studien haben Prädiktoren für das Überleben von Patienten mit IPF dargelegt. Der Wert dieser Prädiktoren ist allerdings durch Unterschiede im Studiendesign (z. B. retrospektive Analyse) eingeschränkt. Die Konsensuskonferenz stellt fest, dass Patienten mit einem erhöhtem Risiko, innerhalb der nächsten 2 Jahre zu versterben, identifiziert werden müssen, damit eine frühzeitige Prüfung auf Transplantationsfähigkeit und Listung bzw. eine reale Option für eine LTX gewährleistet werden kann. Bislang noch eingeschränkte Datensätze legen nahe, dass einige ausgewählte,
Tab.6 Ausgewählte Faktoren, die mit einer erhöhten Mortalität einhergehen.

Ausgangsbefunde:
- Schweregrad der Dyspnoe
- Diffusionskapazität im Single-Breath-Verfahren (DLCo) $<40 \%$ des Soll-
wertes
- Abfall der transkutanen $\mathrm{O}_{2}$-Sättigung $\leq 88 \%$ während des 6-Minuten-
Gehtests
- Ausmaß der Honigwabenbildung in der hoch-auflösenden CT
- pulmonale Hypertonie
Verlaufsbefunde:
- Zunahme der Dyspnoe
- Abfall der FVC $\geq 10 \%$ (absolut)
- Abfall der DLco $\geq 15 \%$ (absolut)
- Zunahme der Fibrose in der HRCT

in der klinischen Praxis regelmäßig erfasste Parameter mit einer erhöhten Sterblichkeit einhergehen (siehe auch Tab.6). Aufgrund der Variabilität des Spontanverlaufs der IPF ist nicht bekannt, ob das Vorliegen eines oder mehrerer dieser Parameter geeignet ist, eine Subpopulation von Patienten mit „fortgeschrittener IPF“ oder „IPF im Endstadium“ zu identifizieren.

\subsection{Demografische Faktoren}

Für ältere, männliche Patienten berichten einige, aber nicht alle Studien eine schlechtere Prognose [7,130,174-180]. Es wurde auch gezeigt, dass Zigarettenrauchen sowohl mit einem erhöhten $[133,181]$ als auch einem verringerten Mortalitätsrisiko verbunden sein kann. Der prognostische Wert geografischer, ethnischer und kultureller Faktoren ist unbekannt.

Einer neueren Studie an 1099 IPF-Patienten zufolge ist das Alter, nicht aber das Geschlecht oder der ethnische Hintergrund ein unabhängiger prognostischer Faktor [182].

\subsection{Ausmaß der Dyspnoe}

Eine Korrelation zwischen dem anfänglichen Schweregrad der Dyspnoe und der Lebensqualität sowie dem Überleben wurde in verschiedenen Studien festgestellt [7,183-186]. Die Dyspnoe wurde mit verschiedenen Messinstrumenten erfasst, wie der MRC (Medical Research Council)-Dyspnoeskala, dem BaselineDyspnea-Index, Instrumenten zur Messung der Lebensqualität (QoL) mit Fragebögen zu respiratorischen Problemen, der BorgSkala, dem Atemnot-Fragebogen (shortness of breath questionnaire) der University of California San Diego (UCSD SOBQ) sowie einem Scoring-System, das klinische, radiologische und physiologische Parameter der Dyspnoe erfasst [187-189]. Unklar bleibt, welches dieser Werkzeuge am besten geeignet ist, prognostisch relevante Aussagen für die IPF zu liefern. Nach einer neueren Studie ist dies zumindest für den UCSD SOBQ wie auch für den St George Respiratory Questionnaire (SGRQ) der Fall [186]. Auch eine Zunahme der Dyspnoe mit der Zeit hat sich als negativer Prädiktor für das Überleben erwiesen [190].

\subsection{Physiologische Parameter}

Die Ausgangswerte der Lungenfunktion zeigten keine konsistente Beziehung zum Überleben bei IPF. Dies kann teilweise auf Begleiterkrankungen, wie ein Emphysem, eine pulmonale Gefäßerkrankung und Adipositas, oder aber auf technische Unterschiede bei der Funktionsprüfung zurückzuführen sein. Der Ausgangswert der forcierten Vitalkapazität (FVC) ist von unklarem prädiktivem Wert [7,176,178,180,184,190-193]. Der Ausgangswert der Diffusionskapazität für Kohlenmonoxid (DLco, Ein-Atemzug- 
methode, Hämoglobin-korrigiert) ist hingegen ein zuverlässigerer Prädiktor für das Überleben, wobei eine Schwelle von ca. $40 \%$ des Sollwertes mit einem erhöhten Mortalitätsrisiko verbunden ist [190,191,194,195]. Es liegen begrenzt Daten vor, denen zufolge der Ausgangswert der totalen Lungenkapazität (TLC) und der alveolo-arteriellen Sauerstoffdifferenz $\left(\mathrm{P}(\mathrm{A}-\mathrm{a}) \mathrm{O}_{2}\right)$ das Überleben prognostizieren können, aber es gibt keinen eindeutigen Schwellenwert [189]. Auch der Ausgangswert des kardiopulmonalen Belastungstests (maximale Sauerstoffaufnahme) wurde als Prädiktor für das Überleben vorgeschlagen [196].

Eine longitudinale Veränderung physiologischer Parameter ist eindeutig ein wichtiger, wenn nicht in der klinischen Routine der wichtigste Prädiktor der Mortalität bei IPF. Eine Abnahme der FVC im Verlauf von 6 oder 12 Monaten ist konsistent mit einem verringerten Überleben assoziiert [180,190,191,195,197]. Auch eine Verschlechterung der DLco ist mit einem verkürzten Überleben verbunden, wenn auch weniger zuverlässig [190,191, 195,197]. Eine Zunahme der $\mathrm{P}(\mathrm{A}-\mathrm{a}) \mathrm{O}_{2}$ um mehr als $15 \mathrm{mmHg}$ nach 12 Monaten erwies sich als Prädiktor für das Überleben [191]. Veränderungen der TLC und $\mathrm{P}(\mathrm{A}-\mathrm{a}) \mathrm{O}_{2}$ über 6 Monate können ebenfalls prognostisch für das Überleben sein [190].

In einer jüngst publizierten Studie mit 1099 IPF-Patienten erwiesen sich neben dem Alter der Patienten auch eine vorangegangene Hospitalisierung aufgrund respiratorischer Beschwerden, der Ausgangswert der FVC und der DLco in Prozent des Solls und der Abfall der FVC bzw. der DLco sowie von Parametern der Lebensqualität binnen 24 Wochen als unabhängige, prognostisch relevante Faktoren [182]. Dieser Studie zufolge ist ein 5-10\%iger Abfall der FVC binnen 24 Wochen mit einem mehr als zweifach erhöhten, ein mehr als 10\%iger Abfall mit einem achtfach erhöhten Mortalitätsrisiko innerhalb des nächsten Jahres verbunden [182,198]. In einer weiteren, jüngeren Arbeit wurde bei 1156 IPF-Patienten die minimale, klinisch relevante Veränderung (minimal clinically important difference: MCID) der FVC mit verschiedenen Methoden ermittelt [198]. Entsprechend dieser Studie liegt dieser Wert bei 2-6\% (je nach angewandter Methode; eher niedriger auf Ebene einer Population, eher höher im Individualfall), d.h. ein Abfall der FVC (in \% Soll) um ca. 5 Prozentpunkte binnen 24 Wochen stellt bereits ein klinisch relevantes Ereignis mit potenziell therapeutischen Implikationen dar.

\section{Kommentar}

Da den hier errechneten MCID-Werten die Mittelwerte eines größeren Studienkollektives, das 50-70\% stabile Patienten umfasst, zugrunde liegen, ist im Einzelfall der einmalige Nachweis eines FVC-Abfalles von 2-6 Prozentpunkten des Sollwertes alleine nicht ausreichend für die Beurteilung einer Therapieansprache oder der Prognose. Hier sollten entweder deutlich stärkere Änderungen der FVC ( $\geq 10 \%)$ bzw. der FVC-Verlauf in der Gesamtschau mit anderen funktionellen (z.B. DLco, Blutgase, 6MWT) und klinischen Befunden (z.B. Dyspnoe, Husten) herangezogen werden. Zudem müssen IPF-unabhängige Ursachen einer klinischen Verschlechterung ausgeschlossen werden. Die Deutsche Konsensuskonferenz ist der Ansicht, dass die in der Literatur vorhandenen Daten zum Stellenwert der forced vital capacity (FVC), die aufgrund der fehlenden Verfügbarkeit der inspiratory vital capacity (IVC) in den USA dominieren, auf die in Deutschland und Europa überwiegend gemessenen IVC Werte übertragbar sind.

(Abstimmung: 20 Ja, 0 Nein, 2 Enthaltungen)

\subsection{HRCT-Veränderungen}

Fibrosierung und Wabenumbau in der HRCT sind eng mit den FVC- und DLco-Werten korreliert [199]. Entsprechend konnte in mehreren Studien gezeigt werden, dass das Ausmaß der Fibrose und der Honigwaben in der HRCT eine prognostische Variable hinsichtlich des Überlebens bei der IPF darstellt [107,200 - 203].

\subsection{Zusammengesetzte Scoring-Systeme}

In dem Bemühen um noch präzisiere prognostische Aussagen wurden zusammengesetzte Scoring-Systeme unter Verwendung physiologischer und radiologischer Variablen entwickelt. So wurde ein zusammengesetzter physiologischer Index (CPI) erstellt, der auf der Basis der FEV1-, FVC- und DLco-Werte den Schweregrad der radiologischen Veränderungen in der HRCT prognostiziert [139,195]. Dieser Index erwies sich als besserer Prädiktor der Mortalität als einzelne Lungenfunktionswerte wie FEV1, FVC, DLco, TLC, $\mathrm{PaO}_{2}$, das klinisch-radiologisch-physiologische Scoring-System (CRP) [187] oder das neue CRP-Scoring-System [7]. Allerdings wurde dieser Ansatz bislang noch nicht in prospektiven klinischen Studien überprüft und seine klinische Brauchbarkeit ist daher nur eingeschränkt beurteilbar. Einer jüngst publizierten Studie mit 1099 IPF-Patienten zufolge ist ein zusammengesetztes Scoring-System, in das das Alter, vorausgegangene Hospitalisierungen wegen respiratorischer Verschlechterungen, die Ausgangs-FVC in \% der Norm und die halbjährliche Veränderung der FVC eingehen, in der Lage, die Wahrscheinlichkeit des Überlebens sehr akkurat anzuzeigen, muss aber noch prospektiv evaluiert werden [182].

\subsection{Sechs-Minuten-Gehstrecke}

Der 6-Minuten-Gehstreckentest (6MWT) ist zwar in der klinischen Praxis weit verbreitet, sein prognostischer Wert war, wahrscheinlich infolge der fehlenden Standardisierung bei IPFPatienten, bis dato begrenzt. Einigen früheren Studien zufolge ist die Desaturation (d.h. Abfall der Sauerstoffsättigung auf unter $88 \%$ ) während eines 6MWT ein Marker für ein erhöhtes Mortalitätsrisiko [192,204,205]. Kürzere Gehstrecken und eine verzögerte Erholung der Herzfrequenz nach dem Gehstreckentest sind mit einem erhöhten Mortalitätsrisiko verbunden [192, 206 208]. Allerdings ist unklar, ob Desaturation, Gehstrecke und andere beim 6MWT gemessene Variablen in dieser Population reproduzierbar sind [209]. In einer neueren klinischen Studie in Japan wurde bei IPF-Patienten ein 6-minütiger Steady-State-Belastungstest mit Gehen auf dem Laufband verwendet, die Frage der klinischen Brauchbarkeit dieses nicht validierten Tests ist allerdings nicht geklärt [144]. In einer Studie bei 822 IPF-Patienten zeigte sich eine sehr gute Reliabilität und Validität der 6MWT-Gehstrecke [210]. Außerdem konnte beobachtet werden, dass ein Abfall der 6MWT-Gehstrecke ein sehr zuverlässiger prognostischer Marker ist: So war ein Abfall um 50 m binnen 24 Wochen mit einem vierfach erhöhten Risiko verbunden, binnen Jahresfrist zu versterben. Die miminale, klinisch relevante Veränderung der 6MWT-Gehstrecke wurde, je nach verwendeter Methodik, mit 24-45 m angegeben [210].

\section{Kommentar}

Auch hier gilt, dass die MICD bzgl. der 6MWT auf der Basis eines großen Studienkollektives entstanden ist und eine Übertragung auf den Individualfall nicht ohne Weiteres gegeben ist. Daher gilt auch hier, dass im Individualfall Therapie- bzw. Prognose-relevante Aussagen nur in der Gesamtschau des Verlaufes klinischer und funktioneller Daten möglich sind. 


\subsection{Histopathologische Parameter}

Werden von einem Patienten mehrere Biopsate entnommen, kann man durchaus unterschiedliche histopathologische Muster beobachten. So fand sich eine Koexistenz eines UIP- und eines NSIP-Musters bei $12-26 \%$ der Patienten mit Gewebeproben aus mehreren Lungenlappen $[113,114]$, was nochmals eindrücklich die Bedeutung der Durchführung einer 2- bis 3-Etagen-Biopsie unterstreicht. Die Prognose für Patienten mit diskordanter UIP (UIP- und NSIP-Muster beim selben Patienten) scheint ähnlich zu sein wie für Patienten mit konkordanter UIP (UIP in allen biopsierten Lappen) $[113,114]$.

Vermehrtes Auftreten von Fibroblastenherden ist einigen Studien zufolge mit einem erhöhten Mortalitätsrisiko assoziiert [133, 178,211-213]. Eine stärkere Häufung von Fibroblastenherden war auch mit einer Abnahme der FVC und DLco über einen Beobachtungszeitraum von 6 und 12 Monaten verbunden [211]. Die Brauchbarkeit detaillierter histopathologischer Scoring-Systeme im täglichen klinischen Management von Patienten mit IPF wurde bisher nicht untersucht.

\subsection{Pulmonale Hypertonie}

Daten zur pulmonalen Hypertonie und ihrer Bedeutung stammen mehrheitlich von IPF-Patienten, die wegen einer anstehenden Lungentransplantation untersucht werden. Das Vorliegen einer pulmonalen Hypertonie (definiert als mittlerer Pulmonalisdruck $>25 \mathrm{mmHg}$ in Ruhe) ist mit einem erhöhten Mortalitätsrisiko assoziiert $[139,140,179]$. In einer separaten Serie von 70 IPFPatienten ergab eine Receiver-Operating-Characteristic (ROC)Analyse, dass ein mittlerer Pulmonalisdruck von $17 \mathrm{mmHg}$ den besten Diskriminator für Mortalität darstellt [193]. Diese Daten müssen validiert werden. Die echokardiographische Schätzung systolischer Pulmonalisdrücke korreliert bei IPF-Patienten nicht gut mit den Ergebnissen der Rechtsherzkatheterisierung [214216] und eignet sich daher nur begrenzt zur Abschätzung einer eventuell vorliegenden pulmonalen Hypertonie [217]. Ein erhöhter pulmonaler Gefäßwiderstand wurde ebenfalls mit einer schlechteren Überlebensrate in Verbindung gebracht [218]. Ob eine IPF mit pulmonaler Hypertonie einen eigenen klinischen Phänotyp (IPF-PH) darstellt, ist nicht geklärt. Bezüglich der spezifischen Aspekte der pulmonalen Hypertonie bei IPF bzw. Lungenerkrankungen im Allgemeinen wird auf die Ergebnisse der Kölner Konsensus Konferenz hingewiesen [219].

\subsection{Emphysem}

Aus neueren retrospektiven Studien geht hervor, dass Patienten mit IPF und gleichzeitig bestehendem Emphysem eine schlechtere Prognose haben als diejenigen ohne Emphysem [139,220]. Bei diesen Patienten mit gleichzeitigem Bestehen von IPF und Emphysem kann eine Behandlung beider Krankheiten erforderlich sein. Es liegen eingeschränkte Daten vor, wonach Patienten mit IPF und Emphysem häufiger und früher eine Langzeit-Sauerstofftherapie benötigen und eine signifikante pulmonale Hypertonie entwickeln können. Unter Berücksichtigung dieser Unterschiede war das Vorliegen eines Emphysems nicht signifikant prädiktiv für das Überleben [139]. Daher ist nicht klar, ob eine IPF mit gleichzeitig bestehendem Emphysem einen eigenen klinischen Phänotyp (kombinierte Lungenfibrose und Emphysem) mit einer eigenen Prognose darstellt, oder ob das Emphysem in diesen Fällen einfach eine Begleiterkrankung ist. An dieser Stelle sei auch noch auf weitere, möglicherweise relevante Komorbiditäten hingewiesen, wie z.B. kardiovaskuläre Erkrankungen (siehe oben; [221], gastroösophageale Refluxerkrankung [222], Lungentumoren [223] und schlafassoziierte Atemstörungen [224].

\subsection{Biomarker in Serum und BAL}

Zum prädiktiven Wert von Serum- und BAL-Biomarkern bei der IPF liegen einige ältere, retrospektive Analysen vor, in der klinischen Routine aber stehen prädiktive Biomarker in der Regel nicht zur Verfügung. „Krebs von den Lungen-6“ (KL-6) ist ein Glykoprotein mit hohem Molekulargewicht, das als humanes MUC1Mucin klassifiziert ist und von regenerierenden Typ-II-Pneumozyten gebildet wird [225]. Bei Patienten mit IPF finden sich erhöhte Serumspiegel von KL-6, die wiederum mit einem erhöhten Risiko nachfolgender Mortalität korreliert sein können [226, 227]. Auch die Serumspiegel von Surfactant Protein (SP-) A und D sind bei IPF-Patienten erhöht und prädiktiv für das Überleben [228230]. Neuere Daten zeigen einen Zusammenhang von SerumCCL18, anderen Chemokinen sowie dem Brain Natriuretic Peptide (BNP) im Serum mit der Mortalität [231 - 235]. Untersuchungen der Matrix-Metalloproteinase (MMP)-Spiegel im Plasma und in der BAL-Flüssigkeit lassen bei IPF-Patienten eine Erhöhung von MMP1 und MMP7 erkennen, wobei die MMP7-Spiegel mit dem Schweregrad der Krankheit korreliert sein können [236]. Die BAL-Spiegel von SP-A scheinen für das Überleben prädiktiv zu sein $[237,238]$. Die BAL-Zytologie ist von unklarem prognostischem Wert bei IPF [238,239]. Die vorläufigen Ergebnisse zeigen, dass der Nachweis zirkulierender Fibrozyten (mesenchymale Vorläuferzellen) mit einem schlechteren Kurzzeitüberleben verbunden ist [240]. In einer neueren Studie wurden MMP7, ICAM1, IL-8, VCAM1 und S100A12 als prognostisch relevante Faktoren identifiziert [241]. Es sollte festgehalten werden, dass der relative Stellenwert eines Biomarkers versus einer sorgfältigen klinischen Evaluation als Prognoseindikator zum jetzigen Zeitpunkt unklar ist und im Rahmen zukünftiger Studien untersucht werden muss.

\section{Therapie}

\section{$\nabla$}

\subsection{Pharmakologische Therapie}

Beantwortung der therapierelevanten Fragen in der ATS/ERS/JRS/ ALAT-IPF-Guideline 2011 [1]:

Frage: Sollen IPF-Patienten mit einer CorticosteroidMonotherapie behandelt werden?

Es liegen keine randomisierten, kontrollierten Studien zur Corticosteroid-Monotherapie vor [242,243]. Retrospektive Studien ohne Kontrollgruppen berichten zwar keinen Überlebensvorteil, lassen aber bei einer Minderheit der Patienten unter Corticosteroid-Monotherapie eine Besserung der Lungenfunktion erkennen [248-250]. Kontrollierte Studien stellten keinen Überlebensvorteil fest [6, 247]. Eine langfristige Corticosteroidbehandlung ist mit einer erheblichen Morbidität verbunden [245,246]. Empfehlung: IPF-Patienten sollen nicht mit einer CorticosteroidMonotherapie behandelt werden (starke Empfehlung, sehr geringe Evidenz).

\section{Frage: Sollen IPF-Patienten mit Colchicin behandelt werden?}

In vitro wurde für Colchicin eine Hemmung der Fibroblastenproliferation und Kollagensynthese nachgewiesen [248], auch eine Pilotstudie zeigte einen potenziellen Nutzen [249]. In mehreren prospektiven klinischen Studien wurde Colchicin mit unterschiedlichen Therapien verglichen, wobei sich hinsichtlich des 
Behandlungserfolgs kein Unterschied zeigte [250-253]. Keine dieser Studien enthielt einen „reinen“ Plazeboarm. In einer retrospektiven Untersuchung von 487 IPF-Patienten hatte Colchicin keinen Einfluss auf das Überleben [6].

Empfehlung: IPF-Patienten sollen nicht mit Colchicin behandelt werden (starke Empfehlung, sehr geringe Evidenz).

\section{Frage: Sollen IPF-Patienten mit Ciclosporin behandelt werden?}

In der englischsprachigen Literatur ist die Datenlage zur Verwendung von Ciclosporin begrenzt. Erste Berichte aus kleinen, nicht kontrollierten Kollektiven von IPF-Patienten lassen einen möglichen Nutzen erkennen [254,255]. Eine retrospektive Studie jüngeren Datums mit 10 IPF-Patienten zeigte keinen offensichtlichen Nutzen von Ciclosporin [256]. Zwei Untersuchungen kleiner Gruppen von IPF-Patienten nach Lungentransplantation, die Ciclosporin im Rahmen der immunsuppressiven Therapie erhielten, zeigten eine Progression der Erkrankung in der Nativlunge $[257,258]$.

Empfehlung: IPF-Patienten sollen nicht mit Ciclosporin behandelt werden (starke Empfehlung, sehr geringe Evidenz).

Frage: Sollen IPF-Patienten mit der Kombination eines Corticosteroids und eines Immunsupressivums (z. B. Azathioprin oder Cyclophosphamid) behandelt werden? Eine retrospektive Studie ließ in einer kleinen Fallserie einen möglichen Nutzen für Azathioprin plus Prednison erkennen [259]. Eine kleine randomisierte Studie mit einem Corticosteroid im Vergleich zu Corticosteroid plus Azathioprin zeigte für diese Kombinationstherapie einen Trend zu einem Überlebensvorteil [260]. Die Kombination Corticosteroid plus Cyclophosphamid wurde mit Corticosteroid alleine verglichen, wobei mit Cyclophosphamid ein Überlebensvorteil gezeigt werden konnte [261]. Allerdings sind die Ergebnisse dieser Studie durch den Einschluss von Patienten, die nicht den aktuellen diagnostischen Kriterien für IPF [2] entsprechen, eingeschränkt. Es wurden 2 retrospektive kontrollierte Studien mit Cyclophosphamid veröffentlicht. Die erste verglich an 164 Patienten die Behandlung mit Corticosteroid plus Cyclophosphamid gegen Nichtbehandlung und stellte keinen Unterschied in der Überlebensrate fest [262]. Die zweite verglich an 82 Patienten die Behandlung mit Corticosteroid plus Cyclophosphamid gegen Corticosteroid alleine und beobachtete einen Überlebensvorteil für die Kombinationstherapie [263].

Empfehlung: IPF-Patienten sollen nicht mit der Kombination eines Corticosteroids und eines Immunsuppressivums behandelt werden (starke Empfehlung, geringe Evidenz).

Wertung: Diese Empfehlung misst der Vermeidung der behandlungsbedingten Morbidität einen hohen Wert bei, ebenso den jüngsten Daten, denen zufolge der Zusatz von Acetylcystein zu diesem Behandlungsregime die Verringerung der Lungenfunktion verlangsamte, sodass insbesondere bei Entscheidung für eine Therapie mit Corticosteroiden plus Immunmodulator (Azathioprin oder Cyclophosphamid) hoch-dosiertes N-Acetylcystein zusätzlich verabreicht werden sollte (s.u.). Niedriger wertet sie die mögliche Verbesserung der Lungenfunktion. Es wurde mehrheitlich für eine „starke Empfehlung“ gestimmt.

\section{Frage: Sollen IPF-Patienten mit Interferon-y 1b behandelt} werden?

Bei Interferon- $\gamma 1 \mathrm{~b}(\mathrm{IFN}-\gamma 1 \mathrm{~b})$ handelt es sich um einen Wirkstoff mit antifibrotischen und immunmodulatorischen Eigenschaften, der in zwei großen klinischen Studie evaluiert wurde, nachdem eine Pilotstudie einen möglichen Nutzen gezeigt hatte [269]. In der ersten Studie wurde die Zeit beurteilt, die bis zur klinischen Verschlechterung bzw. bis zum Tod verstrich. Dazu wurden 330 IPF-Patienten im Verhältnis 1:1 entweder zur Behandlung mit IFN- $\gamma 1 b(200 \mu$ g dreimal wöchentlich, subkutan) oder einem Plazebo randomisiert, wobei niedrigdosiertes Prednison als Begleitmedikation in beiden Gruppen zulässig war [270]. Für den primären Endpunkt zeigte sich kein Unterschied zwischen beiden Gruppen. Die Post-hoc-Analyse deutete einen Trend zu einem verbesserten Überleben unter IFN- $\gamma$ bei einer Subgruppe von Patienten an, deren physiologischer Krankheitszustand vor Studienbeginn weniger schwerwiegend war. Eine anschließende offene Studie zum Vergleich von IFN- $\gamma$ mit Colchicin bei Patienten mit weniger schweren physiologischen Veränderungen ließ ebenfalls auf einen potenziellen Nutzen schließen [252]. Eine kürzlich durchgeführte, definitive Studie prüfte diese Hypothese an mehr als 800 Patienten mit physiologisch leichter Erkrankung und wies nach, dass keine Unterschiede in der Gesamtmortalität (14,5\% in der IFN- $\gamma$-Gruppe im Vergleich zu 12,7\% in der PlazeboGruppe) bestanden [271].

Empfehlung: IPF-Patienten sollen nicht mit IFN- $\gamma$ behandelt werden (starke Empfehlung, hohe Evidenz).

\section{Frage: Sollen IPF-Patienten mit Bosentan behandelt} werden?

Endothelin-1 (ET-1) ist ein hochwirksamer Vasokonstriktor und Wachstumsfaktor, der an der Pathogenese der pulmonalen Hypertonie und möglicherweise auch der IPF beteiligt ist. Bei Patienten mit IPF wurden erhöhte Endothelin-Werte im Serum und der BAL sowie eine übermäßige Expression von EndothelinRezeptoren und ET-1 im Lungengewebe festgestellt [272]. Bosentan, ein dualer Endothelin-Rezeptor-Antagonist (A- und B-Rezeptoren), wurde in einer randomisierten Phase-II-Studie geprüft, in der eine Veränderung des modifizierten 6MWT als primärer Endpunkt diente [273]. Der primäre Endpunkt wurde nicht erreicht. Trends zugunsten von Bosentan waren für den vordefinierten Endpunkt „Zeit bis zur Krankheitsprogression oder Tod“ sowie im Hinblick auf Dyspnoe und Lebensqualität erkennbar. Eine Post-hoc-Analyse ließ vermuten, dass Bosentan bei Patienten mit chirurgischer Lungenbiopsie zur IPF-Diagnostik einen günstigen Effekt auf den vordefinierten Endpunkt „Zeit bis zur Krankheitsprogression bzw. Tod und auf die Lebensqualität“ hatte [274]. Derzeit (zum Zeitpunkt der Fertigstellung der internationalen Leitlinie) wird eine Nachfolgestudie durchgeführt, um zu untersuchen, ob Bosentan bei chirurgisch biopsierten IPF-Patienten einen positiven Effekt hat.

Empfehlung: IPF-Patienten sollen nicht mit Bosentan behandelt werden (starke Empfehlung, moderate Evidenz).

\section{Frage: Sollen IPF-Patienten mit Etanercept behandelt werden?}

Bei Etanercept handelt es sich um einen rekombinanten, löslichen, humanen Tumornekrosefaktor-Rezeptor (TNF-Rezeptor), der an TNF bindet und seine Aktivität in vitro neutralisiert [275]. Der TNF ist vermutlich an der Pathogenese der Lungenfibrose beteiligt $[276,277]$. In einer kürzlich durchgeführten, randomisierten, kontrollierten Studie zu Etanercept bei IPF-Patienten konnte kein Unterschied beim primären Endpunkt, einer Veränderung der FVC über einen Zeitraum von 48 Wochen, nachgewiesen werden. Allerdings war die Trennschärfe der Studie zu gering. Nichtsignifikante Trends wurden bei den Parametern DLco und 6MWT bzw. den patientenbezogenen Ergebnissen beobachtet [278]. 
Empfehlung: IPF-Patienten sollen nicht mit Etanercept behandelt werden (starke Empfehlung, moderate Evidenz).

\section{Kommentar}

Die deutsche Konsensuskonferenz unterstützt alle in der internationalen Leitlinie getroffenen stark negativen Therapieempfehlungen. So ist basierend auf der existierenden Datenlage unstrittig, dass es keine wissenschaftlich hinreichende Grundlage für eine Behandlung von IPF-Patienten mit einer Monotherapie aus Prednisolon, Colchizin, Ciclosporin, Inteferon-gamma-1b, Bosentan oder Etanercept gibt. Auch für die Immunsuppressiva Azathioprin und Cyclophosphamid als Monotherapie liegt keine Evidenz vor. Speziell im Fall von Bosentan wurde zwischenzeitlich eine weitere prospektive, randomisierte, plazebo-kontrollierte Studie mit negativem Ergebnis publiziert [288].

Im Fall der kombinierten Behandlung mit Prednisolon und einem Immunsuppressivum (Azathioprin oder Cyclophosphamid) sind die vorliegenden Studien älter, weshalb es zweifelhaft ist, ob die heute gültigen Diagnosestandards eingehalten wurden. Auch die Patientenzahlen waren viel zu gering, um zuverlässige Aussagen zu erlauben. Darüber hinaus entsprach auch das Studiendesign nicht heutigen Standards und die Ergebnisse waren überwiegend statistisch nicht signifikant.

Frage: Sollen IPF-Patienten mit einer Kombinationstherapie aus Corticosteroid, Azathioprin und Acetylcystein behandelt werden?

Acetylcystein ist ein Vorläufer des Antioxidans Glutathion, das in der Lunge von Patienten mit IPF verringert sein kann [264,265]. Es liegt eine randomisierte kontrollierte Studie vor, die bei Patienten unter Behandlung mit Prednison plus Azathioprin den Effekt von hoch dosiertem Acetylcystein gegenüber Plazebo vergleicht [266]. In dieser Studie fiel die Verringerung der Vitalkapazität und Diffusionskapazität nach 12 Monaten in dem Behandlungsarm mit Acetylcystein signifikant geringer aus (Vitalkapazität: Unterschied von 0,18 1; 95\% Konfidenzintervall [CI], 0,030,32; $\mathrm{P}=0,02$; Diffusionskapazität: Unterschied von $0,75 \mathrm{mmol} /$ $\mathrm{min} / \mathrm{kPa} ; 95 \% \mathrm{CI}, 0,27-1,23 ; \mathrm{P}=0.003)$. Bei der Mortalität oder anderen sekundären Endpunkten einschließlich Dyspnoe, Lebensqualität, Belastungsphysiologie oder radiologischem Erscheinungsbild waren keine Unterschiede zu beobachten. $\mathrm{Zu}$ den Limitationen dieser Studie zählt eine erhebliche Abbruchrate (ca. 30\%), die unklare klinische Relevanz des beobachteten Behandlungseffekts sowie das Fehlen eines reinen Plazeboarms $[267,268]$.

Empfehlung: IPF-Patienten sollten nicht mit einer Kombinationstherapie aus Corticosteroid, Azathioprin und Acetylcystein behandelt werden (schwache Empfehlung, geringe Evidenz).

\section{Kommentar}

Für die Dreifach-Kombination aus Prednisolon plus Azathioprin plus NAC versus Prednisolon plus Azathioprin plus Plazebo existiert eine qualitativ hochwertige Studie, die ein signifikant positives Ergebnis für den primären Endpunkt Abfall der Vitalkapazität und Abfall der Diffusionskapazität über 12 Monate - erbrachte [266]. Hauptkritikpunkt an dieser
Studie war das Fehlen eines Therapiearmes mit alleiniger Plazebogabe. Die inzwischen publizierte PANTHER-IPF-Studie war daher als dreiarmige Studie angelegt: 1.Prednison plus Azathioprin plus N-Acetylcystein vs. 2. N-Acetylcystein-Monotherapie plus Plazebo vs. 3. Plazebo alleine [375]. Eine Interimsanalyse von 238 der 390 geplanten Patienten zeigte unter der Kombinationstherapie im Vergleich zu Plazebo eine erhöhte Mortalität (11\% vs. $1 \%$ ), gehäufte Hospitalisationen ( $29 \%$ vs. $8 \%$ ) und vermehrt schwere Nebenwirkungen (31\% vs. 9\%), zusätzlich zeigte sich kein Effekt auf die Lungenfunktionsmesswerte [375]. Aus diesem Grunde wurde der Triple-Therapiearm gestoppt, während die beiden Arme NAC-Monotherapie vs. Plazebo fortgesetzt werden.

(Abstimmung: 22 Ja, 7 Nein, 1 Enthaltung) ${ }^{1}$

Auch wenn die Publikation viele Fragen unbeantwortet lässt [376], ist aus Sicht der deutschen Experten die schwach negative Empfehlung für die Triple-Therapie bei Patienten mit definitiver IPF-Diagnose nicht aufrecht zu erhalten und es muss eine stark negative Empfehlung ausgesprochen werden. Ausdrücklich ist anzumerken, dass sich diese Empfehlung ausschließlich auf Patienten mit „definitiver IPF“ bezieht und andere Entitäten der interstitiellen Lungenerkrankungen, insbesondere die nicht-spezifische interstitielle Pneumonie, sowie interstitielle Lungenerkrankungen im Rahmen von Kollagenosen nicht betrifft [289]. Die Fortführung einer bereits laufenden Dreifachtherapie muss im Einzelfall evaluiert und mit dem Patienten besprochen werden [376, 377].

(Abstimmung: 13 Ja, 8 Nein, 1 abwesend)

Frage: Sollen IPF-Patienten mit einer Acetylcystein-Monotherapie behandelt werden?

Die jüngsten Daten zur Acetylcystein-Therapie stammen aus einer randomisierten, kontrollierten Studie, auf die bereits im vorherigen Abschnitt zur Kombinationstherapie mit Corticosteroiden, Azathioprin und oralem Acetylcystein näher eingegangen wurde [266]. In dieser Studie korrelierte die Zugabe von oralem Acetylcystein zu Corticosteroiden und Azathioprin mit einer signifikant geringeren Abnahme der Lungenfunktion. In einer vorausgegangenen, nicht kontrollierten Studie mit 18 Patienten, die über einen Zeitraum von 12 Wochen mit oralem Acetylcystein behandelt wurden, zeigten sich Verbesserungen der Lungenfunktionsindizes wie Vitalkapazität, Diffusionskapazität und kapillärer $\mathrm{PaO}_{2}$ [265].

Empfehlung: IPF-Patienten sollten nicht mit einer AcetylcysteinMonotherapie behandelt werden (schwache Empfehlung, geringe Evidenz).

\section{Kommentar}

In der Frage der Zulässigkeit einer NAC-Monotherapie spricht die internationale Leitlinie eine schwach negative Empfehlung aus [1]. Diese beruht auf der bereits zitierten IFIGENIA-Studie, die, wie oben beschrieben, NAC versus Plazebo randomisiert verglich, wobei allerdings alle Patienten quasi als Basistherapie Prednisolon und Azathioprin erhielten [266]. Es liegt also formal eine plazebo-kontrollierte Studie für NAC vor, wobei der Einfluss der zusätzlichen antientzündlichen Basistherapie

\footnotetext{
${ }^{1}$ Nachträglich Abstimmung aller Autoren per E-Mail.
} 
kontrovers diskutiert wird $[267,268]$. Unstrittig ist, dass die NAC-Monotherapie nicht als solche getestet wurde, weshalb die Ableitung einer Empfehlung zur Monotherapie mit NAC aus den vorliegenden Daten einen „indirekten“ Schluss darstellt $[1,266]$. Die deutsche Konsensuskonferenz schließt sich der Empfehlung der internationalen Experten an, derzufolge nach entsprechender Information des Patienten über Wirkung und potenzielle Nebenwirkungen eine NAC-Monotherapie angebracht sein kann ( Tab. 7).

(Abstimmung: 20 Ja, 1 Nein, 1 Enthaltung)

In der Abwägung von Nutzen, möglichen Nebenwirkungen und Kosten einer solchen Therapie ist die deutsche Konsensuskonferenz der Auffassung, dass die aktuelle Datenlage für eine solche Therapie spricht, auch in Kenntnis der Tatsache, dass eine Zulassung nicht besteht. Dies gilt insbesondere dann, wenn Therapiealternativen nicht zur Verfügung stehen. Diese Therapieempfehlung muss nach Vorliegen der Ergebnisse der PANTHER-IPF-Studie für die beiden noch fortgeführten Therapiearme NAC versus Plazebo kurzfristig überprüft werden.

\section{Frage: Sollen IPF-Patienten mit Gerinnungshemmern} behandelt werden?

Die Therapie mit Gerinnungshemmern zur Behandlung der IPF wurde in einer nicht verblindeten, randomisierten, kontrollierten japanischen Studie evaluiert, bei der die Behandlung mit Corticosteroiden plus Gerinnungshemmern (unfraktioniertes Heparin oder Heparin mit niedrigem Molekulargewicht während des Beobachtungszeitraums bei erneuter Hospitalisierung, und Warfarin bei ambulanter Behandlung) mit Corticosteroiden als Monotherapie verglichen wurde [279]. Im Behandlungsarm mit Gerinnungshemmern wurde ein Überlebensvorteil nachgewiesen, den man der geringeren Mortalitätsrate bei Hospitalisierung wegen akuter Exazerbation oder Krankheitsprogression zuschrieb. $\mathrm{Zu}$ den signifikanten Limitationen dieser Studie zählen die fehlende Verblindung, die differenzielle Abbruchrate zwischen den Therapiearmen, das Nichtausschließen von Lungenembolien als potenzielle Ursache für die klinische Verschlechterung sowie die unzureichende Dokumentation der Effizienz der Antikoagulation während der ambulanten Phasen.

Empfehlung: IPF-Patienten sollten nicht mit Gerinnungshemmern behandelt werden (schwache Empfehlung, sehr geringe Evidenz).

\section{Kommentar}

Zur Therapie der IPF mittels systemischer Antikoagulation liegt bisher eine publizierte japanische Studie vor, die bei Patienten, die im Rahmen einer respiratorischen Verschlechterung zunächst mit Heparin (stationär) und sodann mit Vitamin-K-Antagonisten (ambulant) antikoaguliert wurden, einen Überlebensvorteil beobachtete [279]. Trotz der erheblichen qualitativen Limitationen dieser Studie votierten die internationalen Experten, angesichts des beschriebenen Überlebensvorteils, für eine schwach-negative Empfehlung [1]. Zwischenzeitlich wurde eine Studie an IPF-Patienten in den USA aufgelegt, die dieses Konzept überprüfen sollte. Diese Studie wurde im Frühjahr 2011 wegen einer signifikanten Übersterblichkeit, vermehrten Hospitalisierungen und fehlendem
Effekt auf die Krankheitsprogression im Verumarm vorzeitig abgebrochen [378]. Unter Berücksichtigung dieser Information hat die deutsche Konsensuskonferenz abweichend von den internationalen Empfehlungen, eine starke negative Empfehlung für die systemische Antikoagulation mit Vitamin-KAntagonisten als Therapie der IPF ausgesprochen (starke Empfehlung dagegen, geringe Evidenz).

(Abstimmung: 22 Ja, 0 Nein, 0 Enthaltung)

\section{Frage: Sollen IPF-Patienten mit Pirfenidon behandelt} werden?

Bei Pirfenidon handelt es sich um eine Pyridonverbindung mit pleiotropen, entzündungshemmenden, antifibrotischen und antioxidativen Eigenschaften im Sinne einer Antagonisierung der Effekte von TGF-ß1. Pilotstudien ließen einen möglichen Nutzen durch dieses Medikament bei IPF erkennen [280,281]. Eine nachfolgende, randomisierte, kontrollierte Studie aus Japan, in der Pirfenidon mit einem Plazebo verglichen wurde, musste vorzeitig beendet werden, nachdem ein sekundärer Endpunkt - akute Exazerbation - in der Plazebogruppe signifikant häufiger als im Verum-Behandlungsarm aufgetreten war [282]. Obwohl die Daten aufgrund des vorzeitigen Abbruchs der Studie unvollständig waren, ließen sie einen positiven Behandlungseffekt auf die Sauerstoffsättigung während des 6-minütigen Steady-State-Belastungstests (primärer Endpunkt) sowie eine signifikant verringerte Abnahme der Vitalkapazität im Verum-Behandlungsarm im Vergleich zu Plazebo erkennen. In einer zweiten randomisierten, kontrollierten Studie aus Japan zum Vergleich von Pirfenidon mit Plazebo wurde im Pirfenidon-Arm eine geringere Abnahme der Vitalkapazität über einen Zeitraum von 52 Wochen festgestellt ( $-90 \mathrm{ml}$ im Vergleich $\mathrm{zu}-160 \mathrm{ml}, \mathrm{P}=0,04)$ (283). Zudem trat ein Unterschied beim progressionsfreien Überleben (definiert als Tod oder $>10 \%$ Verringerung der Vitalkapazität) zugunsten der Pirfenidon-Gruppe zutage $(P=0,03)$. Diese Studie wies jedoch bedeutsame Limitationen auf. Dazu zählte die hochselektive Aufnahme von Patienten, die in einem nichtvalidierten Belastungstest eine Sauerstoff-Entsättigung zeigten. Des Weiteren wurde der primäre Endpunkt der Studie (der eigentliche Grund für die Auswahl der Patientenpopulation) vor der Entblindung geändert.

Die Ergebnisse zweier weiterer internationaler, randomisierter, kontrollierter Studien zu Pirfenidon wurden kürzlich durch die US-amerikanische Food and Drug Administration (USFDA) geprüft. Dazu liegt ein detaillierter Bericht vor [284-287]. In einer der Studien (PIPF-004) wurde der primäre Endpunkt, die absolute Veränderung der vorhergesagten FVC (in \%) gegenüber dem Ausgangswert, mit einer Effektstärke von 4,4\% erreicht, womit Pirfenidon im Vergleich zu Plazebo besser abschnitt. In der anderen Studie (PIPF-006) wurde derselbe primäre Endpunkt nicht erreicht. Einige sekundäre Wirksamkeitsvariablen schienen die Ergebnisse zahlenmäßig zu stützen, erwiesen sich aber von Studie zu Studie als heterogen. Ein Überlebensvorteil konnte im Hinblick auf die Mortalität jeglicher Ursache während der Behandlung (unabhängig von der Ursache) nicht festgestellt werden. Die Behandlung mit Pirfenidon war mit signifikanten unerwünschten gastrointestinalen Ereignissen, pathologischen Leberwerten, Photosensibilität und Hauteffloreszenzen verbunden.

Empfehlung: IPF-Patienten sollten nicht mit Pirfenidon behandelt werden (schwache Empfehlung, geringe bis moderate Evidenz). 


\section{Kommentar}

Hinsichtlich der Empfehlung zur Therapie der IPF mit Pirfenidon lag zum Zeitpunkt der Verabschiedung der internationalen Leitlinie die Vollpublikation der zulassungsrelevanten CAPACITY-Studien noch nicht vor, wenngleich die Daten auf der Website der US-Amerikanischen Federal Drug Administration (FDA) öffentlich zugänglich waren [1, 284 - 287]. In beide Studien wurden Patienten im Alter von 40-80 Jahren mit gesicherter IPF-Diagnose eingeschlossen, deren FVC $\geq 50 \%$ des Sollwertes, deren TLco $\geq 35 \%$ des Sollwertes und deren 6-Minuten-Gehstrecke mindestens $150 \mathrm{~m}$ betrug [290]. Interpretationsschwierigkeiten bereitete die Tatsache, dass die beiden Studien CAPACITY-1 und CAPACITY-2 uneinheitliche Ergebnisse lieferten; so war der primäre Endpunkt - Abfall der forcierten Vitalkapazität (FVC) in \% des Sollwertes vom Ausgangswert über 72 Wochen - und die progressionsfreie Überlebenszeit in CAPACITY-1 signifikant positiv, die Änderung der 6-MinutenGehstrecke als wichtiger sekundärer Endpunkt aber negativ, während diese Endpunkte in CAPACTY-2 ein genau umgekehrtes Verhalten zeigten [290]. Basierend auf diesen uneinheitlichen Ergebnissen verweigerte die FDA die Zulassung des Medikaments zur Therapie der IPF. Die inzwischen vorliegende Publikation der beiden Studien zeigt in der gepoolten Analyse beider Datensätze signifikant positive Ergebnisse für den primären Endpunkt wie auch für die progressionsfreie Überlebenszeit und die Änderung der 6-Minuten-Gehstrecke [290]. Zusätzlich fand sich eine signifikante Reduktion der IPF-assoziierten Mortalität und auch in der kategorischen Analyse der FVC fand sich eine signifikante ca. 30\%ige Reduktion eines prognoserelevanten Abfalls der FVC um 10\% [290]. In Würdigung dieser Befunde und der in Japan durchgeführten klinischen Therapiestudien $[282,283]$ hat die europäische Arzneimittelbehörde EMA eine Zulassung für Pirfenidon zur Behandlung von Patienten mit leichter bis mittelschwerer IPF für die Europäische Union im Frühjahr 2011 erteilt. Auch eine in der Cochrane Library publizierte Meta-Analyse kommt unter Berücksichtigung der japanischen Studie [283] sowie der beiden Capacity Studien [290] zu dem Schluss, dass Pirfenidon einen signifikant positiven Effekt auf das progressionsfreie Überleben von IPF-Patienten hat [291]. Unter Berücksichtigung der inzwischen vorliegenden, vertieften Datenanalyse spricht sich die deutsche IPF-Konsensuskonferenz für eine schwach positive Empfehlung für Pirfenidon zur Therapie der IPF geringen und mittleren Schweregrades aus (siehe Einschlusskriterien). Diese Empfehlung berücksichtigt die Tatsache, dass Pirfenidon bei fortgeschrittener IPF bisher nur in einer Beobachtungsstudie ohne Kontrollgruppe untersucht wurde [280] und deshalb nicht vorbehaltlos für alle IPF-Patienten - auch entsprechend der Zulassungsbeschränkung in der EU - empfohlen werden kann. Sie steht insofern auch in Einklang mit der GRADE-Systematik (schwach positive Empfehlung, moderate Evidenz) ( Tab.7).

(Abstimmung: 20 Ja, 0 Nein, 2 Enthaltungen)

Weitere medikamentöse Therapieansätze Als weiterer Therapieansatz wurde der Einsatz von Imatinib, einem Tyrosinkinaseinhibitor, in einer Phase-2-Studie untersucht, die den primären Endpunkt (progressionsfreies Überleben) nicht erreichte [292]. Angesichts möglicher Nebenwirkungen, relativ hoher Kosten und fehlendem Wirksamkeitsnachweis wird eine stark negative Empfehlung für den Einsatz von Imatinib bei IPF-Patienten aus-
Tab.7 Zusammenfassung der Therapieempfehlungen der deutschen IPF-Konsensuskonferenz.

\begin{tabular}{|c|c|c|}
\hline & Empfehlungsgrad & Evidenzgrad \\
\hline Pirfenidon ${ }^{1}$ & schwach positiv & moderat \\
\hline $\begin{array}{l}\text { Corticosteroid plus Immun- } \\
\text { modulator plus NAC }\end{array}$ & stark negativ & gering \\
\hline NAC-Monotherapie & schwach negativ & gering \\
\hline Corticosteroid-Monotherapie & stark negativ & sehr gering \\
\hline $\begin{array}{l}\text { Corticosteroid plus Immun- } \\
\text { suppressivum }\end{array}$ & stark negativ & gering \\
\hline Colchicin & stark negativ & sehr gering \\
\hline Ciclosporin & stark negativ & sehr gering \\
\hline Interferon-gamma-1b & stark negativ & hoch \\
\hline Bosentan $^{3}$ & stark negativ & hoch \\
\hline Etanercept & stark negativ & moderat \\
\hline Antikoagulation ${ }^{4}$ & stark negativ & sehr gering \\
\hline Imatinib & stark negativ & moderat \\
\hline
\end{tabular}

Abweichungen von den Empfehlungen der internationalen Leitlinie (Details siehe Text) 1 Die Behandlung der IPF mit Pirfenidon wurde in der internationalen Leitlinie mit einer schwach negativen Empfehlung und gering-moderater Evidenz bewertet [1]. Auf Grund der inzwischen vorliegenden, vertieften Datenanalyse sowie einer Metaanalyse bewertet die deutsche Konsensuskonferenz die Pirfenidontherapie schwach positiv mit moderater Evidenz [292, 293]

2 Unter Berücksichtigung der inzwischen als Vollpublikation vorliegenden Ergebnisse der PANTHER-IPF-Studie wurde die Kombinationstherapie aus Prednisolon plus Azathioprin plus N-Acetylcystein für Patienten mit definitiver IPF mehrheitlich mit einer stark negativen Empfehlung bewertet [375].

Die Behandlung der IPF mit dem dualen Endothelinrezeptorantagonisten Bosentan wird aufgrund der inzwischen publizierten BUILD-3 Studie mit negativem Ergebnis übereinstimmend mit der internationalen Leitlinie mit einer stark negativen Empfehlung bewertet, die Qualität der Evidenz wird von moderat (internationale Leitlinie) auf hoch (deutsche Konsensuskonferenz) angehoben [288]

${ }^{4}$ Die systemische Antikoagulation wird wegen der inzwischen aufgrund von erhöhter Mortalität und Hospitalisierungsraten sowie fehlendem positiven Therapieeffekt abgebrochenen US-amerikanischen Studie und abweichend von der internationalen Leitlinien mit einer stark negativen Empfehlung bewertet, bei sehr geringer Qualität der Evidenz.

gesprochen. Eine inzwischen vorliegende Phase-II-Studie an IPFPatienten mit dem Multikinase-Inhibtor BIBF-1120 (Nintedanib) konnte positive Effekte auf Lungenfunktion, Lebensqualität und akute Exazerbationen zeigen, sodass eine Phase-III-Studie gestartet wurde [293].

In Anbetracht der begrenzten Wirksamkeit der verfügbaren Therapien empfiehlt die Deutsche Konsensuskonferenz generell, geeignete Patienten in klinische Studien einzuschließen und mit Expertenzentren auf diesem Gebiet zu kooperieren. Es wird weiter festgehalten, dass bei gering- oder nicht-symptomatischen IPF-Patienten mit dokumentiert stabilem Verlauf ein abwartendes Verhalten ohne Einleitung einer Pharmakotherapie gerechtfertigt sein kann.

(Abstimmung: 13 Ja, 6 Nein, 3 Enthaltungen)

Des Weiteren ist hier kritisch anzumerken, dass die unterschiedlichen Grade der Diagnosesicherheit einer IPF (IPF, wahrscheinliche IPF, mögliche IPF) keine Entsprechung in den Therapieempfehlungen haben, sodass sich die Relevanz dieser Unterscheidung erst im klinischen Alltag erweisen muss.

Die Empfehlungen der Deutschen IPF-Konsensuskonferenz zur pharmakologischen Therapie der IPF sind in $\bullet$ Tab. 7 zusammengefasst.

(Abstimmung über die pharmakologischen Therapieempfehlungen in Tab. 7 insgesamt: 20 Ja, 1 Nein, 0 Enthaltung, 1 abwesend)

\subsection{Nichtpharmakologische Therapie}

Die Kommission empfiehlt den Einsatz einiger nichtpharmakologischer Therapieformen bei geeigneten Patienten mit IPF. 
Frage: Sollen Patienten mit IPF und Ruhe-Hypoxämie eine Langzeit-Sauerstofftherapie erhalten?

Zum Nutzen der Langzeit-Sauerstofftherapie bei IPF-Patienten liegen keine direkten Daten vor. In einer Studie wurde retrospektiv das Überleben in einer IPF-Patientenkohorte verglichen, in der viele Patienten (27\%) Sauerstoff erhalten hatten [6]. In einer multivariaten Analyse wurde kein Überlebensvorteil durch die Gabe von Sauerstoff nachgewiesen. Diese Studie war jedoch durch ihr retrospektives Design limitiert. Eingeschränkte Evidenz belegt eine Verbesserung der körperlichen Leistungsfähigkeit bei Patienten mit Ruhe-Hypoxämie, die Sauerstoff erhalten [294]. Indirekte Evidenz aus zwei großen randomisierten Studien mit obstruktiver Lungenerkrankung zeigt für die Langzeit-Sauerstofftherapie einen deutlichen Überlebensvorteil $[295,296]$. Diese Studien arbeiteten allerdings mit unterschiedlichen Definitionen der Hypoxämie $\left(\mathrm{PaO}_{2}\right.$ von $\left.55-65 \mathrm{mmHg}\right)$.

Empfehlung: Patienten mit IPF und klinisch signifikanter RuheHypoxämie sollen eine Langzeit-Sauerstofftherapie erhalten (starke Empfehlung, sehr geringe Evidenz).

Frage: Sollen sich geeignete IPF-Patienten einer Lungentransplantation unterziehen?

Für IPF-Patienten liegt die Fünfjahresüberlebensrate nach Lungentransplantation bei 50 bis 56\% [297,298]. Die Erfahrungen zur langfristigen Prognose der Lungentransplantation bei IPF im Vergleich zu anderen Indikationen sind uneinheitlich $[298,299]$. In einer monozentrischen, retrospektiven Untersuchung mit 46 für eine Lungentransplantation vorgesehenen IPF-Patienten wurde nach 5 Jahren ein vermindertes Mortalitätsrisiko bei den Patienten festgestellt, die eine Lungentransplantation erhalten hatten [300]. Prospektive Studien zur Frage einer Prognoseverbesserung fehlen. Internationale Leitlinien empfehlen zur Kandidatenselektion die Aufnahme auf die Warteliste von unter 65-jährigen Patienten ohne Kontraindikationen u.a. bei Verlust an>10\% FVC in 6 Monaten, Sauerstoffbedarf, und Entsättigung $\left(\mathrm{SpO}_{2}<89 \%\right)$ unter Belastung (301). Es ist bisher nicht bekannt, ob es Unterschiede hinsichtlich des Überlebensvorteils bei Einzellungentransplantationen im Vergleich zu Doppellungentransplantationen gibt [302].

Empfehlung: Geeignete IPF-Patienten sollen sich einer Lungentransplantation unterziehen (starke Empfehlung, geringe Evidenz).

Frage: Soll bei Patienten mit respiratorischem Versagen infolge IPF eine mechanische Beatmung durchgeführt werden?

Es gibt mehrere kleine Studien zur mechanischen Beatmung bei IPF-Patienten mit respiratorischem Versagen, die alle eine hohe Krankenhausmortalitätsrate aufweisen [303-314]. Die Einschlusskriterien der einzelnen Studien sind unterschiedlich, wobei einige ausschließlich Patienten mit respiratorischem Versagen unbekannter Ätiologie einschlossen [304,309]. In einer repräsentativen Studie an 23 IPF-Patienten mit beatmungspflichtigem respiratorischem Versagen wurde eine Krankenhausmortalität von $96 \%$ berichtet [308]. Der einzige überlebende Patient erhielt 6 Stunden nach der Intubation ein Lungentransplantat. Eine systematische Übersicht zur mechanischen Beatmung bei IPF-Patienten mit respiratorischem Versagen ergab eine ähnlich schlechte Krankenhausmortalitätsrate von $87 \%$ bei 135 berichteten Fällen [314]. Die erfolgreiche Lungentransplantation von IPF-Patienten nach mechanischer Beatmung ist beschrieben, allerdings sind die Ergebnisse deutlich schlechter als bei nicht-intubierten Kandidaten [315].

Empfehlung: Patienten mit respiratorischem Versagen infolge Progression der IPF sollten nicht mechanisch beatmet werden. Ausnahmen hiervon sind Patienten mit potenziell reversiblen zusätzlichen Erkrankungen (z. B. Lungenembolie, bakterielle Pneumonie) oder bereits evaluierte Lungentransplantationskandidaten. Bei Letzteren kann die Beatmung eine Überbrückungsmaßnahme zur Transplantation sein (schwache negative Empfehlung, geringe Evidenz).

Frage: Soll bei IPF-Patienten eine pulmonale Rehabilitation durchgeführt werden?

Pulmonale Rehabilitationsprogramme umfassen aerobe Konditionierung, Kraft- und Beweglichkeitstraining, Schulungen, Ernährungsberatung und psychosoziale Betreuung. Sie wurden kürzlich auf ihren Nutzen bei Patienten mit interstitiellen Lungenerkrankungen (ILD) untersucht. Zwei kontrollierte Studien zur pulmonalen Rehabilitation bei IPF zeigten eine Verbesserung der Gehstrecke sowie der Symptome und Lebensqualität [316, 317]. In anderen, nicht kontrollierten Studien wurden ähnliche Ergebnisse beobachtet [318-321]. Der Nutzen der pulmonalen Rehabilitation tritt möglicherweise bei Patienten mit einem initial schlechteren Funktionsstatus deutlicher hervor [318].

Empfehlung: IPF-Patienten sollten eine pulmonale Rehabilitation erhalten (schwache Empfehlung, geringe Evidenz).

Kommentar

Die Empfehlungen zu nicht-pharmakologischen Therapien bei IPF-Patienten konnten von der deutschen IPF-Konsensuskonferenz ohne Änderung von der internationalen Leitlinie übernommen werden [1]. Während die Versorgung der IPF-Patienten mit einer Langzeitsauerstofftherapie entsprechend der deutschen Leitlinie [322] sowie die pulmonale Rehabilitation und die Lungentransplantationsindikation unstrittig sind, ist die Frage der mechanischen Beatmung problematischer, da sie direkt über Leben oder Tod des Patienten entscheiden kann. In Übereinstimmung mit der internationalen Leitlinie waren die deutschen Experten der Meinung, dass es gerechtfertigt ist, eine Intubation und Beatmung eines IPF-Patienten zu unterlassen, wenn die Ursache der Beatmungspflichtigkeit in der IPF begründet ist und eine Behandlungsperspektive i.e. Lungentransplantation - nicht in Betracht kommt, eine NIV kann erwogen werden.

(Abstimmung: 21 Ja, 0 Nein, 0 Enthaltung, 1 abwesend)

Darüber hinaus kann es an ausgewiesenen Zentren sinnvoll und Erfolg versprechend sein, Patienten als Überbrückungsmaßnahme bis zu einer möglichen Lungentransplantation zu beatmen oder sogar einer extrakorporalen Lungenersatztherapie zuzuführen [323].

Neben den in der Leitlinie genannten Therapien sollten allgemeine Behandlungsgrundsätze, die für Patienten mit chronischen Lungenerkrankungen gelten, auch auf Patienten mit IPF Anwendung finden, selbst wenn entsprechende Studien für IPF-Populationen hier nicht vorliegen. Zu diesen Allgemeinmaßnahmen gehören nach Ansicht der deutschen Experten die absolute Nikotinkarenz bzw. das Angebot einer Tabakentwöhnung, dies umso mehr, als Tabakrauch ein bekannter Risikofaktor für das Auftreten der IPF ist (siehe Artikel „Definition und Epidemiologie“), sowie Impfungen gegen Influenza und Pneumokokken (siehe auch aktuelle STIKO-Empfehlungen). 


\section{Behandlung ausgewählter Komplikationen und Begleiterkrankungen \\ $\nabla$}

Es besteht eine zunehmende Sensibilisierung für die Komplikationen und Begleiterkrankungen im Zusammenhang mit der IPF. Dazu zählen akute Exazerbation der IPF, pulmonale Hypertonie, gastroösophagealer Reflux, Adipositas, Emphysem und obstruktive Schlafapnoe [324]. Es ist bisher nicht bekannt, ob die Behandlung dieser Begleiterkrankungen das klinische Outcome beeinflusst. Es liegen keine Daten vor, die als Basis für Empfehlungen zur Behandlung von Adipositas, Emphysem und obstruktiver Schlafapnoe infolge IPF verwertbar wären.

Frage: Sollen Patienten mit einer akuten Exazerbation der IPF mit Corticosteroiden behandelt werden?

Obwohl hochdosierte Corticosteroide häufig für die Behandlung einer akuten Exazerbation der IPF verordnet werden [279,282, 303,325 - 332], liegen keine kontrollierten Studien zur Beurteilung der Wirksamkeit dieser Behandlung vor. Ciclosporin, Cyclophosphamid und Gerinnungshemmer werden ebenfalls ohne schlüssige Wirksamkeitsdaten eingesetzt [256,279,332].

Empfehlung: IPF-Patienten mit akuten Exazerbationen sollen mit Corticosteroiden behandelt werden (schwache Empfehlung, sehr geringe Evidenz).

\section{Frage: Soll eine pulmonale Hypertonie bei IPF-Patienten} behandelt werden?

Zur Behandlung einer pulmonalen Hypertonie (allgemein definiert als mittlerer Pulmonalisdruck von $\geq 25 \mathrm{mmHg}$ bei Messung mittels Rechtsherzkatheter) bei Patienten mit IPF liegen nur begrenzt Daten vor. In einer Einzeldosis-Studie mit intravenös und aerosoliert verabreichtem Epoprostenol bei 8 Patienten mit ILD und pulmonaler Hypertonie (in einem Fall IPF) konnte eine Verbesserung der pulmonalen Hämodynamik bei gleichzeitiger $\mathrm{Zu}-$ nahme des Shuntflusses und konsekutiver Verschlechterung der Oxygenierung beobachtet werden [333]. Eine retrospektive Studie zur Langzeittherapie mit intravenösem Epoprostenol oder oralem Bosentan bei 19 Patienten mit ILD und pulmonaler Hypertonie (8 Fälle von IPF) ließ Verbesserungen der 6-Minuten-Gehstrecke sowie der Lebensqualität über einen Zeitraum von 6 Monaten erkennen [334]. Eine Einzeldosis Sildenafil hat nachweislich zur Verbesserung der pulmonalen Hämodynamik ohne gleichzeitige Erhöhung des Shuntflows oder Verschlechterung der Oxygenierung geführt [335]. In zwei kleinen, unkontrollierten prospektiven Studien zu Sildenafil bei Patienten mit IPF und pulmonaler Hypertonie konnte über einen Zeitraum von 8 bis 12 Wochen eine Verbesserung der Gehstrecke sowie der pulmonalen Hämodynamik beobachtet werden [336,337].

Empfehlung: Eine pulmonale Hypertonie sollte bei IPF-Patienten nicht behandelt werden (schwache Empfehlung, sehr geringe Evidenz).

Frage: Soll eine asymptomatische gastroösophageale Refluxkrankheit bei IPF-Patienten medikamentös behandelt werden?

Ein abnormer saurer gastroösophagealer Reflux (GER) ist bei IPFPatienten weit verbreitet und verläuft bei bis zur Hälfte der Patienten asymptomatisch [338 - 340]. GER stellt ein Risiko für die Aspiration von Mageninhalt dar und ist eine bekannte Pneumonieursache; er kann chronische Atemwegsentzündungen und Fibrose begünstigen [341-343]. Zwei retrospektive Fallserien beschreiben die Stabilisierung von Lungenfunktion und Sauer- stoffbedarf durch die medikamentöse und chirurgische Behandlung des gastroösophagealen Refluxes [338, 344].

Empfehlung: Ein asymptomatischer gastroösophagealer Reflux sollte bei IPF-Patienten medikamentös behandelt werden (schwache Empfehlung, sehr geringe Evidenz).

\section{Kommentar}

Die deutsche IPF-Konferenz schließt sich den Empfehlungen der internationalen IPF-Leitlinie hinsichtlich der Behandlung von akuten Exazerbationen der IPF an. Hinsichtlich des asymptomtischen GER sah die deutsche Konsensus-Konferenz die Problematik der Diagnosestellung und spricht aufgrund der sehr geringen Evidenz keine Empfehlung aus.

(Abstimmung: 21 Ja, 0 Nein, 0 Enthaltung, 1 abwesend)

Sie verweist hinsichtlich der Therapie der pulmonalen Hypertonie auf die entsprechende Empfehlung der Kölner Konsensuskonferenz [219]. Danach sollte ein gezielter PH-Behandlungsversuch über 3-6 Monate unter engmaschiger Kontrolle einschließlich Blutgasanalysen bei IPF-Patienten mit schwerer pulmonaler Hypertonie entsprechend $\bullet$ Tab. 8 vorgenommen werden, sofern andere Ursachen einer pulmonalen Hypertonie wie Linksherzinsuffizienz und Lungenembolien ausgeschlossen sind und die restriktive Ventilationseinschränkung durch die IPF selbst nur gering bis moderat ausgeprägt ist (TLC $>60 \%$ des Sollwertes) [219].

Tab. 8 Kriterien für das Vorliegen einer schweren pulmonalen Hypertonie bei Patienten mit chronischen Lungenerkrankungen ${ }^{1}$ [219].

\begin{tabular}{l} 
Mindestens 2 der nachfolgenden Kriterien müssen erfüllt sein: \\
\hline 1. Mittlerer PA-Druck (PAPm) $>35 \mathrm{mmHg}$ \\
\hline 2. PAPm $\geq 25 \mathrm{mmHg}$ mit eingeschränktem Herzzeitvolumen $(\mathrm{Cl}<2.0 \mathrm{I} /$ \\
\hline 3. Pulmonal-vaskulärer Widerstand (PVR) $>480$ dyn $\cdot \mathrm{s} \cdot \mathrm{cm}^{-5}$
\end{tabular}

${ }^{1}$ Grundsätzlich gelten diese Kriterien nur bei Ausschluss weiterer Ursachen einer pulmonalen Hypertonie (z. B. chronisch thromboembolische pulmonale Hypertonie oder Linksherzerkrankung).

\section{Palliativmedizin}

$\nabla$

Die Palliativmedizin konzentriert sich mehr auf die Linderung der Symptome und das Wohlbefinden der Patienten als auf die Behandlung der Grunderkrankung. Zu den Zielen der palliativmedizinischen Versorgung zählen insbesondere die Linderung des physischen und psychischen Leidens sowie die Ermöglichung psychologischer und spiritueller Unterstützung für die Patienten und deren Betreuungspersonen. Eine solche Versorgung kann nur individualisiert erfolgen und sollte als Ergänzung zur krankheitsbezogenen Therapie verstanden werden.

Eine Verschlechterung der Symptome wie Husten und Dyspnoe tritt bei IPF häufig ein und ist nur schwer behandelbar. Limitierte Daten lassen darauf schließen, dass Corticosteroide und Thalidomid für die Behandlung des chronischen Hustens bei IPF nützlich sein können [345,346]. Chronische Opioidgabe ist bei schwerwiegender Dyspnoe und Husten eine Option, erfordert aber ein sorgfältiges Therapiemonitoring auf Nebenwirkungen [347]. 


\section{Kommentar}

Die Deutsche Konsensusgruppe ist der Ansicht, dass die Opioidtherapie nicht vorenthalten werden soll.

(Abstimmung: 21 Ja, 0 Nein, 0 Enthaltung, 1 abwesend)

Die Themen Patientenverfügung sowie Sterbebetreuung sollten bei allen IPF-Patienten in der ambulanten Betreuung angesprochen werden, vor allem bei Patienten mit hochgradigen Funktionseinschränkungen und Begleiterkrankungen. Bei bettlägerigen Patienten kann eine Hospizbetreuung in Betracht gezogen werden.

Die Empfehlungen der deutschen IPF-Konsensuskonferenz zu nicht-pharmakolgischen Therapien der IPF und zur Behandlung der Komplikationen sind in $\bullet$ Tab. 9 zusammengefasst.

Tab.9 Empfehlungen der Deutschen IPF-Konsensuskonferenz zur nichtpharmakologischen Therapie der IPF und zur Behandlung von Komplikationen.

\begin{tabular}{|c|c|c|}
\hline & Empfehlungsgrad & Evidenzgrad \\
\hline Langzeitsauerstofftherapie $^{1}$ & stark positiv & sehr gering \\
\hline Lungentransplantation & stark positiv & gering \\
\hline $\begin{array}{l}\text { Mechanische Beatmung } \\
\text { (IPF-bedingt) }\end{array}$ & schwach negativ & gering \\
\hline Pulmonale Rehabilitation & schwach positiv & gering \\
\hline $\begin{array}{l}\text { Kortikosteroide bei akuter } \\
\text { IPF-Exazerbation }\end{array}$ & schwach positiv & sehr gering \\
\hline Gezielte PH-Therapie ${ }^{2}$ & schwach negativ & sehr gering \\
\hline Asymptomatischer GER ${ }^{3}$ & keine Empfehlung & sehr gering \\
\hline
\end{tabular}

unter Berücksichtigung der deutschen Leitlinie zur Langzeitsauerstofftherapie [322]

unter Berücksichtigung der Kölner Konsensuskonferenz [219]

${ }^{3}$ Abweichend von der internationalen Leitlinie sah die deutsche IPF-Konsensuskonferenz keine ausreichende Evidenz zur Empfehlung der Therapie des asymptomatischen GER, insbesondere, da die Diagnostik eines asymptomatischen GER schwierig und nur mittels aufwendiger Verfahren möglich ist, die als Screening nicht empfohlen werden können.

\section{Klinische Verlaufskontrolle}

$\nabla$

Verlaufskontrollen sind erforderlich, um eine mögliche Progression der Erkrankung, eine Verschlechterung der Symptome oder der Oxygenierung sowie die Entstehung von erkrankungs- oder therapiebedingten Komplikationen frühzeitig zu erkennen. Darüber hinaus hilft die sorgfältige Beurteilung des klinischen Verlaufs den Patienten, den Verlauf ihrer Erkrankung besser zu verstehen und ermöglicht die rechtzeitige Einleitung geeigneter Therapiemaßnahmen, so z. B. auch einer etwaigen Lungentransplantation.

\subsection{Krankheitsprogression}

Die Krankheitsprogression manifestiert sich durch eine Zunahme der respiratorischen Symptome, Verschlechterung der Lungenfunktionswerte, Zunahme der Fibrose in der HRCT oder akute respiratorische Dekompensation.

Liegen keine anderen erkennbaren Ursachen vor, entspricht jede der folgenden Veränderungen einer Progression:

- progrediente Dyspnoe (objektiv beurteilt)

- progrediente, nachhaltige Verschlechterung der FVC gegenüber dem Ausgangswert

- progrediente, nachhaltige Verschlechterung der DLco gegenüber dem Ausgangswert (Hämoglobin-korrigiert)

- Progression der Fibrose gegenüber dem Ausgangsbefund in der HRCT
- akute Exazerbation

- Tod durch respiratorisches Versagen

Diese Parameter basieren auf Daten aus klinischen Studien. Wenngleich es sich bei der progredienten Dyspnoe um eine wichtige subjektive Variable handelt, wird ein objektives Assessment der Dyspnoe empfohlen (z. B. durch Dyspnoe-Scores). Die Einbeziehung des Dyspnoe-Assessments und anderer Variablen muss allerdings in weiteren Studien validiert werden. Daten aus verschiedenen klinischen Kohorten bestätigen bisher, dass eine Veränderung der absoluten FVC von $10 \%$ (mit oder ohne gleichzeitige Veränderung der DLco) oder eine Veränderung der absoluten DLco von 15\% (mit oder ohne gleichzeitige Veränderung der FVC) einen Surrogatmarker für die Mortalität und, bei fehlenden alternativen Ursachen, auch einen Progressionsbeleg darstellen [182, 198, 348 - 352]. Kleinere (5-10\%) aber progrediente, nachhaltige Veränderungen der FVC können ebenfalls eine Progression anzeigen $[182,198,353]$. Die Kommission konnte zwar kein absolutes Mindestmaß für die Veränderung der FVC und DLco benennen, ab dem diese als Progression zu werten sind, aber isolierte Veränderungen von weniger als 5\% der FVC oder weniger als 10\% der DLco sind mit Vorsicht zu interpretieren. Veränderungen dieser Größenordnung können im Bereich der unvermeidlichen Testvariabilität liegen [354-358]. Die Krankheitsprogression wird durchschnittlich über Zeiträume von 3 bis 6 Monaten kontrolliert, allerdings können nachhaltige Veränderungen der Symptomatik, der physiologischen oder radiologischen Parameter innerhalb kürzerer Zeiträume ebenfalls eine Progression kennzeichnen.

Von den vorstehend genannten Parametern bietet der Lungenfunktionstest den am besten standardisierten Ansatz für die objektive Kontrolle und Quantifizierung der Krankheitsprogression. Die Datenlage zeigt, dass eine progrediente Fibrose mit einer allmählichen Abnahme der Lungenfunktion sowie einer Verschlimmerung der Symptome einhergeht [359]. Wie im Plazeboarm mehrerer großer, randomisierter kontrollierter Behandlungsstudien zu IPF beobachtet werden konnte, beträgt die durchschnittliche Abnahme der FVC bei der Gesamtpopulation der IPF-Patienten, die bei Studienbeginn eine leichte bis mäßige Lungenfunktionseinschränkung hatten, etwa 0,2 Liter pro Jahr [270,273,278, 282]. Diese Rate variiert jedoch stark von Patient zu Patient.

Eine nicht anderweitig erklärbare Verringerung der absoluten DLco entspricht einer Krankheitsprogression, kann aber auch Ausdruck von pulmonalvaskulären Veränderungen oder einer begleitenden pulmonalen Hypertonie sein. Mit unseren derzeit verfügbaren Techniken weisen longitudinale Messungen anderer klinischer und physiologischer Parameter (z. B. TLC, P(A-a) $\mathrm{O}_{2}$ ) sowie der 6MWT eine zu hohe Variabilität auf und werden derzeit nicht für die routinemäßige Anwendung im Rahmen der Verlaufskontrolle empfohlen. Eine Kontrolle auf Entsättigung während des 6MWT ist jedoch bei Patienten mit signifikant eingeschränkter körperlicher Belastungsfähigkeit sinnvoll, um festzustellen, ob eine Sauerstoffgabe notwendig ist.

Der physiologische Effekt bestimmter Begleiterkrankungen wie eines koexistenten Emphysems auf den Prognosewert serieller Veränderungen der Lungenfunktion ist noch ungeklärt, dürfte aber wahrscheinlich einen Confounding Factor darstellen [360]. Die internationale Expertenkommission stellt fest, dass das Vorliegen eines signifikanten Emphysems die FVC-Messung beeinträchtigt und die Veränderungen der FVC unter diesen Umständen kein verlässlicher Indikator für die Krankheitsprogression sein können [361 - 363]. In diesem Fall kann die kombinierte Bestimmung von sowohl FVC als auch DLco zur Progressionsbeurteilung sinnvoll sein. 
FVC- und DLco-Messungen sollten nach den gültigen ATS/ERSStandards durchgeführt werden, um Trends zu erfassen [354358]. Obwohl es natürlich sinnvoll ist, den Krankheitsverlauf durch FVC- und DLco-Messungen in 3- bis 6-monatigen Abständen routinemäßig zu überwachen, kann es Subgruppen von Patienten mit sehr schneller Krankheitsprogression oder einer akuten Exazerbation geben, die im vorausgegangenen Intervall keine Anzeichen einer Progression gezeigt hatten [364]. Welcher Zeitraum für Wiederholungsmessungen der FVC und DLco optimal ist, war bisher nicht Gegenstand von Untersuchungen. Die Kontrolle der Krankheitsprogression erfordert einen flexiblen Ansatz, wobei eine progrediente Dyspnoe oder sonstige rasch fortschreitende Veränderungen frühzeitigere Wiederholungsmessungen der FVC und DLco erfordern.

\subsection{Verschlechterung der Symptome}

Die Erkennung von Patienten, deren respiratorische Symptome (z.B. Dyspnoe) sich verschlechtern, hat wichtige Konsequenzen für das Management der Erkrankung. Diese Patienten müssen auf eine Krankheitsprogression untersucht werden, die Oxygenierung muss in Ruhe und unter Belastung bestimmt werden und sekundäre Komplikationen (z.B. Infektionen, tiefe Venenthrombose oder Lungenembolie) müssen diagnostiziert oder ausgeschlossen werden. Zusätzlich können Patienten auch von einer symptomatischen Therapie profitieren. Für die Quantifizierung der Dyspnoe stehen mehrere Messinstrumente zur Verfügung. Die Frage ihrer klinischen Brauchbarkeit ist allerdings nicht geklärt.

\subsection{Verschlechterung der Oxygenierung}

Bei der Eingangsuntersuchung und den Kontrolluntersuchungen sollte bei allen Patienten unabhängig von der Symptomatik die Sauerstoffsättigung mittels Pulsoxymetrie in Ruhe und bei Belastung gemessen werden, um eine ausreichende Oxygenierung zu gewährleisten bzw. den Bedarf für eine Sauerstoffgabe festzustellen. In Anbetracht der häufig schlechten Durchblutung ist dabei besonders auf eine gute Aufzeichnungs- und Signalqualität zu achten. Eine Entsättigung unter 88\% während des 6MWT oder eines vergleichbaren Tests gilt als Richtwert für die Sauerstoffgabe [365]. Die Messungen sollten bei der Eingangsuntersuchung sowie in 3- bis 6-monatigen Kontrollintervallen durchgeführt werden. Die Spiroergometrie spielt bisher keine besondere Rolle und wird für die routinemäßige Verlaufskontrolle nicht empfohlen.

\subsection{Erkennung von Komplikationen und Begleiterkrankungen}

Zu den bekannten Begleiterkrankungen bei der IPF zählen pulmonale Hypertonie, Lungenembolie, Lungenkarzinom und koronare Herzerkrankung. Zwar können diese Komorbiditäten Auswirkungen auf das Überleben haben, der Stellenwert eines routinemäßigen Screenings bei IPF-Patienten (z. B. jährliche HRCT als Lungenkarzinomkontrolle) ist aber bisher unbekannt. Daher kann keine Empfehlung für ein routinemäßiges Screening gegeben werden. Bei Patienten, die eine Krankheitsprogression aufweisen, kann das Auftreten einer pulmonalen Hypertonie Einfluss auf die Frage einer Lungentransplantation haben, auch bei sonstiger Eignung des Patienten. Daher ist eine entsprechende Abklärung erforderlich. Die Echokardiographie erlaubt eine nur ungenaue Bestimmung der pulmonalen Hämodynamik bei Patienten mit Lungenfibrose und sollte nicht zum Ausschluss oder zur Beurteilung des Schweregrads einer pulmonalen Hypertonie herangezogen werden [219, 366-368]. Das BNP (Brain Natriuret- ic Peptide) ist nachweislich mit dem Vorliegen einer mäßigen bis hochgradigen pulmonalen Hypertonie korreliert, aber noch nicht abschließend als Screening-Instrument validiert [219,369,370]. Ein klinisches Prädiktionsmodell der pulmonalen Hypertonie wurde ebenfalls vorgestellt, das aber einer unabhängigen Validierung bedarf [371]. Derzeit ist zum Nachweis einer pulmonalen Hypertonie daher eine Rechtsherzkatheterisierung erforderlich [219].

Da einige Patienten mit Bindegewebserkrankungen (z. B. jüngere Frauen) isolierte, für die IPF charakteristische pulmonale Veränderungen aufweisen können, bevor sich die systemische Erkrankung offen manifestiert, sollte eine geeignete serologische Kontrolle auf Bindegewebserkrankungen erfolgen, sobald bei diesen Patienten erste Symptome auftreten.

Bei Patienten mit einer akuten Verschlechterung der respiratorischen Symptomatik sollte die Möglichkeit einer akuten Exazerbation der IPF in Betracht gezogen und die sofortige Suche nach anderen Ursachen der akuten Verschlechterung (z. B. Lungenembolie, Pneumothorax, Atemwegsinfektionen oder Aspiration) veranlasst werden.

Die Verlaufskontrolle auf Komplikationen in Zusammenhang mit der pharmakologischen Therapie muss auf die bekannten Nebenwirkungsprofile der jeweiligen Therapie zugeschnitten sein.

\subsection{Zusammenfassung des klinischen Managements der IPF}

Die Kommission hat ihre Empfehlungen in einem schematischen Algorithmus zum klinischen Management zusammengefasst (๑ Abb.5).

\section{Kommentar}

Die deutsche IPF-Konsensuskonferenz schließt sich den Empfehlungen der internationalen Leitlinie an. So sind regelmäßige Kontrolluntersuchungen in 3- bis 6-monatigen Intervallen erforderlich, um Änderungen des Krankheitsverlaufs zu entdecken. Diese Untersuchungen sollten immer eine Spirometrie mit Bestimmung der FVC und eine Diffusionsmessung umfassen, zusätzlich sollte die Oxygenierung mittels Bestimmung der transkutanen Sauerstoffsättigung und/oder der kapillären Blutgase in Ruhe überprüft werden. Zur Indikationsstellung für eine Langzeitsauerstofftherapie kann die zusätzliche Blutgasanalyse und transkutane Sauerstoffsättigungsmessung unter körperlicher Belastung hilfreich sein. Die Beurteilung der Befunde sollte berücksichtigen, dass neuere Studien bestätigen, dass bereits ein Abfall der FVC (\% Soll) von 5-10\% des Sollwertes (z. B. entspricht der Abfall der FCV \% Soll von 50\% auf 45\% einer Abnahme von 5\%) im Verlauf von 6 Monaten mit einer ungünstigeren Prognose einhergeht [198], sodass behandelbare Ursachen und weitere Therapieoptionen (z. B. Therapiestudien oder Lungentransplantation) erwogen werden müssen. Für die FVC wurde in diesem Zusammenhang die „Minimal Clinically Important Difference“ (MCID) mit 2-6\% bestimmt [198].

(Abstimmung: 21 Ja, 0 Nein, 0 Enthaltung, 1 abwesend)

Für die Diffusionskapazität ist die Datenlage weniger ergiebig, hier sollte ein Abfall der DLco (\% Soll) von 10-15\% im Verlauf von 6 Monaten als prognostisch negativer Prädiktor gewertet werden, ggf. sollte das Hinzutreten einer pulmonalen Hypertonie evaluiert werden. 


\begin{tabular}{|c|c|c|c|}
\hline \multicolumn{4}{|c|}{ Zeit } \\
\hline $\begin{array}{l}\text { Diagnose } \\
\text { der IPF } \\
\text { (هTab. 3-5, } \\
\text { Abb. 3) }\end{array}$ & $\begin{array}{l}\text { Erhöhtes Mortalitätsrisiko: } \\
\text { Evaluierung und Listung für } \\
\text { Lungentransplantation zum } \\
\text { Zeitpunkt der Diagnose } \\
\text { Überlegungen zur } \\
\text { Behandlung } \\
\\
\text { nicht-pharmakologisch } \\
\text { - Sauerstoffzufuhr } \\
\text { (bei Hypoxämie) } \\
\text { - pulmonale Rehabilitation } \\
\text { pharmakologisch } \\
\text { Patienten werden über } \\
\text { Therapien mit schwacher } \\
\text { Empfehlung informiert und } \\
\text { in ihrer Entscheidung gemäß } \\
\text { ihren persönlichen Werten } \\
\text { und Präferenzen unterstützt. } \\
\text { Begleiterkrankungen } \\
\text { - pulmonale Hypertonie } \\
\text { gastroösophagealer Reflux } \\
\text { symptomatische Therapie }\end{array}$ & $\begin{array}{l}\text { Krankheits-Progression } \\
\text { (siehe Text) } \\
\text { Kontrolle alle 4-6 Monate } \\
\text { oder früher falls klinisch } \\
\text { indiziert }\end{array}$ & $\begin{array}{l}\text { Vorbereitende } \\
\text { Untersuchung } \\
\text { und Listung für } \\
\text { Lungentrans- } \\
\text { plantation }\end{array}$ \\
\hline 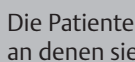 & $\begin{array}{l}\text { en in jedem Stadium auf } \\
\text { eilnehmen können. }\end{array}$ & hingewiesen $\mathrm{v}$ & \\
\hline
\end{tabular}

Abb.5 Schematischer Algorithmus des klinischen Managements von IPF-Patienten. Aufgabe des Arztes ist es, sich ausreichend Zeit zu nehmen, um mit den Patienten über deren Wertvorstellungen, Präferenzen und über die Prognose der IPF zu sprechen. Alle Patienten sollten auf aktuelle klinische Studien hingewiesen werden, an denen sie gegebenenfalls teilnehmen können. Bei Patienten mit erhöhtem Mortalitätsrisiko sollte eine Lungentransplantation erwogen werden. Die pharmakologische Behandlung sollte auf umfassend informierte Patienten beschränkt werden, die bereit sind, die möglichen unerwünschten Folgen zu akzeptieren selbst wenn der zu erwartende Nutzen gering ist. Sauerstofftherapie (bei Hypoxämie) und pulmonale Rehabilitation sind empfohlene Behandlungsmaßnahmen. Die Patienten sollten alle 4 bis 6 Monate (falls klinisch indiziert auch früher) auf Progression und Komplikationen kontrolliert werden.

\section{Ausblick}

Die vorliegende Leitlinie fasst das gegenwärtige Wissen über die idiopathische Lungenfibrose zusammen und nimmt dieses zur Grundlage für klinisch relevante Empfehlungen auf den Gebieten der Diagnostik, Therapie und Verlaufsbeurteilung dieser Erkrankung. Durch neue Studien werden Erkenntnisse verfügbar, die es erforderlich machen werden, wesentliche Teile dieser Leitlinie zu überarbeiten. Dies ist spätestens nach 5 Jahren, wahrscheinlich aber erheblich früher erforderlich [379]. Viele Fragen, insbesondere zur Wertigkeit der transbronchialen Kryobiopsie in Relation zur chirurgischen Lungenbiopsie oder auch die Möglichkeit der Kombination verschiedener verfügbarer Behandlungsansätze können aktuell nicht beantwortet werden und müssen durch kontrollierte Studien geklärt werden, die zum Teil bereits initiiert sind.

Beispielhaft sollen an dieser Stelle potentiell zukunftsweisende Studien und Entwicklungen aufgezeigt werden. Ein interessanter Aspekt ist die potenzielle Rolle von Virusinfektionen für die Entstehung und Progression der IPF. In einer aktuellen, offenen Pilotstudie konnten nach einer zweiwöchigen antiviralen Therapie mit Ganciclovir bei 9/14 Patienten mit fortgeschrittener IPF und serologischem Nachweis einer früheren EBV-Infektion positive Effekte auf die Lungenfunktion (FVC) und die Belastbarkeit sowie die DTPA-Clearance bei verminderter Steroiddosis festgestellt werden [372]. Die Ergebnisse dieser Pilotstudie sind zwar bestenfalls als vorläufig zu werten, könnten aber einen zukünftigen, für IPF-Patienten grundsätzlich neuen Therapieansatz aufzeigen.

Ein weiteres Problemfeld ist die Behandlung der pulmonalen Hypertonie (PH), die häufig in Assoziation mit der IPF anzutreffen ist und mit einer verminderten Belastbarkeit und verkürzten Überlebenszeit einhergeht. Die Beteiligung der Lungengefäße im Rahmen des fibrotischen Umbaus des Lungenparenchyms könnte von Bedeutung für die Krankheitsentwicklung sein. Die Frage, ob mit einer auf die pulmonale Strombahn abzielenden Therapie positive Effekte erreicht werden können, ist bisher nicht abschließend beantwortet. Neuere Studien zeigen allerdings, dass sowohl mit dem Phosphodiesterase-5-Inhibitor Sildenafil als auch mit dem Stimulator der löslichen Guanylatcyclase (sGC) günstige Effekte bei Patienten mit IPF erzielt werden können $[373,374]$. Auch diese Untersuchungen lassen noch keine abschließende Bewertung dieses Behandlungsansatzes zu, sind jedoch Ausgangspunkt für weitere Forschungsarbeiten auf diesem Gebiet. Nach der vielversprechenden Phase-II-Studie wird in Hinblick auf neue Therapieoptionen das Ergebnis der aktuell bereits laufenden Phase-III-Studie mit dem Multikinaseinhibitor Nentadinib (BIBF-1120) mit Spannung erwartet [293].

Ein weiteres wichtiges Feld für zukünftige Entwicklungen ist die Etablierung von allgemein anerkannten Studienendpunkten und von prädiktiven Biomarkern, die es erlauben, kürzere und weniger aufwendige Therapiestudien durchzuführen und so neue Behandlungsansätze mit vertretbarem Aufwand zu erproben. Nur durch die Zusammenarbeit der erfahrenen IPF-Zentren mit der Industrie und mit öffentlichen Stellen der Forschungsförderung kann es gelingen, die nächsten notwendigen Schritte in Richtung Frühdiagnose, Monitoring und medikamentöser Therapie erfolgreich zu gehen.

Nach langen Jahren der Stagnation sind in den vergangenen Jahren erhebliche Fortschritte in Diagnostik und Therapie der IPF erzielt worden und es sind derzeit vielfältige klinisch- und grundlagenwissenschaftlichen Aktivitäten auf diesem Gebiet zur verzeichnen, die weitere Änderungen in den diagnostischen und therapeutischen Strategien sowie auch neue Therapieansätze in naher Zukunft erwarten lassen. Aufgrund dieser sehr zu begrüßenden Entwicklung ist damit zu rechenen, dass die vorliegende Leitlinie schon bald erneut aktualisiert werden muss. 


\section{Danksagung}

Die Autoren danken Frau Lunemann für die organisatorische Unterstützung und Boehringer Ingelheim für die Überlassung des Textes einer im Auftrag erstellten deutschen Übersetzung der ATS/ERS/JRS/ALAT-Leitlinie.

\section{Interessenkonflikt}

$\checkmark$

J. Behr: Honorare für Vorträge und/oder Beratertätigkeit von Actelion, Allmiral, Bayer, Boehringer, Gilead, GSK, InterMune, Lilly, Novartis, Pfizer, Takeda. Forschunsförderung von Actelion.

A. Günther: Honorare für Vorträge und/oder Beratung von Activero, Boehringer-Ingelheim, GSK, InterMune, Novartis, Roche, Takeda.

R. Bonnet: Honorare für Vorträge und/oder Beratung von InterMune.

R. Buhl: Honorare für Vorträge und/oder Beratung von AstraZeneca, Boehringer-Ingelheim, Chiesi, GSK, InterMune, Novartis, Nycomed, Talecris. Forschungsunterstützung von Boehringer-Ingelheim, Novartis und Roche.

O. Eickelberg: Honorare für Vorträge und/oder Beratertätigkeit von Bayer, Boehringer, InterMune, Pfizer, Roche. Forschunsförderung von Bayer und Roche.

R. Ewert: Honorare für Vorträge und/oder Beratertätigkeit von Actelion, Bayer, GSK, InterMune, Lilly, Novartis, Pfizer. Forschungsförderung von Actelion und Pfizer.

S. Gläser: Honorare für Vorträge von Actelion, Bayer, BoehringerIngelheim, GSK, InterMune und Novartis

J. Gottlieb: Honorare für Vorträge und/oder Beratertätigkeit von Boehringer, Gilead, GSK, InterMune, Novartis, Astellas, Pfizer, Roche. Forschungsförderung durch Alnylam, Astellas, Roche, Novartis.

C. Grohé: Honorare für Vorträge und/oder Beratertätigkeit von Actelion, Bayer, Boehringer, GSK, InterMune, Lilly, Novartis, Pfizer.

M. Kreuter: Honorare für Vorträge und Beratung von InterMune.

C. Krögel: Honorare für Vorträge und/oder Beratertätigkeit von Allmiral, Chiesi, GSK, InterMune, Novartis, Takeda, Roche. Forschungsförderung von Bayer, Genentech, InterMune, MSD, Mundipharma, SmithKline Beecham Pharma.

P. Markart: Honorare für Vorträge von InterMune und Roche.

C. Neurohr: Honorare für Vorträge und/oder Beratertätigkeit von Actelion, Bayer, Boehringer, GSK, InterMune, Lilly, Novartis, Pfizer.

M. Pfeifer: Honorare für Vorträge und/oder Beratertätigkeit und/ oder Forschungsförderung von Actelion, Bayer, Boehringer, GSK, InterMune, Lilly, Novartis, Pfizer, BerlinChemie, Astra, Linde, Klosterfrau, Nycomed.

A. Prasse: Honorare für Vorträge und/oder Beratertätigkeit von Boehringer, Sanofi-Aventis, Pfizer, InterMune, GSK, Roche, Novartis, Allmiral, Chiesi. Forschungsförderung von Stromedix, Biogen Idec, Novartis.

J. Schreiber: Honorare für Vorträge und/oder Beratertätigkeit von Actelion, Astra-Zeneca,Boehringer, GSK, InterMune, Lilly, Novartis.

A. Wilke: Honorare für Vorträge und Beratertätigkeit von Boehringer-Ingelheim und InterMune.

H. Wirtz: Honorare für Vorträge und/oder Beratung von InterMune, Roche, Novartis, Boehringer-Ingelheim.

C. Witt: Referenten-Honorare: Actelion, Lilly, Pfizer, GSK
H. Worth: Honorare für Vorträge und/oder Beratung von Astra Zeneca, Bayer, Boehringer-Ingelheim, Chiesie, Klosterfrau, InterMune, Novartis, Nycomed, Talecris, Almirall und Berlin Chemie. Forschungsförderung von Klosterfrau, Nycomed.

J. Müller-Quernheim: Honorare für Vorträge und/oder Beratung von InterMune. Einnahmen der Klinik im Rahmen von Studien von Boehringer Ingelheim, Actelion, Roche und Gilead.

U. Costabel: Honorare für Vorträge und/oder Beratertätigkeit von Actelion, Boehringer, Centocor, Gilead, InterMune, Nycomed, Serono. Forschungsförderung von Intermune.

W. Ammenwerth, I. Bittmann, D. Kauschka, L. Kauschka, N. Schönfeld, H. Sitter, D. Theegarten, A. Theile, D. Zühl und P. Zabel geben an, dass kein Interessenkonflikt besteht.

\section{Patientenvertretung:}

Dagmar Kauschka, Erwachsenen Histiozytose X und Lungenfibrose e.V., Essen

Lothar Kauschka, Erwachsenen Histiozytose X und

Lungenfibrose e.V., Essen

Dieter Zühl, Gruppenleiter der Lungenfibrose

Brandenburg \& Umgebung

Industriebeobachter:

Rosa Schlenker-Hercig (Boehringer-Ingelheim)

Lara Stockhecke (InterMune)

Jens Zimmermann (InterMune)

\section{Institute}

${ }^{1}$ Asklepios Fachkliniken München-Gauting und Medizinische Klinik V, Klinikum der Ludwig-Maximilians-Universität München

${ }^{2}$ Med. Klinik II, Klinische Forschergruppe „Lungenfibrose“, Universitätsklinikum Gießen und Marburg

${ }^{3}$ Lungenfachklinik Waldhof-Elgershausen, Greifenstein

${ }^{4}$ Klinik für Pneumologie, Lungenklinik Heckeshorn, HELIOS Klinikum Emil von Behring, Berlin

${ }^{5}$ Pathologisches Institut, Diakoniekrankenhaus Rotenburg (Wümme)

${ }^{6}$ Klinik für Pneumologie, Zentralklinik Bad Berka GmbH

${ }^{7}$ Medizinische Klinik III, Schwerpunkt Pneumologie, Universität Mainz

${ }^{8}$ Comprehensive Pneumology Center, Ludwig-Maximilians-Universität und Helmholtz Zentrum München

${ }^{9}$ Klinik für Innere Medizin B, Universitätsmedizin Greifswald

${ }^{10}$ Abteilung Pneumologie, Medizinische Hochschule Hannove

${ }^{11}$ Klinik für Pneumologie, Evangelische Lungenklinik Berlin

12 Pneumologie und Beatmungsmedizin, Thoraxklinik, Universitätsklinikum Heidelberg

${ }^{13}$ Klinik für Innere Medizin I, Pneumologie und Allergologie, Universität Jena

${ }^{14}$ Medizinische Klinik V, Klinikum der Universität München

${ }^{15}$ Zentrum für Pneumologie, Klinik Donaustauf

${ }^{16}$ Abteilung für Pneumologie, Universitätsklinikum, Freiburg

${ }_{17}$ Universitätsklinikum Magdeburg, Abteilung für Pneumologie

${ }^{18}$ Inst. für Chir. Forschung, Universität Marburg

${ }^{19}$ Leitlinienkommission der AWMF

20 Institut für Pathologie und Neuropathologie, Universitätsklinikum Essen, Universität Duisburg-Essen

21 Institut für Pathologie, Ruhr-Universität Bochum

${ }^{22}$ Abteilung Pneumologie, Universitätsklinikum Leipzig

23 Arbeitsbereich Pneumologie, Universätsklinikum Charité, Berlin

${ }^{24}$ Medizinische Klinik I, Klinikum Fürth, Fürth

${ }_{25}$ Med. Klinik Borstel, Med. Klinik III Forschungszentrum Borstel, UK-S-H, Campus Lübeck, Borstel

${ }^{26}$ Abt. Pneumologie/Allergologie, Ruhrlandklinik, Westdeutsches Lungenzentrum am Universitätsklinikum Essen, Essen 


\section{Literatur}

1 American Thoracic Society. European Respiratory Society. Idiopathic pulmonary fibrosis: diagnosis and treatment: international consensus statement. Am J Respir Crit Care Med 2000; 161: 646-664

2 Raghu G, Collard HR, Egan JJ et al. An official ATS/ERS/JRS/ALAT statement: idiopathic pulmonary fibrosis: evidence-based guidelines for diagnosis and management. Am J Respir Crit Care Med 2011; 183: $788-824$

3 Schunemann HJ, Jaeschke R, Cook DJ et al. An official ATS statement: grading the quality of evidence and strength of recommendations in ATS guidelines and recommendations. Am J Respir Crit Care Med 2006; 174: 605-614

4 American Thoracic Society. European Respiratory Society. Consensus Classification of the Idiopathic Interstitial Pneumonias. Am J Respir Crit Care Med 2002; 165: 277-304

5 Visscher DW, Myers JL. Histologic spectrum of idiopathic interstitial pneumonias. Proc Am Thorac Soc 2006; 3: 322 - 329

6 Douglas WW, Ryu JH, Schroeder DR. Idiopathic pulmonary fibrosis: Impact of oxygen and colchicine, prednisone, or no therapy on survival. Am J Respir Crit Care Med 2000; 161: 1172-1178

7 King TE Jr, Tooze JA, Schwarz MI et al. Predicting survival in idiopathic pulmonary fibrosis: scoring system and survival model. Am J Respir Crit Care Med 2001; 164: 1171-1181

8 Gribbin J, Hubbard RB, Le Jeune I et al. Incidence and mortality of idiopathic pulmonary fibrosis and sarcoidosis in the UK. Thorax 2006; 61: $980-985$

9 Scott J, Johnston I, Britton J. What causes cryptogenic fibrosing alveolitis? A case-control study of environmental exposure to dust BMJ 1990; 301: 1015-1017

10 Mannino DM, Etzel RA, Parrish RG. Pulmonary fibrosis deaths in the United States, 1979-1991: an analysis of multiple-cause mortality data. Am J Respir Crit Care Med 1996; 153: 1548-1552

11 Raghu G, Freudenberger TD, Yang S et al. High prevalence of abnormal acid gastro-oesophageal reflux in idiopathic pulmonary fibrosis. Eur Respir J 2006; 27: 136-142

12 Raghu G, Weycker D, Edelsberg $J$ et al. Incidence and prevalence of idiopathic pulmonary fibrosis. Am J Respir Crit Care Med 2006; 174 : $810-816$

13 Nadrous HF, Myers JL, Decker PA et al. Idiopathic pulmonary fibrosis in patients younger than 50 years. Mayo Clin Proc 2005; 80: 37-40

14 Iwai $K$, Mori T, Yamada $N$ et al. Idiopathic pulmonary fibrosis: epidemiologic approaches to occupational exposure. Am J Respir Crit Care Med 1994; 150: 670-675

15 Coultas DB, Zumwalt RE, Black WC et al. The epidemiology of interstitial lung diseases. Am J Respir Crit Care Med 1994; 150: 967-972

16 von Plessen C, Grinde O, Gulsvik A. Incidence and prevalence of cryptogenic fibrosing alveolitis in a Norwegian community. Respir Med 2003; 97: $428-435$

17 Karakatsani A, Papakosta D, Rapti A et al. Hellenic Interstitial Lung Diseases Group. Epidemiology of interstitial lung diseases in Greece. Respir Med 2009; 103: 1122-1129

18 Hubbard R, Lewis S, Richards K et al. Occupational exposure to metal or wood dust and aetiology of cryptogenic fibrosing alveolitis. Lancet 1996; 347: 284-289

19 Baumgartner KB, Samet JM, Stidley CA et al. Cigarette smoking: a risk factor for idiopathic pulmonary fibrosis. Am J Respir Crit Care Med 1997; $155: 242-248$

20 Enomoto T, Usuki J, Azuma $A$ et al. Diabetes mellitus may increase risk for idiopathic pulmonary fibrosis. Chest 2003; 123: 2007-2011

21 Steele MP, Speer MC, Loyd JE et al. Clinical and pathologic features of familial interstitial pneumonia. Am J Respir Crit Care Med 2005; 172: $1146-1152$

22 Miyake Y, Sasaki S, Yokoyama T et al. Occupational and environmental factors and idiopathic pulmonary fibrosis in Japan. Ann Occup Hyg 2005; 49: 259-265

23 Taskar VS, Coultas DB. Is idiopathic pulmonary fibrosis an environmental disease? Proc Am Thorac Soc 2006; 3: 293 - 298

24 Johnston ID, Prescott RJ, Chalmers JC et al. British Thoracic Society study of cryptogenic fibrosing alveolitis: current presentation and initial management. Fibrosing Alveolitis Subcommittee of the Research Committee of the British Thoracic Society. Thorax 1997; 52: 38-44

25 Hubbard R, Cooper M, Antoniak $M$ et al. Risk of cryptogenic fibrosing alveolitis in metal workers. Lancet 2000; 355: 466-467
26 Gustafson T, Dahlman-Hoglund A, Nilsson K et al. Occupational exposure and severe pulmonary fibrosis. Respir Med 2007; 101: $2207-$ 2212

27 Kitamura H, Ichinose S, Hosoya $T$ et al. Inhalation of inorganic particles as a risk factor for idiopathic pulmonary fibrosis: elemental microanalysis of pulmonary lymph nodes obtained at autopsy cases. Pathol Res Pract 2007; 203: 575-585

28 Ueda T, Ohta K, Suzuki $N$ et al. Idiopathic pulmonary fibrosis and high prevalence of serum antibodies to hepatitis C virus. Am Rev Respir Dis 1992; 146: $266-268$

29 Irving WL, Day S, Johnston ID. Idiopathic pulmonary fibrosis and hepatitis C virus infection. Am Rev Respir Dis 1993; 148: 1683-1684

30 Egan JJ, Stewart JP, Hasleton PS et al. Epstein-Barr virus replication within pulmonary epithelial cells in cryptogenic fibrosing alveolitis. Thorax 1995; 50: 1234-1239

31 Meliconi R, Andreone P, Fasano $L$ et al. Incidence of hepatitis $C$ virus infection in Italian patients with idiopathic pulmonary fibrosis. Tho$\operatorname{rax} 1996 ; 51: 315-317$

32 Kuwano K, Nomoto Y, Kunitake $R$ et al. Detection of adenovirus E1A DNA in pulmonary fibrosis using nested polymerase chain reaction. Eur Respir J 1997; 10: 1445 - 1449

33 Wangoo A, Shaw RJ, Diss TC et al. Cryptogenic fibrosing alveolitis: lack of association with Epstein-Barr virus infection. Thorax 1997; 52: $888-891$

34 Yamaguchi S, Kubo K, Fujimoto K et al. Analysis of bronchoalveolar lavage fluid in patients with chronic hepatitis $C$ before and after treatment with interferon alpha. Thorax 1997; 52: 33 - 37

35 Yonemaru M, Kasuga I, Kusumoto $\mathrm{H}$ et al. Elevation of antibodies to cytomegalovirus and other herpes viruses in pulmonary fibrosis. Eur Respir J 1997; 10: 2040-2045

36 Stewart JP, Egan JJ, Ross AJ et al. The detection of Epstein-Barr virus DNA in lung tissue from patients with idiopathic pulmonary fibrosis. Am J Respir Crit Care Med 1999; 159: 1336-1341

37 Tsukamoto K, Hayakawa H, Sato A et al. Involvement of Epstein-Barr virus latent membrane protein 1 in disease progression in patients with idiopathic pulmonary fibrosis. Thorax 2000; 55: 958 -961

38 Lok SS, Stewart JP, Kelly BG et al. Epstein-Barr virus and wild p53 in idiopathic pulmonary fibrosis. Respir Med 2001; 95: 787-791

39 Idilman R, Cetinkaya H, Savas I et al. Bronchoalveolar lavage fluid analysis in individuals with chronic hepatitis C. J Med Virol 2002; 66: $34-39$

40 Kelly BG, Lok SS, Hasleton PS et al. A rearranged form of Epstein-Barr virus DNA is associated with idiopathic pulmonary fibrosis. Am J Respir Crit Care Med 2002; 166: 510-513

41 Arase Y, Ikeda K, Tsubota A et al. Usefulness of serum KL-6 for early diagnosis of idiopathic pulmonary fibrosis in patients with hepatitis $C$ virus. Hepatol Res 2003; 27: 89-94

42 Tang YW, Johnson JE, Browning PJ et al. Herpesvirus DNA is consistently detected in lungs of patients with idiopathic pulmonary fibrosis. J Clin Microbiol 2003; 41: 2633-2640

43 Procop GW, Kohn DJ, Johnson JE et al. BK and JC polyomaviruses are not associated with idiopathic pulmonary fibrosis. J Clin Microbiol 2005; 43: 1385-1386

44 Zamo A, Poletti V, Reghellin D et al. HHV-8 and EBV are not commonly found in idiopathic pulmonary fibrosis. Sarcoidosis Vasc Diffuse Lung Dis 2005; 22 : $123-128$

45 Tobin RW, Pope CEII, Pellegrini CA et al. Increased prevalence of gastroesophageal reflux in patients with idiopathic pulmonary fibrosis. Am J Respir Crit Care Med 1998; 158: 1804-1808

46 Patti MG, Tedesco P, Golden J et al. Idiopathic pulmonary fibrosis: how often is it really idiopathic? J Gastrointest Surg 2005; 9: 1053 - 1056

47 el-Serag HB, Sonnenberg A. Comorbid occurrence of laryngeal or pulmonary disease with esophagitis in United States military veterans. Gastroenterology 1997; 113: 755-760

48 D'Ovidio F, Singer LG, Hadjiliadis D et al. Prevalence of American Thoracic Society Documents 817 gastroesophageal reflux in end-stage lung disease candidates for lung transplant. Ann Thorac Surg 2005; 80: $1254-1260$

49 Gribbin J, Hubbard R, Smith C. Role of diabetes mellitus and gastrooesophageal reflux in the aetiology of idiopathic pulmonary fibrosis. Respir Med 2009; 103: 927-931

50 Bitterman PB, Rennard SI, Keogh BA et al. Familial idiopathic pulmonary fibrosis: evidence of lung inflammation in unaffected family members. N Engl J Med 1986; 314: 1343-1347 
51 Marshall RP, Puddicombe A, Cookson WO et al. Adult familial cryptogenic fibrosing alveolitis in the UK. Thorax 2000; 55: $143-146$

52 Hodgson U, Laitinen T, Tukiainen P. Nationwide prevalence of sporadic and familial idiopathic pulmonary fibrosis: evidence of founder effect among multiplex families in Finland. Thorax 2002; 57: 338 - 342

53 Allam JS, Limper AH. Idiopathic pulmonary fibrosis: is it a familial disease? Curr Opin Pulm Med 2006; 12: 312 - 317

54 Lee H, Ryu JH, Wittmer MH et al. Familial idiopathic pulmonary fibrosis: clinical features and outcome. Chest 2005; 127: 2034-2041

55 Raghu G, Hert R. Interstitial lung diseases: genetic predisposition and inherited interstitial lung diseases. Sem Respir Med 1993; 14: 323 332

56 Mageto YN, Raghu G. Genetic predisposition of idiopathic pulmonary fibrosis. Curr Opin Pulm Med 1997; 3: 336-340

57 Yang IV, Burch LH, Steele MP et al. Gene expression profiling of familial and sporadic interstitial pneumonia. Am J Respir Crit Care Med 2007 175: $45-54$

58 Hodgson $U$, Pulkkinen $V$, Dixon $M$ et al. ELMOD2 is a candidate gene for familial idiopathic pulmonary fibrosis. Am J Hum Genet 2006; 79: $149-154$

59 Rosas IO, Ren P, Avila NA et al. Early interstitial lung disease in familial pulmonary fibrosis. Am J Respir Crit Care Med 2007; 176: 698 - 705

60 Musk AW, Zilko PJ, Manners P et al. Genetic studies in familial fibrosing alveolitis. Possible linkage with immunoglobulin allotypes $(\mathrm{Gm})$ Chest 1986; 89: $206-210$

61 Thomas AQ Lane K, Phillips JIII et al. Heterozygosity for a surfactant protein $C$ gene mutation associated with usual interstitial pneumonitis and cellular nonspecific interstitial pneumonitis in one kindred. Am J Respir Crit Care Med 2002; 165: 1322 - 1328

62 Selman M, Lin H, Montano $M$ et al. Surfactant protein A and B genetic variants predispose to idiopathic pulmonary fibrosis. Hum Genet 2003; $113: 542-550$

63 Lawson WE, Grant SW, Ambrosini V et al. Genetic mutations in surfactant protein $C$ are a rare cause of sporadic cases of IPF. Thorax 2004; 59: 977 -980

64 Markart P, Ruppert C, Wygrecka M et al. Surfactant protein C mutations in sporadic forms of idiopathic interstitial pneumonias. Eur Respir J 2007; 29: 134-137

65 Wang Y, Kuan PJ, Xing C et al. Genetic defects in surfactant protein A2 are associated with pulmonary fibrosis and lung cancer. Am J Hum Genet 2009; 84: 52 - 59

66 Armanios MY, Chen JJ, Cogan JD et al. Telomerase mutations in families with idiopathic pulmonary fibrosis. N Engl J Med 2007; 356: $1317-1326$

67 Tsakiri KD, Cronkhite JT, Kuan PJ et al. Adult-onset pulmonary fibrosis caused by mutations in telomerase. Proc Natl Acad Sci USA 2007 104: $7552-7557$

68 Cronkhite JT, Xing C, Raghu G et al. Telomere shortening in familial and sporadic pulmonary fibrosis. Am J Respir Crit Care Med 2008 178: $729-737$

69 Alder JK, Chen JJ, Lancaster $L$ et al. Short telomeres are a risk factor for idiopathic pulmonary fibrosis. Proc Natl Acad Sci USA 2008; 105: $13051-13056$

70 Mushiroda T, Wattanapokayakit S, Takahashi A et al. A genome-wide association study identifies an association of a common variant in TERT with susceptibility to idiopathic pulmonary fibrosis. J Med Genet 2008; 45: 654-656

71 Renzoni E, Lympany P, Sestini $P$ et al. Distribution of novel polymorphisms of the interleukin- 8 and CXC receptor 1 and 2 genes in systemic sclerosis and cryptogenic fibrosing alveolitis. Arthritis Rheum 2000; 43: $1633-1640$

72 Whyte M, Hubbard R, Meliconi R et al. Increased risk of fibrosing alveolitis associated with interleukin-1 receptor antagonist and tumor necrosis factor-alpha gene polymorphisms. Am J Respir Crit Care Med 2000; 162: $755-758$

73 Freeburn $R W$, Kendall H, Dobson $L$ et al. The 39 untranslated region of tumor necrosis factor-alpha is highly conserved in idiopathic pulmonary fibrosis (IPF). Eur Cytokine Netw 2001; 12: 33-38

74 Pantelidis P, Fanning GC, Wells AU et al. Analysis of tumor necrosis factor-alpha, lymphotoxin-alpha, tumor necrosis factor receptor II, and interleukin-6 polymorphisms in patients with idiopathic pulmonary fibrosis. Am J Respir Crit Care Med 2001; 163: 1432 - 1436

75 Hutyrova B, Pantelidis $P$, Drabek J et al. Interleukin-1 gene cluster polymorphisms in sarcoidosis and idiopathic pulmonary fibrosis. Am J Respir Crit Care Med 2002; 165: 148-151
76 Latsi P, Pantelidis P, Vassilakis D et al. Analysis of IL-12 p40 subunit gene and IFN-gamma G5644A polymorphisms in Idiopathic Pulmonary Fibrosis. Respir Res 2003; 4: 6

77 Whittington HA, Freeburn RW, Godinho SIH et al. Analysis of an IL-10 polymorphism in idiopathic pulmonary fibrosis. Genes Immun 2003; 4: $258-264$

78 Riha RL, Yang IA, Rabnott GC et al. Cytokine gene polymorphisms in idiopathic pulmonary fibrosis. Intern Med J 2004; 34: 126-129

79 Vasakova M, Striz I, Slavcev A et al. Correlation of IL-1alpha and IL-4 gene polymorphisms and clinical parameters in idiopathic pulmonary fibrosis. Scand J Immunol 2007; 65: 265 - 270

80 Vasakova M, Striz I, Slavcev A et al. Th1/Th2 cytokine gene polymorphisms in patients with idiopathic pulmonary fibrosis. Tissue Antigens 2006; 67: 229-232

81 Geddes DM, Webley M, Brewerton DA et al. alpha 1-antitrypsin phenotypes in fibrosing alveolitis and rheumatoid arthritis. Lancet $1977 ; 2$ : $1049-1051$

82 Hubbard R, Baoku Y, Kalsheker N et al. Alpha1-antitrypsin phenotypes in patients with cryptogenic fibrosing alveolitis: a case-control study. Eur Respir J 1997; 10: 2881 - 2883

83 Morrison $C D$, Papp AC, Hejmanowski AQ et al. Increased D allele frequency of the angiotensin-converting enzyme gene in pulmonary fibrosis. Hum Pathol 2001; 32: 521 - 528

84 Xaubet A, Marin-Arguedas A, Lario $S$ et al. Transforming growth factor-beta1 gene polymorphisms are associated with disease progression in idiopathic pulmonary fibrosis. Am J Respir Crit Care Med 2003; 168: 431 - 435

85 Zorzetto M, Ferrarotti I, Campo I et al. NOD2/CARD15 gene polymorphisms in idiopathic pulmonary fibrosis. Sarcoidosis Vasc Diffuse Lung Dis 2005; 22: 180-185

86 Checa $M$, Ruiz $V$, Montano $M$ et al. MMP-1 polymorphisms and the risk of idiopathic pulmonary fibrosis. Hum Genet 2008; 124: 465 472

87 Falfan-Valencia R, Camarena A, Juarez A et al. Major histocompatibility complex and alveolar epithelial apoptosis in idiopathic pulmonary fibrosis. Hum Genet 2005; 118: 235-244

88 Lederer DJ, Arcasoy SM, Barr RG et al. Racial and ethnic disparities in idiopathic pulmonary fibrosis: A UNOS/OPTN database analysis. Am J Transplant 2006; 6: 2436-2442

89 Zuo F, Kaminski N, Eugui $E$ et al. Gene expression analysis reveals matrilysin as a key regulator of pulmonary fibrosis in mice and humans. Proc Natl Acad Sci USA 2002; 99: 6292-6297

90 Seibold MA, Wise AL, Speer MC et al. A common MUC5B promoter polymorphism and pulmonary fibrosis. N Engl J Med 2011; 364: 1503 1512

91 Zhang Y, Noth I, Garcia JG et al. A variant in the promoter of MUC5B and idiopathic pulmonary fibrosis. N Engl J Med 2011; 364: 1576 1577

92 Armanios M. Telomerase and idiopathic pulmonary fibrosis. Mutat Res 2012; 730: $52-58$

93 Lawson WE, Loyd JE, Degryse AL. Genetics in pulmonary fibrosis familial cases provide clues to the pathogenesis of idiopathic pulmonary fibrosis. Am J Med Sci 2011; 341: 439-443

94 Diaz de Leon A, Cronkhite J, Katzenstein A et al. Telomere Lengths, Pulmonary Fibrosis and Telomerase (TERT) Mutations. PLOS One 2010 5: e10680

95 van Moorsel C, van Oosterhout M, Barlo N et al. Surfactant Protein C Mutations Are the Basis of a Significant Portion of Adult Familial Pulmonary Fibrosis in a Dutch Cohort. Am J Respir Crit Care Med 2011; 182: $1419-1425$

96 Nishimura K, Kitaichi M, Izumi T et al. Usual interstitial pneumonia: histologic correlation with high-resolution CT. Radiology 1992; 182: $337-342$

97 Johkoh T, Muller NL, Cartier Yet al. Idiopathic interstitial pneumonias: diagnostic accuracy of thin-section CT in 129 patients. Radiology 1999; 211: 555-560

98 Hansell DM, Bankier AA, Macmahon $H$ et al. Fleischner Society: Glossary of terms for thoracic imaging. Radiology 2008; 246: 697-722

99 Hwang JH, Misumi S, Sahin H et al. Computed tomographic features of idiopathic fibrosing interstitial pneumonia: comparison with pulmonary fibrosis related to collagen vascular disease. J Comput Assist Tomogr 2009; 33: 410-415

100 Souza CA, Muller NL, Lee KS et al. Idiopathic interstitial pneumonias: prevalence of mediastinal lymph node enlargement in 206 patients. AJR Am J Roentgenol 2006; 186: 995-999 
101 Mathieson JR, Mayo JR, Staples CA et al. Chronic diffuse infiltrative lung disease: comparison of diagnostic accuracy of CT and chest radiography. Radiology 1989; 171: 111 -116

102 Hunninghake GW, Zimmerman MB, Schwartz DA et al. Utility of a lung biopsy for the diagnosis of idiopathic pulmonary fibrosis. Am J Respir Crit Care Med 2001; 164: 193-196

103 Raghu G, Mageto YN, Lockhart D et al. The accuracy of the clinical diagnosis of new-onset idiopathic pulmonary fibrosis and other interstitial lung disease: A prospective study. Chest 1999; 116: 1168 1174

104 Grenier P, Valeyre D, Cluzel $P$ et al. Chronic diffuse interstitial lung disease: diagnostic value of chest radiography and high-resolution CT. Radiology 1991; 179: 123 - 132

105 Lee KS, Primack SL, Staples CA et al. Chronic infiltrative lung disease: comparison of diagnostic accuracies of radiography and low- and conventional-dose thin-section CT. Radiology 1994; 191: 669-673

106 Swensen SJ, Aughenbaugh GL, Myers JL. Diffuse lung disease: diagnostic accuracy of CT in patients undergoing surgical biopsy of the lung. Radiology 1997; 205: 229-234

107 Flaherty KR, Thwaite EL, Kazerooni EA et al. Radiological versus histological diagnosis in UIP and NSIP: survival implications. Thorax 2003; 58: $143-148$

108 Quadrelli S, Molinari L, Ciallella L et al. Radiological versus histopathological diagnosis of usual interstitial pneumonia in the clinical practice: does it have any survival difference? Respiration 2010; 79: 32 37

109 Flaherty KR, King TE Jr, Raghu G et al. Idiopathic interstitial pneumonia: what is the effect of a multidisciplinary approach to diagnosis? Am J Respir Crit Care Med 2004; 170: 904-910

110 Lynch JP III, Saggar R, Weigt SS et al. Usual interstitial pneumonia. Semin Respir Crit Care Med 2006; 27: 634-651

111 Trahan S, Hanak V, Ryu JH et al. Role of surgical lung biopsy in separating chronic hypersensitivity pneumonia from usual interstitial pneumonia/idiopathic pulmonary fibrosis: analysis of 31 biopsies from 15 patients. Chest 2008; 134: 126-132

112 Silva CI, Muller NL, Lynch DA et al. Chronic hypersensitivity pneumonitis: differentiation from idiopathic pulmonary fibrosis and nonspecific interstitial pneumonia by using thin-section CT. Radiology 2008; 246: $288-297$

113 Monaghan H, Wells AU, Colby TV et al. Prognostic implications of histologic patterns in multiple surgical lung biopsies from patients with idiopathic interstitial pneumonias. Chest 2004; 125: 522-526

114 Flaherty KR, Travis WD, Colby TV et al. Histopathologic variability in usual and nonspecific interstitial pneumonias. Am J Respir Crit Care Med 2001; 164: 1722 - 1727

115 Bensard DD, McIntyre RC Jr, Waring BJ et al. Comparison of video thoracoscopic lung biopsy to open lung biopsy in the diagnosis of interstitial lung disease. Chest 1993; 103: $765-770$

116 Miller JD, Urschel JD, Cox G et al. A randomized, controlled trial comparing thoracoscopy and limited thoracotomy for lung biopsy in interstitial lung disease. Ann Thorac Surg 2000; 70: 1647-1650

117 Carnochan FM, Walker WS, Cameron EW. Efficacy of video assisted thoracoscopic lung biopsy: an historical comparison with open lung biopsy. Thorax 1994; 49: 361 - 363

118 Ferson PF, Landreneau RJ, Dowling RD et al. Comparison of open versus thoracoscopic lung biopsy for diffuse infiltrative pulmonary disease. J Thorac Cardiovasc Surg 1993; 106: 194-199

119 Vourlekis JS, Schwarz MI, Cherniack RM et al. The effect of pulmonary fibrosis on survival in patients with hypersensitivity pneumonitis. Am J Med 2004; 116: $662-668$

120 Ohshimo S, Bonella F, Cui A et al. Significance of bronchoalveolar lavage for the diagnosis of idiopathic pulmonary fibrosis. Am J Respir Crit Care Med 2009; 179: 1043-1047

121 Berbescu EA, Katzenstein AA, Snow JL et al. Transbronchial biopsy in usual interstitial pneumonia. Chest 2006; 129: 1126-1131

122 Park JH, Kim DS, Park IN et al. Prognosis of fibrotic interstitial pneumonia: idiopathic versus collagen vascular disease-related subtypes. Am J Respir Crit Care Med 2007; 175: 705-711

123 Wasicek CA, Reichlin M, Montes M et al. Polymyositis and interstitial lung disease in a patient with anti-Jo1 prototype. Am J Med 1984; 76: $538-544$

124 Flaherty KR, Andrei A, King TE Jr et al. Idiopathic interstitial pneumonia: do community and academic physicians agree on diagnosis? Am J Respir Crit Care Med 2007; 175: 1054-1060
125 Carrington $C B$, Gaensler EA, Coutu RE et al. Natural history and treated course of usual and desquamative interstitial pneumonia. $\mathrm{N}$ Engl J Med 1978; 298: $801-809$

126 Tukiainen P, Taskinen E, Holsti P et al. Prognosis of cryptogenic fibrosing alveolitis. Thorax 1983; 38: 349-355

127 Gross TJ, Hunninghake GW. Idiopathic pulmonary fibrosis. N Engl J Med 2001; 345: $517-525$

128 Ley B, Collard HR, King TE. Clinical course and prediction of survival in Idiopathic Pulmonary Fibrosis. Am J Respir Crit Care Med 2011; 183: $431-440$

129 Bjoraker JA, Ryu JH, Edwin MK et al. Prognostic significance of histopathologic subsets in idiopathic pulmonary fibrosis. Am J Respir Crit Care Med 1998; 157: 199-203

130 Flaherty KR, Toews GB, Travis WD et al. Clinical significance of histological classification of idiopathic interstitial pneumonia. Eur Respir J 2002; 19: $275-283$

131 Nicholson AG, Colby TV, du Bois RM et al. The prognostic significance of the histologic pattern of interstitial pneumonia in patients presenting with the clinical entity of cryptogenic fibrosing alveolitis. Am J Respir Crit Care Med 2000; 162: 2213-2217

132 Rudd RM, Prescott RJ, Chalmers JC et al. British Thoracic Society Study on cryptogenic fibrosing alveolitis: Response to treatment and survival. Thorax 2007; 62: $62-66$

133 King TE Jr, Schwarz MI, Brown K et al. Idiopathic pulmonary fibrosis: relationship between histopathologic features and mortality. Am J Respir Crit Care Med 2001; 164: 1025-1032

134 Raghu G, Brown KK, Bradford WZ et al. A placebo-controlled trial of interferon gamma-1b in patients with idiopathic pulmonary fibrosis. N Engl J Med 2004; 350: 125 - 133

135 King TE Jr, Albera C, Bradford WZ et al., INSPIRE Study Group. Effect of interferon gamma-1b on survival in patients with idiopathic pulmonary fibrosis (INSPIRE): a multicentre, randomised, placebo-controlled trial. Lancet 2009; 374: 222 -228

136 King TE Jr, Behr J, Brown KK et al. BUILD-1: a randomized placebo-controlled trial of bosentan in idiopathic pulmonary fibrosis. Am J Respir Crit Care Med 2008; 177: 75-81

137 Raghu G. Idiopathic pulmonary fibrosis: a rational clinical approach. Chest 1987; 92: 148-154

138 Selman M, Carrillo G, Estrada A et al. Accelerated variant of idiopathic pulmonary fibrosis: clinical behavior and gene expression pattern. PLOS ONE 2007; 2: e482

139 Mejia M, Carrillo G, Rojas-Serrano J et al. Idiopathic pulmonary fibrosis and emphysema: decreased survival associated with severe pulmonary arterial hypertension. Chest 2009; 136: 10-15

140 Wells $A U$, Desai SR, Rubens $M B$ et al. Idiopathic pulmonary fibrosis: a composite physiologic index derived from disease extent observed by computed tomography. Am J Respir Crit Care Med 2003; 167 : $962-969$

141 Lettieri CJ, Nathan SD, Barnett SD et al. Prevalence and outcomes of pulmonary arterial hypertension in advanced idiopathic pulmonary fibrosis. Chest 2006; 129: 746-752

142 Collard HR, Moore BB, Flaherty KR et al. Idiopathic Pulmonary Fibrosis Clinical Research Network Investigators. Acute exacerbations of idiopathic pulmonary fibrosis. Am J Respir Crit Care Med 2007; 176: 636- 643

143 Azuma A, Nukiwa T, Tsuboi E et al. Double-blind, placebo-controlled trial of pirfenidone in patients with idiopathic pulmonary fibrosis. Am J Respir Crit Care Med 2005; 171: 1040-1047

144 Song JW, Hong S-B, Koh Y et al. Acute exacerbation of idiopathic pulmonary fibrosis: incidence, risk factors and outcome. Eur Respir J 2011; 37: $356-363$

145 Martinez FJ, Safrin S, Weycker D et al., IPF Study Group. The clinical course of patients with idiopathic pulmonary fibrosis. Ann Intern Med 2005; 142: 963 -967

146 Panos RJ, Mortenson RL, Niccoli SA et al. Clinical deterioration in patients with idiopathic pulmonary fibrosis: causes and assessment. Am J Med 1990; 88: 396-404

147 Akira M, Hamada $H$, Sakatani $M$ et al. CT findings during phase of accelerated deterioration in patients with idiopathic pulmonary fibrosis. AJR Am J Roentgenol 1997; 168: 79-83

148 Ambrosini V, Cancellieri A, Chilosi M et al. Acute exacerbation of idiopathic pulmonary fibrosis: report of a series. Eur Respir J 2003; 22: $821-826$ 
149 Kim DS, Park JH, Park BK et al. Acute exacerbation of idiopathic pulmonary fibrosis: frequency and clinical features. Eur Respir J 2006; 27: $143-150$

150 Kondoh Y, Taniguchi H, Kawabata Y et al. Acute exacerbation in idiopathic pulmonary fibrosis: analysis of clinical and pathologic findings in three cases. Chest 1993; 103: $1808-1812$

151 Kondoh Y, Taniguchi H, Yokoi T et al. Cyclophosphamide and low-dose prednisolone in idiopathic pulmonary fibrosis and fibrosing nonspecific interstitial pneumonia. Eur Respir J 2005; 25: 528 - 533

152 Kubo H, Nakayama K, Yanai M et al. Anticoagulant therapy for idiopathic pulmonary fibrosis. Chest 2005; 128: 1475 - 1482

153 Parambil JG, Myers JL, Ryu JH. Histopathologic features and outcome of patients with acute exacerbation of idiopathic pulmonary fibrosis undergoing surgical lung biopsy. Chest 2005; 128: 3310-3315

154 Tiitto L, Bloigu R, Heiskanen $U$ et al. Relationship between histopathological features and the course of idiopathic pulmonary fibrosis/usual interstitial pneumonia. Thorax 2006; 61: 1091 -1095

155 Rice AJ, Wells AU, Bouros D et al. Terminal diffuse alveolar damage in relation to interstitial pneumonias: an autopsy study. Am J Clin Pathol 2003; 119: 709-714

156 Churg A, Muller NL, Silva CIS et al. Acute exacerbation (acute lung injury of unknown cause) in UIP and other forms of fibrotic interstitial pneumonias. Am J Surg Pathol 2007; 31: 277 -284

157 Kondo A, Saiki S. Acute exacerbation in idiopathic interstitial pneumonia (IIP). In: Harasawa M, Fukuchi Y, Morinari H, eds. Interstitial pneumonia of unknown etiology. Tokyo: University of Tokyo Press; 1989: $33-42$

158 Konishi K, Gibson KF, Lindell KO et al. Gene expression profiles of acute exacerbations of idiopathic pulmonary fibrosis. Am J Respir Crit Care Med 2009; 180: 167-175

159 Wootton SC, Kim DS, Kondoh Yet al. Viral infection in acute exacerbation of Idiopathic Pulmonary Fibrosis. Am J Respir Crit Care Med 2011; 183: $1698-1702$

160 Sakamoto K, Taniguchi H, Kondoh $Y$ et al. Acute exacerbation of idiopathic pulmonary fibrosis as the initial presentation of the disease. Eur Respir Rev 2009; 18: 129-132

161 Kondoh $Y$, Taniguchi $H$, Kataoka $K$ et al. Prognostic factors in rapidly progressive interstitial pneumonia. Respirology 2010; 15: 257 -264

162 Kumar P, Goldstraw P, Yamada K et al. Pulmonary fibrosis and lung cancer: risk and benefit analysis of pulmonary resection. J Thorac Cardiovasc Surg 2003; 125: 1321 - 1327

163 Yuksel M, Ozyurtkan MO, Bostanci K et al. Acute exacerbation of interstitial fibrosis after pulmonary resection. Ann Thorac Surg 2006; 82: $336-338$

164 Utz JP, Ryu JH, Douglas WW et al. High short-term mortality following lung biopsy for usual interstitial pneumonia. Eur Respir J 2001; 17: $175-179$

165 Zegdi R, Azorin J, Tremblay B et al. Videothoracoscopic lung biopsy in diffuse infiltrative lung diseases: a 5-year surgical experience. Ann Thorac Surg 1998; 66: 1170-1173

166 Kondoh Y, Taniguchi H, Kitaichi M et al. Acute exacerbation of interstitial pneumonia following surgical lung biopsy. Respir Med 2006; 100 : $1753-1759$

167 Hiwatari $N$, Shimura S, Takishima T et al. Bronchoalveolar lavage as a possible cause of acute exacerbation in idiopathic pulmonary fibrosis patients. Tohoku J Exp Med 1994; 174: 379-386

168 Olson AL, Swigris JJ, Lezotte DC et al. Mortality from pulmonary fibrosis increased in the United States from 1992 to 2003. Am J Respir Crit Care Med 2007; 176: 277 - 284

169 Navaratnam V, Fleming KM, West J et al. The rising incidence of idiopathic pulmonary fibrosis in the UK. Thorax 2011; 66: $462-467$

170 Jemal A, Siegel R, Ward E et al. Cancer statistics, 2007. CA Cancer J Clin 2007; 57: 43-66

171 Olson AL, Swigris JJ, Raghu G et al. Seasonal variation: mortality from pulmonary fibrosis is greatest in the winter. Chest 2009; 136: 16-22

172 Fernandez Perez ER, Daniels CE, Schroeder DR et al. Incidence, prevalence and clinical course of Idiopathic Pulmonary Fibrosis: a population-based study. Chest 2010; 137: 129-37

173 Hubbard RB, Smith C, Le Jeune I et al. The association between idiopathic pulmonary fibrosis and vascular disease: a population-based study. Am J Respir Crit Care Med 2008; 178: 1257-1261

174 Nadrous HF, Pellikka PA, Krowka MJ et al. Pulmonary hypertension in patients with idiopathic pulmonary fibrosis. Chest 2005; 128: 2393 2399
175 Collard HR, Ryu JH, Douglas WW et al. Combined corticosteroid and cyclophosphamide therapy does not alter survival in idiopathic pulmonary fibrosis. Chest 2004; 125: 2169 -2174

176 Hubbard R, Venn A, Smith $C$ et al. Exposure to commonly prescribed drugs and the etiology of cryptogenic fibrosing alveolitis: a case-control study. Am J Respir Crit Care Med 1998; 157: 743 - 747

177 Schwartz DA, Van Fossen DS, Davis CS et al. Determinants of progression in idiopathic pulmonary fibrosis. Am J Respir Crit Care Med 1994; 149: $444-449$

178 Enomoto $N$, Suda T, Kato $M$ et al. Quantitative analysis of fibroblastic foci in usual interstitial pneumonia. Chest 2006; 130: $22-29$

179 Nadrous HF, Pellikka PA, Krowka MJ et al. The impact of pulmonary hypertension on survival in patients with idiopathic pulmonary fibrosis. Chest 2005; 128: 616-617

$180 \mathrm{Jegal}$ Y, Kim DS, Shim TS et al. Physiology is a stronger predictor of survival than pathology in fibrotic interstitial pneumonia. Am J Respir Crit Care Med 2005; 171: 639-644

181 Wells $A U$, Hogaboam CM. Update in diffuse parenchymal lung disease 2007. Am J Respir Crit Care Med 2008; 177: 580 - 584

182 du Bois RM, Weycker D, Albera C et al. Ascertainment of individual risk of mortality for patients with idiopathic pulmonary fibrosis. Am J Respir Crit Care Med 2011; 184: 459-466

183 Turner-Warwick M, Burrows B, Johnson A. Cryptogenic fibrosing alveolitis: response to corticosteroid treatment and its effect on survival. Thorax 1980; 35: 593 - 599

184 Schwartz DA, Helmers RA, Galvin JR et al. Determinants of survival in idiopathic pulmonary fibrosis. Am J Respir Crit Care Med 1994; 149: $450-454$

185 Nishiyama 0 , Taniguchi $H$, Kondoh Yet al. Health-related quality of life in patients with idiopathic pulmonary fibrosis: what is the main contributing factor? Respir Med 2005; 99: 408-414

186 Nishiyama 0 , Taniguchi $H$, Kondoh $Y$ et al. A simple assessment of dyspnea as a prognostic indicator in idiopathic pulmonary fibrosis. Eur Respir J 2010; 36: 1067 - 1072

187 Watters LC, King TE Jr, Schwarz MI et al. A clinical, radiographic, and physiologic scoring system for the longitudinal assessment of patients with idiopathic pulmonary fibrosis. Am Rev Respir Dis 1986; 133: $97-103$

188 Witek TJ Jr, Mahler DA. Minimal important difference of the transition dyspnoea index in a multinational clinical trial. Eur Respir J 2003; 21 $267-272$

189 Kupferberg DH, Kaplan RM, Slymen DJ et al. Minimal clinically important difference for the UCSD Shortness of Breath Questionnaire. J Cardiopulm Rehabil 2005; 25: 370 - 377

190 Collard HR, King TE Jr, Bartelson BB et al. Changes in clinical and physiologic variables predict survival in idiopathic pulmonary fibrosis Am J Respir Crit Care Med 2003; 168: 538-542

191 King TE Jr, Safrin S, Starko KM et al. Analyses of efficacy end points in a controlled trial of interferon-gamma1b for idiopathic pulmonary fibrosis. Chest 2005; 127: $171-177$

192 Hallstrand TS, Boitano LJ, Johnson WC et al. The timed walk test as a measure of severity and survival in idiopathic pulmonary fibrosis. Eur Respir J 2005; 25: 96-103

193 Hamada K, Nagai S, Tanaka S et al. Significance of pulmonary arterial pressure and diffusion capacity of the lung as prognosticator in patients with idiopathic pulmonary fibrosis. Chest 2007; 131: 650-656

194 Egan JJ, Martinez FJ, Wells AU et al. Lung function estimates in idiopathic pulmonary fibrosis: the potential for a simple classification. Tho$\operatorname{rax} 2005$; 60: 270-273

195 Latsi PI, du Bois RM, Nicholson AG et al. Fibrotic idiopathic interstitial pneumonia: the prognostic value of longitudinal functional trends. Am J Respir Crit Care Med 2003; 168: 531 - 537

196 Fell CD, Liu LX, Motika C et al. The prognostic value of cardiopulmonary exercise testing in idiopathic pulmonary fibrosis. Am J Respir Crit Care Med 2009; 179: 402-407

197 Flaherty KR, Mumford JA, Murray S et al. Prognostic implications of physiologic and radiographic changes in idiopathic interstitial pneumonia. Am J Respir Crit Care Med 2003; 168: 543 - 548

198 du Bois RM, Weycker D, Albera C et al. Forced vital capacity in patients with idiopathic pulmonary fibrosis: test properties and minimal clinically important difference. Am J Respir Crit Care Med 2011; 184 : $1382-1389$

199 Lynch DA, Godwin JD, Safrin S et al., Idiopathic Pulmonary Fibrosis Study Group. High-resolution computed tomography in idiopathic 
pulmonary fibrosis: diagnosis and prognosis. Am J Respir Crit Care Med 2005; 172: 488-493

200 Best AC, Meng J, Lynch AM et al. Idiopathic pulmonary fibrosis: physiologic tests, quantitative $\mathrm{CT}$ indexes, and $\mathrm{CT}$ visual scores as predictors of mortality. Radiology 2008; 246: 935-940

201 Jeong YJ, Lee KS, Muller NL et al. Usual interstitial pneumonia and nonspecific interstitial pneumonia: serial thin-section CT findings correlated with pulmonary function. Korean J Radiol 2005; 6: 143-152

202 Shin KM, Lee KS, Chung MP et al. Prognostic determinants among clinical, thin-section CT, and histopathologic findings for fibrotic idiopathic interstitial pneumonias: tertiary hospital study. Radiology 2008; 249: 328-337

203 Sumikawa H, Johkoh T, Colby TV et al. Computed tomography findings in pathological usual interstitial pneumonia: relationship to survival. Am J Respir Crit Care Med 2008; 177: 433-439

204 Lama VN, Flaherty KR, Toews GB et al. Prognostic value of desaturation during a 6-minute walk test in idiopathic interstitial pneumonia. Am J Respir Crit Care Med 2003; 168: $1084-1090$

205 Enright PL. The six-minute walk test. Respir Care 2003; 48: 783 - 785

206 Lederer DJ, Arcasoy SM, Wilt JS et al. Six-minute-walk distance predicts waiting list survival in idiopathic pulmonary fibrosis. Am J Respir Crit Care Med 2006; 174: 659-664

207 Swigris JJ, Swick J, Wamboldt FS et al. Heart rate recovery after 6-min walk test predicts survival in patients with idiopathic pulmonary fibrosis. Chest 2009; 136: $841-848$

208 Caminati A, Bianchi A, Cassandro R et al. Walking distance on 6-MWT is a prognostic factor in idiopathic pulmonary fibrosis. Respir Med 2009; 103: $117-123$

209 Eaton T, Young P, Milne D et al. Six-minute walk, maximal exercise tests: reproducibility in fibrotic interstitial pneumonia. Am J Respir Crit Care Med 2005; 171: 1150-1157

$210 \mathrm{du}$ Bois RM, Weycker D, Albera C et al. Six-minute-walk test in idiopathic pulmonary fibrosis: test validation and minimal clinically important difference. Am J Respir Crit Care Med 2011; 183: 1231 - 1237

211 Nicholson AG, Fulford LG, Colby TV et al. The relationship between individual histologic features and disease progression in idiopathic pulmonary fibrosis. Am J Respir Crit Care Med 2002; 166: 173-177

212 Flaherty KR, Colby TV, Toews GB et al. Differential presence of fibroblastic foci in UIP patients with or without conntective tissue disease. Am J Respir Crit Care Med 2001; 163: A983

213 Hanak V, Ryu JH, de Carvalho $E$ et al. Profusion of fibroblast foci in patients with idiopathic pulmonary fibrosis does not predict outcome. Respir Med 2008; 102: 852 - 856

214 Arcasoy SM, Christie JD, Ferrari VA et al. Echocardiographic assessment of pulmonary hypertension in patients with advanced lung disease. Am J Respir Crit Care Med 2003; 167: 735 - 740

215 Nathan SD, Shlobin OA, Barnett SD et al. Right ventricular systolic pressure by echocardiography as a predictor of pulmonary hypertension in idiopathic pulmonary fibrosis. Respir Med 2008; 102: 13051310

216 Fisher MR, Forfia PR, Chamera E et al. Accuracy of Doppler echocardiography in the hemodynamic assessment of pulmonary hypertension. Am J Respir Crit Care Med 2009; 179: 615-621

217 Modrykamien AM, Gudavalli R, McCarthy K et al. Echocardiography, 6-minute walk distance, and distance saturation product as predictors of pulmonary arterial hypertension in Idiopathic Pulmonary Fibrosis. Respir Care 2010; 55: 584-88

218 Corte TJ, Wort SJ, Gatzoulis MA et al. Pulmonary vascular resistance predicts early mortality in patients with diffuse fibrotic lung disease and suspected pulmonary hypertension. Thorax 2009; 64: 883-888

219 Hoeper MM, Andreas S, Bastian A et al. Pulmonary hypertension due to chronic lung disease: updated recommendations of the Cologne Consensus Conference 2011. Int J Cardiol 2011; 152S: 45 - 53

220 Cottin V, Nunes H, Brillet PY et al. Combined pulmonary fibrosis and emphysema: a distinct underrecognised entity. Eur Respir J 2005; 26: $586-593$

221 Nathan SD, Basavaraj A, Reichner C et al. Prevalence and impact of coronary artery disease in idiopathic pulmonary fibrosis. Respir Med 2010; 104: $1035-1040$

222 Lee JS, Collard HR, Raghu G et al. Does chronic microaspiration cause idiopathic pulmonary fibrosis. Am J Med 2010; 123: 304-311

223 Bouros D, Hatzakis K, Labrakis $H$ et al. Association of malignancy with diseases causing interstitial pulmonary changes. Chest 2002; 212 : $1278-1289$
224 Mermigkis C, Stagaki E, Amfilochiou A et al. Sleep quality and associated daytime consequences in patients with idiopathic pulmonary fibrosis. Med Princ Pract 2009; 18: 10-15

225 Stahel RA, Gilks WR, Lehmann HP et al. Third International Workshop on Lung Tumor and Differentiation Antigens: overview of the results of the central data analysis. Int J Cancer Suppl 1994; 8: 6-26

226 Kohno N, Kyoizumi S, Awaya Yet al. New serum indicator of interstitial pneumonitis activity: sialylated carbohydrate antigen KL-6. Chest 1989; 96: $68-73$

227 Yokoyama A, Kondo K, Nakajima $M$ et al. Prognostic value of circulating KL-6 in idiopathic pulmonary fibrosis. Respirology 2006; 11 : $164-168$

228 Greene KE, King TE Jr, Kuroki Y et al. Serum surfactant proteins-A and -D as biomarkers in idiopathic pulmonary fibrosis. Eur Respir J 2002; 19: $439-446$

229 Kinder BW, Brown KK, McCormack FX et al. Serum surfactant proteinA is a strong predictor of early mortality in idiopathic pulmonary fibrosis. Chest 2009; 135: 1557-1563

230 Takahashi H, Fujishima T, Koba $\mathrm{H}$ et al. Serum surfactant proteins A and $\mathrm{D}$ as prognostic factors in idiopathic pulmonary fibrosis and American Thoracic Society Documents 821 their relationship to disease extent. Am J Respir Crit Care Med 2000; 162: 1109-1114

231 Prasse A, Probst C, Bargagli E et al. Serum CC-chemokine ligand 18 concentration predicts outcome in idiopathic pulmonary fibrosis. Am J Respir Crit Care Med 2009; 179: 717-723

232 Leuchte HH, Baumgartner RA, Nounou ME et al. Brain natriuretic peptide is a prognostic parameter in chronic lung disease. Am J Respir Crit Care Med 2006; 173: 744-750

233 Leuchte HH, Neurohr C, Baumgartner R et al. Brain natriuretic peptide and exercise capacity in lung fibrosis and pulmonary hypertension. Am J Respir Crit Care Med 2004; 170: 360 - 365

234 Song JW, Song JK, Kim DS. Echocardiography and brain natriuretic peptide as prognostic indicators in idiopathic pulmonary fibrosis. Respir Med 2009; 103: 180-186

235 Shinoda H, Tasaka S, Fujishima S et al. Elevated CC chemokine level in bronchoalveolar lavage fluid is predictive of a poor outcome of idiopathic pulmonary fibrosis. Respiration 2009; 78: 285-292

236 Rosas IO, Richards TJ, Konishi K et al. MMP1 and MMP7 as potential peripheral blood biomarkers in idiopathic pulmonary fibrosis. PLoS Med 2008; 5: e93

237 Phelps DS, Umstead TM, Mejia M et al. Increased surfactant protein-A levels in patients with newly diagnosed idiopathic pulmonary fibrosis. Chest 2004; 125: 617-625

238 McCormack FX, King TE Jr, Bucher BL et al. Surfactant protein A predicts survival in idiopathic pulmonary fibrosis. Am J Respir Crit Care Med 1995; 152: $751-759$

239 Kinder BW, Brown KK, Schwarz MI et al. Baseline BAL neutrophilia predicts early mortality in idiopathic pulmonary fibrosis. Chest 2008; 133: $226-232$

240 Moeller A, Gilpin SE, Ask K et al. Circulating fibrocytes are an indicator of poor prognosis in idiopathic pulmonary fibrosis. Am J Respir Crit Care Med 2009; 179: 588 - 594

241 Richards TJ, Kaminski N, Baribaud $F$ et al. Peripheral blood proteins predict mortality in idiopathic pulmonary fibrosis. Am J Respir Crit Care Med 2012; 185: 67-76

242 Davies HR, Richeldi L, Walters EH. Immunomodulatory agents for idiopathic pulmonary fibrosis. Cochrane Database Syst Rev 2003; 03: CD003134

243 Richeldi L, Davies HR, Ferrara G et al. Corticosteroids for idiopathic pulmonary fibrosis. Cochrane Database Syst Rev 2003; 3: CD002880

244 Turner-Warwick M, Burrows B, Johnson A. Cryptogenic fibrosing alveolitis: response to corticosteroid treatment and its effect on survival. Thorax 1980; 35: 593-599

245 Gay SE, Kazerooni EA, Toews GB et al. Idiopathic pulmonary fibrosis: predicting response to therapy and survival. Am J Respir Crit Care Med 1998; 157: $1063-1072$

246 Flaherty KR, Toews GB, Lynch JPIII et al. Steroids in idiopathic pulmonary fibrosis: a prospective assessment of adverse reactions, response to therapy, and survival. Am J Med 2001; 110: 278-282

247 Nagai S, Kitaichi M, Hamada K et al. Hospital-based historical cohort study of 234 histologically proven Japanese patients with IPF. Sarcoidosis Vasc Diffuse Lung Dis 1999; 16: 209-214

248 Entzian P, Schlaak M, Seitzer $U$ et al. Antiinflammatory and antifibrotic properties of colchicine: implications for idiopathic pulmonary fibrosis. Lung 1997; 175: $41-51$ 
249 Peters SG, McDougall JC, Douglas WW et al. Colchicine in the treatment of pulmonary fibrosis. Chest 1993; 103: 101-104

250 Selman M, Carrillo G, Salas J et al. Colchicine, D-penicillamine, and prednisone in the treatment of idiopathic pulmonary fibrosis: a controlled clinical trial. Chest 1998; 114: 507-512

251 Fiorucci E, Lucantoni G, Paone G et al. Colchicine, cyclophosphamide and prednisone in the treatment of mild-moderate idiopathic pulmonary fibrosis: comparison of three currently available therapeutic regimens. Eur Rev Med Pharmacol Sci 2008; 12: 105 - 111

252 Antoniou KM, Nicholson AG, Dimadi $M$ et al. Longterm clinical effects of interferon gamma-1b and colchicine in idiopathic pulmonary fibrosis. Eur Respir J 2006; 28: 496-504

253 Douglas WW, Ryu JH, Swensen SJ et al. Colchicine versus prednisone in the treatment of idiopathic pulmonary fibrosis: a randomized prospective study. Am J Respir Crit Care Med 1998; 158: 220 - 225

254 Alton EW, Johnson M, Turner-Warwick M. Advanced cryptogenic fibrosing alveolitis: preliminary report on treatment with cyclosporin A. Respir Med 1989; 83: 277-279

255 Moolman JA, Bardin PG, Rossouw DJ et al. Cyclosporin as a treatment for interstitial lung disease of unknown aetiology. Thorax 1991; 46: $592-595$

256 Homma S, Sakamoto S, Kawabata M et al. Cyclosporin treatment in steroid-resistant and acutely exacerbated interstitial pneumonia. Intern Med 2005; 44: 1144-1150

257 Grgic A, Lausberg $H$, Heinrich $M$ et al. Progression of fibrosis in usual interstitial pneumonia: serial evaluation of the native lung after single lung transplantation. Respiration 2008; 76: 139-145

258 Wahidi MM, Ravenel J, Palmer SM et al. Progression of idiopathic pulmonary fibrosis in native lungs after single lung transplantation. Chest 2002; 121: 2072 - 2076

259 Winterbauer RH, Hammar SP, Hallman KO et al. Diffuse interstitial pneumonitis: clinicopathologic correlations in 20 patients treated with prednisone/azathioprine. Am J Med 1978; 65: 661 - 672

260 Raghu G, Depaso WJ, Cain K et al. Azathioprine combined with prednisone in the treatment of idiopathic pulmonary fibrosis: a prospective double-blind, randomized, placebo-controlled clinical trial. Am Rev Respir Dis 1991; 144: 291 - 296

261 Johnson MA, Kwan S, Snell NJ et al. Randomised controlled trial comparing prednisolone alone with cyclophosphamide and low dose prednisolone in combination in cryptogenic fibrosing alveolitis. Thorax 1989; 44: 80-288

262 Collard HR, Ryu JH, Douglas WW et al. Combined corticosteroid and cyclophosphamide therapy does not alter survival in idiopathic pulmonary fibrosis. Chest 2004; 125: 2169-2174

263 Pereira CAC, Malheiros T, Coletta EM et al. Survival in idiopathic pulmonary fibrosiscytotoxic agents compared to corticosteroids. Respir Med 2006; 100: 340 - 347

264 Cantin AM, Hubbard RC, Crystal RG. Glutathione deficiency in the epithelial lining fluid of the lower respiratory tract in idiopathic pulmonary fibrosis. Am Rev Respir Dis 1989; 139: 370 - 372

265 Behr J, Maier K, Degenkolb B et al. Antioxidative and clinical effects of high-dose $\mathrm{N}$-acetylcysteine in fibrosing alveolitis: adjunctive therapy to maintenance immunosuppression. Am J Respir Crit Care Med 1997; 156: 1897-1901

266 Demedts M, Behr J, Buhl R et al., IFIGENIA Study Group. High-dose acetylcysteine in idiopathic pulmonary fibrosis. N Engl J Med 2005; 353: $2229-2242$

267 Hunninghake GW. Antioxidant therapy for idiopathic pulmonary fibrosis. N Engl J Med 2005; 353: 2285-2287

268 Wells $A U$. Antioxidant therapy in idiopathic pulmonary fibrosis: hope is kindled. Eur Respir J 2006; 27: 664-666

269 Ziesche R, Hofbauer E, Wittmann $K$ et al. A preliminary study of longterm treatment with interferon gamma- $1 \mathrm{~b}$ and low-dose prednisolone in patients with idiopathic pulmonary fibrosis. N Engl J Med 1999; 341: $1264-1269$

270 Raghu G, Brown KK, Bradford WZ et al. A placebo-controlled trial of interferon gamma- $1 \mathrm{~b}$ in patients with idiopathic pulmonary fibrosis. N Engl J Med 2004; 350: 125 - 133

271 King TE Jr, Albera C, Bradford WZ. INSPIRE Study Group. et al. Effect of interferon gamma- $1 \mathrm{~b}$ on survival in patients with idiopathic pulmonary fibrosis (INSPIRE): a multicentre, randomised, placebo-controlled trial. Lancet 2009; 374: 222 -228

272 Thannickal VJ, Flaherty KR, Martinez FJ et al. Idiopathic pulmonary fibrosis: emerging concepts on pharmacotherapy. Expert Opin Pharmacother 2004; 5: 1671-1686
273 King TE Jr, Behr J, Brown KK et al. BUILD-1: a randomized placebo-controlled trial of bosentan in idiopathic pulmonary fibrosis. Am J Respir Crit Care Med 2008; 177: 75-81

274 Raghu G, King TE Jr, Behr J et al. Quality of life and dyspnoea in patients treated with bosentan for idiopathic pulmonary fibrosis (BUILD-1). Eur Respir J 2010; 35: 118-123

275 Mohler KM, Torrance DS, Smith CA et al. Soluble tumor necrosis factor (TNF) receptors are effective therapeutic agents in lethal endotoxemia and function simultaneously as both TNF carriers and TNF antagonists. J Immunol 1993; 151: 1548-1561

276 Sime PJ, Marr RA, Gauldie D et al. Transfer of tumor necrosis factor-alpha to rat lung induces severe pulmonary inflammation and patchy interstitial fibrogenesis with induction of transforming growth factor-beta1 and myofibroblasts. Am J Pathol 1998; 153: 825-832

277 Piguet PF, Ribaux C, Karpuz V et al. Expression and localization of tumor necrosis factor-alpha and its mRNA in idiopathic pulmonary fibrosis. Am J Pathol 1993; 143: 651 -655

278 Raghu G, Brown KK, Costabel U et al. Treatment of idiopathic pulmonary fibrosis with etanercept: an exploratory, placebo-controlled trial. Am J Respir Crit Care Med 2008; 178: 948-955

279 Kubo H, Nakayama K, Yanai M et al. Anticoagulant therapy for idiopathic pulmonary fibrosis. Chest 2005; 128: 1475 - 1482

280 Raghu G, Johnson WC, Lockhart D et al. Treatment of idiopathic pulmonary fibrosis with a new antifibrotic agent, pirfenidone: results of a prospective, open-label Phase II study. Am J Respir Crit Care Med 1999; 159: 1061 -1069

281 Nagai S, Hamada K, Shigematsu $M$ et al. Open-label compassionate use one year-treatment with pirfenidone to patients with chronic pulmonary fibrosis. Intern Med 2002; 41: 1118-1123

282 Azuma A, Nukiwa T, Tsuboi E et al. Double-blind, placebo-controlled trial of pirfenidone in patients with idiopathic pulmonary fibrosis. Am J Respir Crit Care Med 2005; 171: 1040-1047

283 Taniguchi H, Ebina M, Kondoh $Y$ et al., Pirfenidone Clinical Study Group in Japan. Pirfenidone in idiopathic pulmonary fibrosis. Eur Respir J 2010; 35: 821 - 829

284 Seymour S. Briefing Information for the March 9, 2010 Meeting of the Pulmonary-Allergy Drugs Advisory Committee. NDA 22-535. Washington, D.C.: US Food and Drug Administration; 2010: Available from: http://www.fda.gov/downloads/AdvisoryCommittees/CommitteesMeetingMaterials/Drugs/Pulmonary-AllergyDrugsAdvisoryCommittee/UCM203081.pdf [accessed 2010 May 10]

285 Seymour S. Division Summary: Overview of the FDA background materials for New Drug Application (NDA) 22-535, Esbriet (pirfenidone) for the treatment of patients with idiopathic pulmonary fibrosis (IPF) to reduce the decline in lung function. In: Seymour S, ed. FDA Briefing Information for the March 9, 2010 Meeting of the Pulmonary-Allergy Drugs Advisory Committee (PADAC). NDA 22-535. Washington, D.C. US Food and Drug Administration; 2010: 2-20 Available from: http://www.fda.gov/downloads/AdvisoryCommittees/CommitteesMeetingMaterials/Drugs/Pulmonary-AllergyDrugsAdvisoryCommittee/UCM203081.pdf [accessed 2010 May 10]

286 Karimi-Shah B. Esbriet (pirfenidone) $2403 \mathrm{mg} /$ day to reduce the decline in lung function in patients with idiopathic pulmonary fibrosis (Clinical Briefing Document). In: Seymour S, ed. FDA Briefing Information for the March 9, 2010 Meeting of the Pulmonary-Allergy Drugs Advisory Committee (PADAC). NDA 22-535. Washington, D.C.: US Food and Drug Administration; Available from: http://www.fda. gov/downloads/AdvisoryCommittees/CommitteesMeetingMaterials/ Drugs/Pulmonary-AllergyDrugsAdvisoryCommittee/UCM203081. pdf [accessed 2010 May 10]

287 Zhou F. Pirfenidone capsules [three 267-mg capsules TID] for treatment of patients with idiopathic pulmonary fibrosis to reduce decline in lung function (Statistical Briefing Document). In: Seymour S, ed. FDA Briefing Information for the March 9, 2010 Meeting of the Pulmonary-Allergy Drugs Advisory Committee (PADAC). NDA 22535. Washington, D.C.: US Food and Drug Administration; 2010: 110-158 Available from: http://www.fda.gov/downloads/AdvisoryCommittees/CommitteesMeetingMaterials/Drugs/Pulmonary-AllergyDrugsAdvisoryCommittee/UCM203081.pdf [accessed 2010 May 10]

288 King TE Jr, Brown KK, Raghu G et al. BUILD-3: A Randomized, Controlled Trial of Bosentan in Idiopathic Pulmonary Fibrosis. Am J Respir Crit Care Med 2011; 184: 92 - 99

289 Behr J, Costabel U, Worth H. Stellungnahme der DGP zur Pressemitteilung des National Heart Lung and Blood Institute zur PANTHER-Stu- 
die bei IPF-Patienten vom 21.10.2011. Pneumologie 2011; 67: 724725

290 Noble PW, Albera C, Bradford WZ et al. Pirfenidone in patients with idiopathic pulmonary fibrosis (CAPACITY): two randomised trials. Lancet 2011; 377: 1760-1769

291 Sagnolo P, Del Giovane C, Luppi F et al. Non-steroid agents for idiopathic pulmonary fibrosis. Cochrane Datbase Syst Rev 2010; 9: CD003134

292 Daniels CE, Lasky JA, Limper AH et al. Imatinib treatment for idiopathic pulmonary fibrosis: randomized placebo-controlled trial results. Am J Respir Crit Care Med 2010; 181: 604-610

293 Richeldi $L$, Costabel $U$, Selman $M$ et al. Efficacy of a tyrosine kinase inhibitor in idiopathic pulmonary fibrosis. New Engl J Med 2011; 365: $1079-1087$

294 Morrison DA, Stovall JR. Increased exercise capacity in hypoxemic patients after long-term oxygen therapy. Chest 1992; 102: $542-550$

295 Nocturnal Oxygen Therapy Trial Group. Continuous or nocturnal oxygen therapy in hypoxemic chronic obstructive lung disease: a clinical trial. Ann Intern Med 1980; 93: 391 - 398

296 Longterm domiciliary oxygen therapy in chronic hypoxic cor pulmonale complicating chronic bronchitis and emphysema: report of the Medical Research Council Working Party. Lancet 1981; 1: 681-686

297 Mason DP, Brizzio ME, Alster JM et al. Lung transplantation for idiopathic pulmonary fibrosis. Ann Thorac Surg 2007; 84: 1121-1128

298 Keating D, Levvey B, Kotsimbos T et al. Lung transplantation in pulmonary fibrosis: challenging early outcomes counterbalanced by surprisingly good outcomes beyond 15 years. Transplant Proc 2009; 41: 289-291

299 Christie JD, Edwards LB, Kucheryavaya AY et al. The Registry of the International Society for Heart and Lung Transplantation: Twentyeighth Adult Lung and Heart-Lung Transplant Report - 2011. J Heart Lung Transplant 2011; 30: 1104-1122

300 Thabut G, Mal H, Castier Y et al. Survival benefit of lung transplantation for patients with idiopathic pulmonary fibrosis. J Thorac Cardiovasc Surg 2003; 126: 469-475

301 Orens J, Estenne M, Arcasoy $S$ et al. International guidelines for the selection of lung transplant candidates: 2006 update - a consensus report from the Pulmonary Scientific Council of the International Society for Heart and Lung Transplantation. J Heart Lung Transplant 2006; 25: 745-55

302 Thabut G, Christie JD, Ravaud P et al. Survival after bilateral versus single-lung transplantation for idiopathic pulmonary fibrosis. Ann Intern Med 2009; 151: 767 - 774

303 Kim DS, Park JH, Park BK et al. Acute exacerbation of idiopathic pulmonary fibrosis: frequency and clinical features. Eur Respir J 2006; 27: $143-150$

304 Blivet S, Philit F, Sab JM et al. Outcome of patients with idiopathic pulmonary fibrosis admitted to the ICU for respiratory failure. Chest 2001; 120: 209-212

305 Molina-Molina M, Badia JR, Marin-Arguedas A et al. Outcomes and clinical characteristics of patients with pulmonary fibrosis and respiratory failure admitted to an intensive care unit: a study of 20 cases. Med Clin (Barc) 2003; 121: 63-67

306 Saydain G, Islam A, Afessa B et al. Outcome of patients with idiopathic pulmonary fibrosis admitted to the intensive care unit. Am J Respir Crit Care Med 2002; 166: 839-842

307 Nava S, Rubini F. Lung and chest wall mechanics in ventilated patients with end stage idiopathic pulmonary fibrosis. Thorax 1999; 54: 390 395

308 Stern JB, Mal H, Groussard O et al. Prognosis of patients with advanced idiopathic pulmonary fibrosis requiring mechanical ventilation for acute respiratory failure. Chest 2001; 120: 213-219

$309 \mathrm{Al}$-Hameed FM, Sharma S. Outcome of patients admitted to the intensive care unit for acute exacerbation of idiopathic pulmonary fibrosis. Can Respir J 2004; 11: 117-122

310 Fumeaux $T$, Rothmeier $C$, Jolliet $P$. Outcome of mechanical ventilation for acute respiratory failure in patients with pulmonary fibrosis. Intensive Care Med 2001; 27: 1868-1874

311 Pitsiou G, Ioannis Trigonis I, Tsiata E et al. Outcome of patients with pulmonary fibrosis admitted to the ICU for acute respiratory failure. Eur Respir J Suppl 2006; 28: E650

312 Mollica C, Paone G, Conti V et al. Mechanical ventilation in patients with end-stage idiopathic pulmonary fibrosis. Respiration 2010; 79 : 209-215
313 Rangappa P, Moran JL. Outcomes of patients admitted to the intensive care unit with idiopathic pulmonary fibrosis. Crit Care Resusc 2009; 11: $102-109$

314 Mallick S. Outcome of patients with idiopathic pulmonary fibrosis (IPF) ventilated in intensive care unit. Respir Med 2008; 102: 13551359

315 Mason DP, Thuita L, Nowicki ER et al. Should lung transplantation be performed for patients on mechanical respiratory support? The US experience J Thorac Cardiovasc Surg 2010; 139: 765 - 773

316 Holland AE, Hill CJ, Conron $M$ et al. Short term improvement in exercise capacity and symptoms following exercise training in interstitial lung disease. Thorax 2008; 63: 549-554

317 Nishiyama 0 , Kondoh Y, Kimura T et al. Effects of pulmonary rehabilitation in patients with idiopathic pulmonary fibrosis. Respirology 2008; 13: 394-399

318 Ferreira A, Garvey C, Connors GL et al. Pulmonary rehabilitation in interstitial lung disease: benefits and predictors of response. Chest 2009; 135: $442-447$

319 Ferreira G, Feuerman M, Spiegler P. Results of an 8-week, outpatient pulmonary rehabilitation program on patients with and without chronic obstructive pulmonary disease. J Cardiopulm Rehabil 2006; 26: $54-60$

320 Jastrzebski D, Gumola A, Gawlik R et al. Dyspnea and quality of life in patients with pulmonary fibrosis after six weeks of respiratory rehabilitation. J Physiol Pharmacol 2006; 57: 139-148

321 Naji NA, Connor MC, Donnelly SC et al. Effectiveness of pulmonary rehabilitation in restrictive lung disease. J Cardiopulm Rehabil 2006; 26: $237-243$

322 Magnussen H, Kirsten AM, Köhler D et al., Deutsche Gesellschaft Für Pneumologie und Beatmungsmedizin e.V. Guidelines for long-termoxygen therapy. German Society for Pneumology and Respiratory Medicine. Pneumologie 2008; 62: 748-756

323 Fischer S, Hoeper MM, Bein T et al. Interventional lung assist: a new concept of protective ventilation in bridge to lung transplantation. ASAIO J 2008; $54: 3-10$

324 Lancaster LH, Mason WR, Parnell JA et al. Obstructive sleep apnea is common in idiopathic pulmonary fibrosis. Chest 2009; 136: 772 778

325 Collard HR, Moore BB, Flaherty KR et al. Idiopathic Pulmonary Fibrosis Clinical Research Network Investigators. Acute exacerbations of idiopathic pulmonary fibrosis. Am J Respir Crit Care Med 2007; 176: 636-643

326 Akira $M$, Hamada $H$, Sakatani $M$ et al. CT findings during phase of accelerated deterioration in patients with idiopathic pulmonary fibrosis. AJR Am J Roentgenol 1997; 168: 79-83

327 Ambrosini V, Cancellieri A, Chilosi $M$ et al. Acute exacerbation of idiopathic pulmonary fibrosis: report of a series. Eur Respir J 2003; 22: $821-826$

328 Parambil JG, Myers JL, Ryu JH. Histopathologic features and outcome of patients with acute exacerbation of idiopathic pulmonary fibrosis undergoing surgical lung biopsy. Chest 2005; 128: 3310-3315

329 Rice AJ, Wells AU, Bouros D et al. Terminal diffuse alveolar damage in relation to interstitial pneumonias: an autopsy study. Am J Clin Pathol 2003; 119: 709-714

330 Kondo A, Saiki S. Acute exacerbation in idiopathic interstitial pneumonia (IIP). In: Harasawa M, Fukuchi Y, Morinari H, ed. Interstitial pneumonia of unknown etiology. Tokyo: University of Tokyo Press; 1989: $33-42$

331 Kim DS, Collard HR, King TE Jr. Classification and natural history of the idiopathic interstitial pneumonias. Proc Am Thorac Soc 2006; 3: $285-292$

332 Sakamoto S, Homma S, Miyamoto A et al. Cyclosporin A in the treatment of acute exacerbation of idiopathic pulmonary fibrosis. Intern Med 2010; 49: 109-115

333 Olschewski H, Ghofrani HA, Walmrath D et al. Inhaled prostacyclin and iloprost in severe pulmonary hypertension secondary to lung fibrosis. Am J Respir Crit Care Med 1999; 160: 600-607

334 Minai OA, Sahoo D, Chapman JT et al. Vaso-active therapy can improve 6-min walk distance in patients with pulmonary hypertension and fibrotic interstitial lung disease. Respir Med 2008; 102: 1015-1020

335 Ghofrani HA, Wiedemann R, Rose F et al. Sildenafil for treatment of lung fibrosis and pulmonary hypertension: a randomised controlled trial. Lancet 2002; 360: 895-900 
336 Madden BP, Allenby M, Loke T et al. A potential role for sildenafil in the management of pulmonary hypertension in patients with parenchymal lung disease. Vascul Pharmacol 2006; 44: 372 - 376

337 Collard HR, Anstrom KJ, Schwarz MI et al. Sildenafil improves walk distance in idiopathic pulmonary fibrosis. Chest 2007; 131: 897-899

338 Raghu G, Freudenberger TD, Yang $S$ et al. High prevalence of abnormal acid gastro-oesophageal reflux in idiopathic pulmonary fibrosis. Eur Respir J 2006; 27: 136-142

339 Tobin RW, Pope CEII, Pellegrini CA et al. Increased prevalence of gastroesophageal reflux in patients with idiopathic pulmonary fibrosis. Am J Respir Crit Care Med 1998; 158: 1804-1808

340 Sweet MP, Patti MG, Leard LE et al. Gastroesophageal reflux in patients with idiopathic pulmonary fibrosis referred for lung transplantation. J Thorac Cardiovasc Surg 2007; 133: 1078 - 1084

341 Marik PE. Aspiration pneumonitis and aspiration pneumonia. N Engl J Med 2001; 344: 665-671

342 Barnes TW, Vassallo R, Tazelaar HD et al. Diffuse bronchiolar disease due to chronic occult aspiration. Mayo Clin Proc 2006; 81: 172-176

343 Davis RD Jr, Lau CL, Eubanks $S$ et al. Improved lung allograft function after fundoplication in patients with gastroesophageal reflux disease undergoing lung transplantation. J Thorac Cardiovasc Surg 2003; 125: $533-542$

344 Linden PA, Gilbert RJ, Yeap BY et al. Laparoscopic fundoplication in patients with end-stage lung disease awaiting transplantation. J Thorac Cardiovasc Surg 2006; 131: 438 - 446

345 Hope-Gill BDM, Hilldrup S, Davies C et al. A study of the cough reflex in idiopathic pulmonary fibrosis. Am J Respir Crit Care Med 2003; 168: 995-1002

346 Horton MR, Danoff SK, Lechtzin N. Thalidomide inhibits the intractable cough of idiopathic pulmonary fibrosis. Thorax 2008; 63: 749

347 Allen S, Raut S, Woollard $J$ et al. Low dose diamorphine reduces breathlessness without causing a fall in oxygen saturation in elderly patients with end-stage idiopathic pulmonary fibrosis. Palliat Med 2005; 19: $128-130$

348 Jegal Y, Kim DS, Shim TS et al. Physiology is a stronger predictor of survival than pathology in fibrotic interstitial pneumonia. Am J Respir Crit Care Med 2005; 171: 639-644

349 Collard HR, King TEJr, Bartelson BB et al. Changes in clinical and physiologic variables predict survival in idiopathic pulmonary fibrosis. Am J Respir Crit Care Med 2003; 168: 538 - 542

350 King TE Jr, Safrin S, Starko KM et al. Analyses of efficacy end points in a controlled trial of interferon-gamma1b for idiopathic pulmonary fibrosis. Chest 2005; 127: 171-177

351 Latsi PI, du Bois RM, Nicholson AG et al. Fibrotic idiopathic interstitial pneumonia: the prognostic value of longitudinal functional trends. Am J Respir Crit Care Med 2003; 168: 531-537

352 Flaherty KR, Mumford JA, Murray S et al. Prognostic implications of physiologic and radiographic changes in idiopathic interstitial pneumonia. Am J Respir Crit Care Med 2003; 168: 543 - 548

353 Zappala CJ, Latsi PI, Nicholson AG et al. Marginal decline in forced vital capacity is associated with a poor outcome in idiopathic pulmonary fibrosis. Eur Respir J 2010; 35: 830-836

354 Miller MR, Crapo R, Hankinson J et al. ATS/ERS Task Force. General considerations for lung function testing. Eur Respir J 2005; 26: $153-$ 161

355 Miller MR, Hankinson J, Brusasco V et al. ATS/ERS Task Force. Standardisation of spirometry. Eur Respir J 2005; 26: 319-338

356 Wanger J, Clausen JL, Coates A et al. Standardisation of the measurement of lung volumes. Eur Respir J 2005; 26: 511 -522

357 Macintyre N, Crapo RO, Viegi G et al. Standardisation of the singlebreath determination of carbon monoxide uptake in the lung. Eur Respir J 2005; 26: 720-735

358 Pellegrino R, Viegi G, Brusasco Vet al. Interpretative strategies for lung function tests. Eur Respir J 2005; 26: $948-968$

359 Selman M, King TEJr, Pardo A. American Thoracic Society. European Respiratory Society. American College of Chest Physicians. Idiopathic pulmonary fibrosis: prevailing and evolving hypotheses about its pathogenesis and implications for therapy. Ann Intern Med 2001; 134: $136-151$

360 Akagi T, Matsumoto T, Harada T et al. Coexistent emphysema delays the decrease of vital capacity in idiopathic pulmonary fibrosis. Respir Med 2009; 103: 1209-1215

361 Mura M, Zompatori M, Pacilli AMG et al. The presence of emphysema further impairs physiologic function in patients with idiopathic pulmonary fibrosis. Respir Care 2006; 51: 257-265

362 Cottin V, Cordier JF. Combined pulmonary fibrosis and emphysema: an experimental and clinically relevant phenotype. Am J Respir Crit Care Med 2005; 172: 1605-1606

363 Wiggins J, Strickland B, Turner-Warwick M. Combined cryptogenic fibrosing alveolitis and emphysema: the value of high resolution computed tomography in assessment. Respir Med 1990; 84: 365 369

364 Martinez FJ, Safrin S, Weycker D. IPF Study Group. et al. The clinical course of patients with idiopathic pulmonary fibrosis. Ann Intern Med 2005; 142: $963-967$

365 ATS Committee on Proficiency Standards for Clinical Pulmonary Function Laboratories. ATS statement: guidelines for the six-minute walk test. Am J Respir Crit Care Med 2002; 166: 111 - 117

366 Arcasoy SM, Christie JD, Ferrari VA et al. Echocardiographic assessment of pulmonary hypertension in patients with advanced lung disease. Am J Respir Crit Care Med 2003; 167: 735 - 740

367 Fisher MR, Forfia PR, Chamera E et al. Accuracy of Doppler echocardiography in the hemodynamic assessment of pulmonary hypertension. Am J Respir Crit Care Med 2009; 179: 615-621

368 Nathan SD, Noble PW, Tuder RM. Idiopathic pulmonary fibrosis and pulmonary hypertension: connecting the dots. Am J Respir Crit Care Med 2007; 175: 875-880

369 Leuchte HH, Baumgartner RA, Nounou ME et al. Brain natriuretic peptide is a prognostic parameter in chronic lung disease. Am J Respir Crit Care Med 2006; 173: 744-750

370 Leuchte HH, Neurohr C, Baumgartner R et al. Brain natriuretic peptide and exercise capacity in lung fibrosis and pulmonary hypertension. Am J Respir Crit Care Med 2004; 170: 360-365

371 Zisman DA, Karlamangla AS, Kawut SM et al. Validation of a method to screen for pulmonary hypertension in advanced idiopathic pulmonary fibrosis. Chest 2008; 133: 640-645

372 Egan JJ, Adamali $H$ et al. Ganciclovir Antiviral Therapy in Advanced Idiopathic Pulmonary Fibrosis: An Open Pilot Study. Pulmonary Medicine 2011: doi 10.1155/2011/24080, Epub 2011 Apr 7

373 Zisman DA, Schwarz M, Anstrom KJ. Idiopathic Pulmonary Fibrosis Clinical Research Network. et al. A controlled trial of sildenafil in advanced idiopathic pulmonary fibrosis. N Engl J Med 2010; 363: 620628

374 Hoeper MM, Halank M, Wilkens $H$ et al. Riociguat for patients with pulmonary hypertension associated with interstitial lung disease. http://www.phaonlineuniv.org/node/5134

375 The Idiopathic Pulmonary Fibrosis Clinical Research Network. Prednisone, Azathiorpine, and n-Acetylcysteine for pulmonary fibrosis. N Engl J Med 2012; 366: 1968 - 1977

$376 \mathrm{Behr} J$. Prednisone, azathioprine, and $\mathrm{N}$-acetylcysteine for pulmonary fibrosis. N Engl J Med 2012; 367: 869 (letter), author reply 870 - 871

377 Wells AU, Behr J, Costabel $U$ et al. Triple therapy in idiopathic pulmonary fibrosis: an alarming press release. Eur Respir J 2012; 39: $805-$ 806

378 Noth I, Anstrom SB, de Andrade J et al. A Placebo-Controlled Randomized Trial of Warfarin in Idiopathic Pulmonary Fibrosis. Am J Respir Crit Care Med 2012; 186: 88-95

379 Müller-Ouernheim J, Wells A. Evidence-based recommendations in idiopathic pulmonary fibrosis: a year is a long time in interstitial lung disease. Am J Respir Crit Care Med 2012; 186: 5-7 